\title{
REMOTE GEOLOGIC STRUCTURAL ANALYSIS OF YUCCA FLAT
}

\author{
M. G.Foley \\ P. G. Heasler \\ K. A. Hoover \\ N. J. Rynes ${ }^{(a)}$ \\ R. L. Thiessen ${ }^{(b)}$ \\ J. L. Alfaro(c)
}

December 1991

Prepared for

the U.S. Department of Energy

under Contract DE-AC06-76RLO 1830

Pacific Northwest Laboratory

Richland, Washington 99352

(a) Department of Geology, Northern Illinois University, DeKalb, Illinois 60115

(b) Department of Geology, Washington State University, Pullman, Washington 99164

(c) Student Research Apprenticeship Program. Administered by Northwest College and University Association for Science (Washington State Untversity) 


\section{SUMMARY}

The Remote Geologic Analysis (RGA) system was developed by Pacific Northwest Laboratory (PNL) to Identify crustal structures that may affect seismic wave propagation from nuclear tests. Using automated methods, the RGA system identifies all valleys in a digital elevation model (DEM), fits three-dimensional vectors to valley bottonis, and catalogs all potential fracture or fault planes defined by coplanar pairs of valley vectors. The system generates a cluster hierarchy of planar features having greater-than-random density that may represent areas of anomalous topography manifesting structural control of erosional drainage development. Because RGA uses computer methods to identify zones of hypothesized structural control of topography, ground truth using a well-characterized test site was critical in our evaluation of RGA's characterization of inaccessible test sites for seismic verification studies. Therefore, we applied RGA to a study area centered on Yucca Flat at the Nevada Test Site (NTS) and compared our results with both mapped geology and geologic structures and with seismic yield-magnitude models. This is the final report of PNL's RGA development project for peer review within the U.S. Department of Energy Office of Arms Control (OAC) seismic-verification cor.umunity. In this report, we discuss the Yucca Flat study area, the analytical basis of the RGA system and its application to Yucca Flat, the results of the analysis, and the relation of the analytical results to known topography. geology, and geologic structures.

Our analysis consisted of three parts. The first part was a geomirphic pattern-recognition analysis in which we applied a valley-finder algorithm, a vector-fitting algorithm, and coplanar analysis to the entire Yucca Flat DEM to identify coplanar valley segments that may be evidence of erosional control by planar fracture zones. The RGA algorithms generated 26.473 planes from the Yucca Flat area of the NTS. In the second part, we used statistical cluster analysis to locate zones of coplanar valley segments that were of anomalously high density (compared with random associations), which were the final output of the remote analysis. We dertved several thousand clusters containing as many as 2,351 planes. From these, we picked the most significant clusters based on statistical and geologic criteria developed in previous test applications; the result was 21 clusters to be evaluated with geologic and geophysical data from Yucca Flat. In the third part, we compared output of the remote analysis with topograpinic, geologic, and geophysical features to evaluate structural significance.

By comparing these clusters with topographic, geologic, and geophysical data for Yucca Flat, we concluded that RGA accurateiy detects valleys in the DEM, performs accurate coplanar correlations, and isolates statistically meaningful plane clusters that can be ranked in order of significance. While segments of RGA plane clusters correlate with numerous mapped faults, no single fault or associations of fault zones seem to correlate with a substantial length of the RGA plane clusters. In part, this is an artifact of the study area; the relief of Yucca Flat is too small for the initial geomorphic pattern-recognition method used in RGA to detect any valleys. Overall, however, we think that the significant RGA plane clusters manifest larger structures than those mapped at the surface in the area of Yucca Flat. This supposition is borne out by correlations of Yucca Flat-crossing RGA plane clusters with features found in isopach, structure-contour, gravity-anomaly, and magnetic-anomaly maps of Yucca Flat. All of the RGA plane clusters that cross Yucca Flat correlate with linear features, such as truncations, thinnings, or offsets, in these maps 
of subsurface features. Further, few features are found in the maps that are not associated with one of these clusters. We are confident that the RGA study of Yucca Flat identified significant fracture zones that, in adition to defining the obvious Basin-and-Range structural bounds of Yucca Flat, affect the down-thrown block underlying the basin and carry through into the bounding ranges.

Based on a preliminary correlation of RGA plane clusters with yield residuals from yield-magnitude models of weapons tests at Yucca Flat, we find that the clusters apparently do not divide the down-iropped block under Yucca Flat into sub-blocks that have systematically different yield residuals. Rather, the clusters apparently affect model residuals for tests conducted in the cluster "zones." Residual values within the cluster zones are in most cases significantly different from those in the bodies of the sub-blosks outside. However, similar differences occur along the traces of the Yucca and Carpetbag faults; because of the north-south distribution of tests for which we have yield residuals, we cannot completely separate correlations between the residuals, the plane clusters, and the faults. At present, we know too little about the derivation of the residuals for this to be a compelling correlation. 


\section{ACKNOWLEDGMENTS}

We thank Don Livingston. Alan Rohay, and Tom Weaver for their careful critiques and helpful comments. Paciflc Northwest Laboratory is operated by Battelle Memorial Institute for the U.S. Department of Energy under Contract DE-AC06-76RLO 1830. This research was supported in part by the Northwest College and Uriversity Association for Science (Washington State University) under Grant DE-FG06-89ER-75522 with the U.S. Department of Energy. 


\section{CONTENTS}

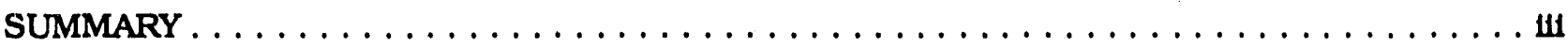

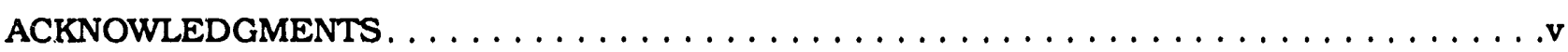

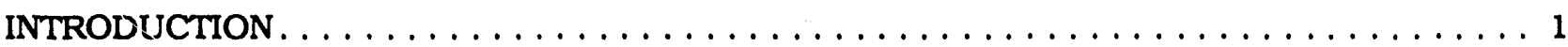

ANALYTICAL APPROACH $\ldots \ldots \ldots \ldots \ldots \ldots \ldots \ldots \ldots \ldots \ldots \ldots \ldots \ldots \ldots$

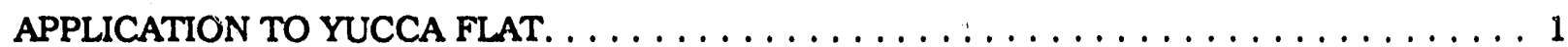

YUCCA FLAT STUDY AREA $\ldots \ldots \ldots \ldots \ldots \ldots \ldots \ldots \ldots \ldots \ldots \ldots \ldots \ldots \ldots$

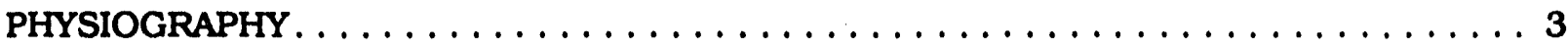

GEOLOGIC HISTORY $\ldots \ldots \ldots \ldots \ldots \ldots \ldots \ldots \ldots \ldots \ldots \ldots \ldots \ldots$

STRUCTURAL GEOLOGY $\ldots \ldots \ldots \ldots \ldots \ldots \ldots \ldots \ldots \ldots \ldots \ldots \ldots \ldots \ldots$

REMOTE GEOLOGIC STRUCTURAL ANALYSIS $\ldots \ldots \ldots \ldots \ldots \ldots \ldots \ldots \ldots \ldots$

COPLANAR ANALYSIS $\ldots \ldots \ldots \ldots \ldots \ldots \ldots \ldots \ldots \ldots \ldots \ldots \ldots \ldots \ldots \ldots$

Digital Elevation Model . . . . . . . . . . . . . . . . . . . 17

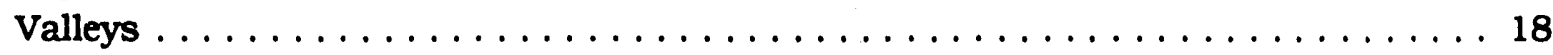

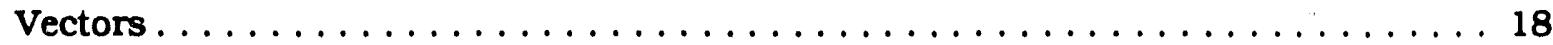

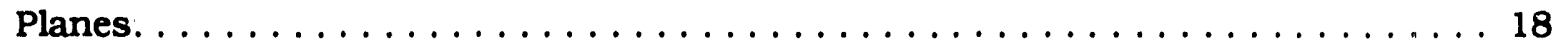

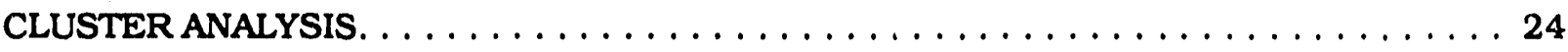

CORRESPONDENCE OF PLANE-CLUSTER SURFACE TRACES TO TOPOGRAPHIC,

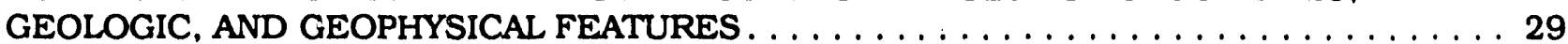

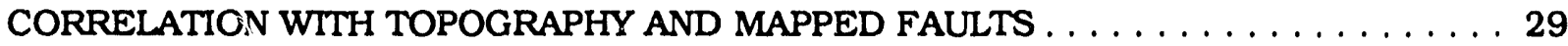

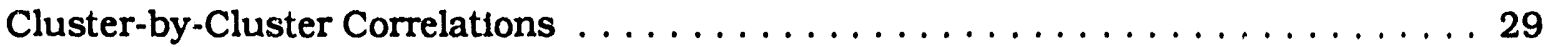

Correlation with Nuclear Test-Induced Fractures $\ldots \ldots \ldots \ldots \ldots \ldots \ldots$

Correlation with Field-Mapped Fractures $\ldots \ldots \ldots \ldots \ldots \ldots \ldots \ldots \ldots \ldots$

CORRELATION WITH SUBSURFACE AND GEOPHYSICAL DATA $\ldots \ldots \ldots \ldots \ldots \ldots$

Isopach and Structural-Contour Maps $\ldots \ldots \ldots \ldots \ldots \ldots \ldots \ldots \ldots$

Gravity Anomalies. . . . . . . . . . . . . . . . . . . . . . 50

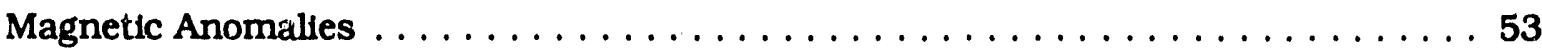

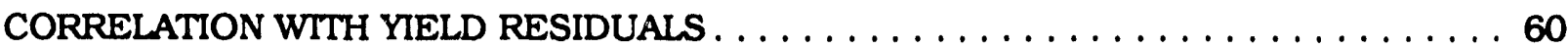

CORRELATION WITH MAPPED LINEAMENTS $\ldots \ldots \ldots \ldots \ldots \ldots \ldots \ldots \ldots \ldots \ldots$

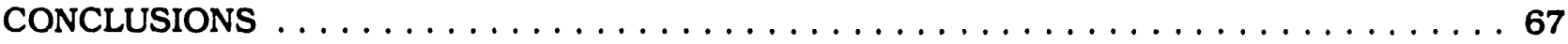

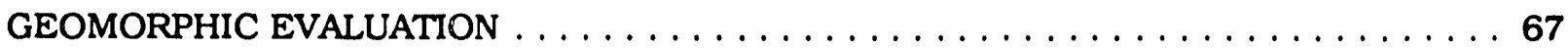

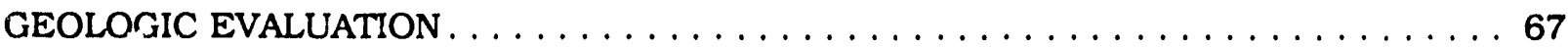

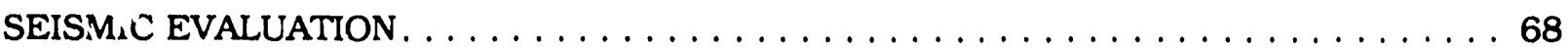

NEELED WORK . . . . . . . . . . . . . . . . . . . . . 69

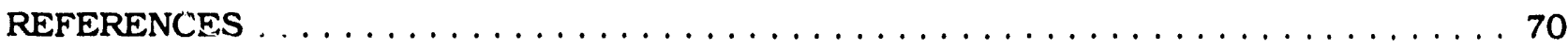

APPENDIX - MATHIEMATICAL AND STATISTICAL BACKGROUND $\ldots \ldots \ldots \ldots \ldots \ldots \ldots \ldots$. . 1 


\section{EIGURES}

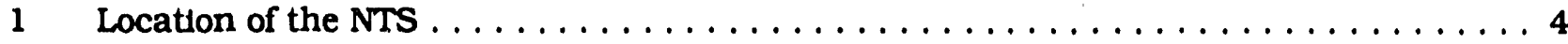

2 Nevada Test Site and Yucca Flat Study Area $\ldots \ldots \ldots \ldots \ldots \ldots \ldots \ldots \ldots$

3 Physiographic Provinces of the Western United States $\ldots \ldots \ldots \ldots \ldots \ldots \ldots \ldots$

4 Physiographic Regions of the NTS Study Area $\ldots \ldots \ldots \ldots \ldots \ldots \ldots \ldots \ldots$

5 Stratigraphic Section of the NTS Study Area $\ldots \ldots \ldots \ldots \ldots \ldots \ldots \ldots$

6 Schematic Time-Line of the Geologic History of the NTS Study Area . . . . . . . . . . . 9

7 Location of the Walker Lane Belt and Calderas of the Greenwater-Shoshone

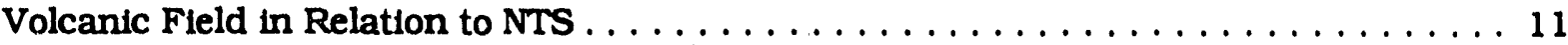

8 Mapped Structures of the Yucca Flat Study Area $\ldots \ldots \ldots \ldots \ldots \ldots \ldots \ldots$

9 Digital Elevation Model for the Yucca Flat Study Area . . . . . . . . . . . . . . 19

10 Locating Low Points in a Digital Elevation Model and Fitting Vectors to Strings of Low

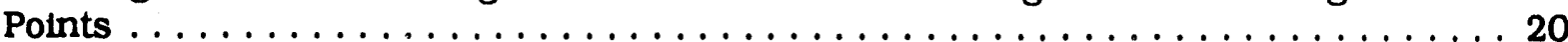

11 Low-Point Strings Detected in the Yucca Flat Study Area DEM by the RGA

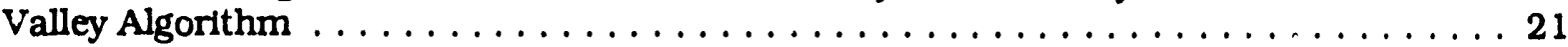

12 Valley Vectors Produced for the Yucca Flat Study Area DEM by the RGA Vector

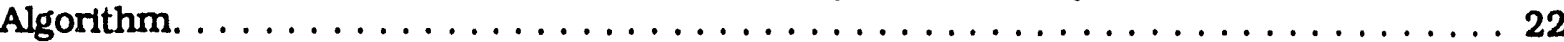

13 Illustration of the Need for the Pole-Magnitude Ratio in RGA Cluster Analysis . . . . . . 23

14 Representative Hierarchical Cluster Tree for RGA Plane Cluster . . . . . . . . . . . . . 25

15 Significant RGA Plane Clusters for the Yucca Flat Study Area . . . . . . . . . . . 27

16 Active Faults in the Yucca Flat Study Area . . . . . . . . . . . . . . . . . . 32

17 Correlation of RGA Plane Clusters with Fractures Induced by Nuclear Tests . . . . . . . 39

18 Equal-Area Stereonet Showing Poles of Field-Mapped Joints and Faults in Paiute Ridge, Nevada Quadrangle and of Principal RGA Plane Clusters. . . . . . . . . . . . . 40

19 Isopach Map of Tuffs Older than the Grouse Canyon Member of the Belted Range

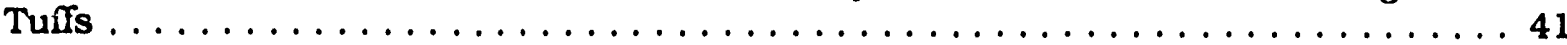

20 Isopach Map of Tuffs of the Grouse Canyon Member of the Belted Range Tuffs. . . . . . 43

21 Isopach Map of Tuffs of the Paintbrush T uff and Three Adjacent Units. . . . . . . . . . 44

22 Isopach Map of the Rainier Mesa Member of the Timber Mountain Tuff . . . . . . . . . 45

23 Isopach Map of Tertiary Through guaternary Alluvium $\ldots \ldots \ldots \ldots \ldots \ldots$

24 Structural Contour Map of the Base of the Grouse Canyon Member of the Belted Range Tuffs . . . . . . . . . . . . . . . . . . . . . . . . . 47

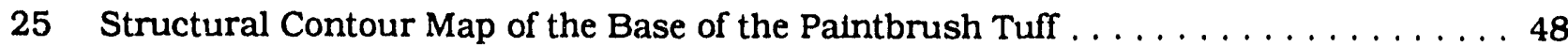

26 Structural Contour Map of the Base of the Rainier Mesa Member of the Timber

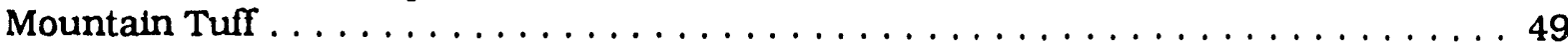

27 Structural Contour Map of the Base of the Ammonta Tanks Member of the Timber

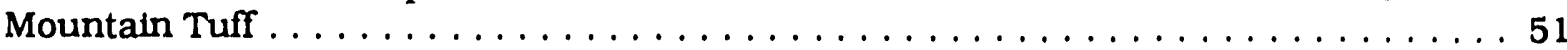


28 RGA Plane Clusters with Corresponding Bouguer Gravity Anomalies after Diment, Healy, and Roller (1960)

29 RGA Plane Clusters with Corresponding Bouguer Gravity Ariomalles after Healey (1968). . . . . . . . . . . . . . . . . . . . . . . . . 54

30 RGA Plane Clusters with Corresponding Bouguer Gravity Anomalies after Ferguson et al.

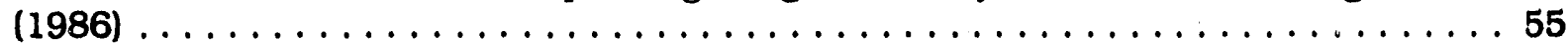

31 RGA Plane Clusters with Corresponding Regional Gravity Anomalies (Fourler trend sur-

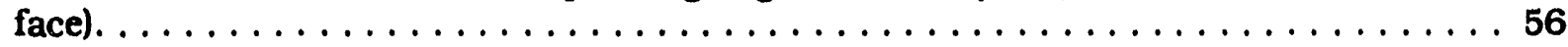

32 RGA Plane Clusters with Model of Depths to Tertiary/Paleozoic Unconformity . . . . . . 57

33 Magnetic Anomalies for the Northern Portion of Yucca Flat . . . . . . . . . . 58

34 Detalled Magnetic Anomalles for Part of Yucca Flat . . . . . . . . . . . . . . 59

35 Yield Residuals for 160 Nuclear Weapons Tests at Yucca Flat. . . . . . . . . . . . 61

36 Lineament Map of the Palute Ridge Quadrangle, NTS, Based on Landsat TM

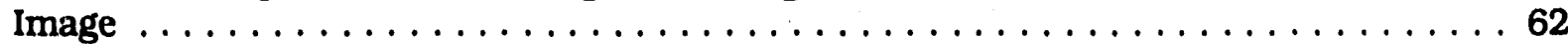

37 Lineament Map of the Palute Ridge Quadrangle, NTS, Based on Shaded-Relief

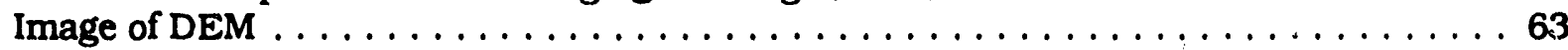

38 Lineament Map of the Paiute Rdge Quadrangle, NTS, Based on Shadow-Corrected

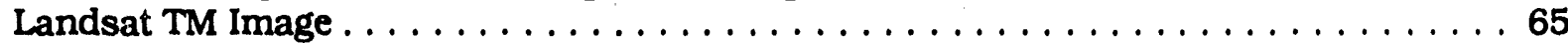

39 Lineament Map of the Palute Ridge Quadrangle, NTS, Based on Stereographic Projection of Shadow-Corrected Landsat TM Image $\ldots \ldots \ldots \ldots \ldots \ldots \ldots$

\section{TABLES}

1 Significant RGA Plane Clusters for the Yucca Flat Study Area . . . . . . . . . . . 26

2 Summary Correlations for RGA-Determined Plane Clusters for Yucca Flat . . . . . . . . 30 


\section{INTRODUCTION}

Using teleseismic data to discriminate underground nuclear tests from earthquakes and to estimate yields requires knowledge of the seismic responses of both test and receiver sites and of the seismic-wave propagation paths between sites. Because characterlzations of the crustal heterogeneities that affect seismic-wave propagation are generally unavallable, current yleld-estimation methods use empirical models that require statistical analysis of data from several blasts to evaluate each test-site/receiver-site couple. This approach is clearly subject to relattvely large random and systematic errors that can conceivably be reduced by partitioning a test site into areas of potentially different seismic response before developing the empirical yield-magnitude models. Because most test sites are inaccessible, the method for characterizing such crustal heterogeneities must be able to rely solely on remotely sensed data; however, the characterization method must also be able to use whatever field geological and geophysical data may become avallable.

\section{ANALYTICAL APPROACH}

Beginning in FY 1986, Pacific Northwest Laboratory (PNL) developed the initial automated geomorphic pattern-recognition part of a Remote Geologic Analysis (RGA) system to Identify crustal structures that may affect seismic wave propagation from nuclear tests. The RGA approach to geomorphic pattern-recognition is to first use simple, automated methods to identify primitive geometric surface features such as valleys, ridges, facets, and terraces, and then to aggregate successively larger, more complex features.' Using a DEM as its only input data, the initial RGA pattern-recognition system identifles linear segments of valley bottoms and fits planes to those segments that are coplanar. Specifically, RGA algorithms identify all points in the DEM that are lower in elevation than their neighbors, string these low points together into continuous valley bottoms, and fit vectors to colinear seginents of the valleys. The analysis then compares valley-segment vectors to find those that are coplanar, and calculates the locations and orientations of the resulting planes. The RGA system uses statistical clustering of the planes to spatially locate zones of anomalously high density for comparison with mapped geologic features.

Implicit in the prototype RGA pattern-recognition approach is Eliason's (1984) hypothesis that segments of erosional valleys that lie along approximately planar faults or fracture zones are coplanar. Of all the stream valleys in a landscape, then, the parts of interest are those segments that lie along zones of shearing or fracturing where erosion is enhanced as a result of weakening of the rocks, percolation of meteoric water, and accelerated weathering. By using vectors fitted to these valley segments, the RGA system further assumes the segments that serve to identify planar shear zones are linear. These assumptions are reasonable because most stream longitudinal profiles are only slightly curved, and a shear-zone-defined valley is, by definition, almost straight in map view. There will be other, linear valley segments in topography that are unrelated to enhanced erosion along faults or fractures, but RGA assumes that the pattern-recognition analysis for planes eliminates most of these uncorrelated vectors.

\section{APPLICATION TO YUCCA FLAT}

Because RGA uses computer methods to identify zones of hypothesized structural control of topography, ground truth using a well-characterized test site was critical for evaluating RGA's 
characterization of inaccessible test sites for seismic verification studies. Therefore, RGA was applied to a study area centered on Yucca Flat at the Nevada Test Site (NTS) and results were compared with both mapped geology and geologic structures and with seismic yleld-magnitude models. 


\section{YUCCA ELAT STUDY AREA}

In a March 1988 workshup on PNL's RGA system, arms-control verification community participants concluded that the initial RGA geomorphic pattern-recognition concept was sufficiently developed and showed promise for geologic studies in support of yield determination. The participants further concluded that long-term support of the RGA technology by OAC should be predicated upon the results of a proof-of-principle application to a real test site. We selected the Yucca Flat area of the NTS for this trial application because the topography, geology, and seismology are relattvely well known. Because the RGA pattern-recognition methods are more easlly lllustrated using an application, we first describe the study area in this section before proceeding in the next sections to describe the analysis and to evaluate the results.

\section{PHYSIOGRAPHY}

The NTS lies in the Great Basin section of the Basin and Range Province (see Figures 1, 2. and 3), and our study area is itself characterized by a large basin. Yucca Flat. Yucca Flat is located in the northeast quadrant of NTS and is bordered by irregularly oriented sub-basins and ranges (Sinnock 1982). This study area consists of nine $71 / 2^{\prime}$ quadrangles and can be divided into six physiographic regions (see Figure 4). At the center is Yucca Flat, an alluvium-fllled basin generally oriented with the long axds north-south. The Halfpint Range lies east of Yucca Flat and consists of north-northwest trending sub-basins and ranges; the ranges trend more northeasterly toward the southern part of the region. South of Yucca Flat lies the CP Ridge region that contains the northwesterly trending CP Ridge as well as the CP Hills. North of the CP Ridge region is the Mid Valley region including Mine Mountain and the Calico Hills. In this region ranges trend north to northeast. North of the Mid Valley region and to the west of Yucca Flat is the Eleana Range, which contains north to northeast trending ridges and valleys with some east-west trending valleys as well. Finally, to the north of Yucca Flat is the Quartzite Ridge region, characterized by north to northeast trending ridges and valleys.

\section{GEOLOGIC HISTORY}

The oldest rocks exposed in the NTS date from late Precambrian time and overlay an even older igneous-metamorphic complex that is not exposed in the study area (Sinnock 1982). The Precambrian rocks are overlain by a series of miogeoclinal deposits, or marine deposits derived from the erosion of a stable continental landmass. Figure 5 illustrates a stratigraphic column of rocks at the NTS; Figure 6 summarizes the geologic history of the site.

The stratigraphic sequence at the NTS begins with the Johnnie Formation, followed by the Sterling Quartzite and the early Wood Canyon Formations. These three formations are predominantly quartzites with local sandstones, siltstones, and dolostones in the Johnnie Formation and siltstones and shales in the Wood Canyon Formation. Deposition of the Wood Canyon Formation continued into the Cambrian. It was overlain by the Zabriskie Quartzite, which was followed by the deeper-water marine shales of the Carrara Formation. Carbonate deposition of the Bonanza King Formation and clastic deposition of the Dunderburg Shale began after the Carrara. The Dunderburg Shale may represent a minor pulse of uplift to the east, and the erosion that produced this clastic sequence was followed by the deposition of carbonates of the Nopah Formation and the Pogonip Group of the Ordovician. These later carbonates could indicate a reefal en- 


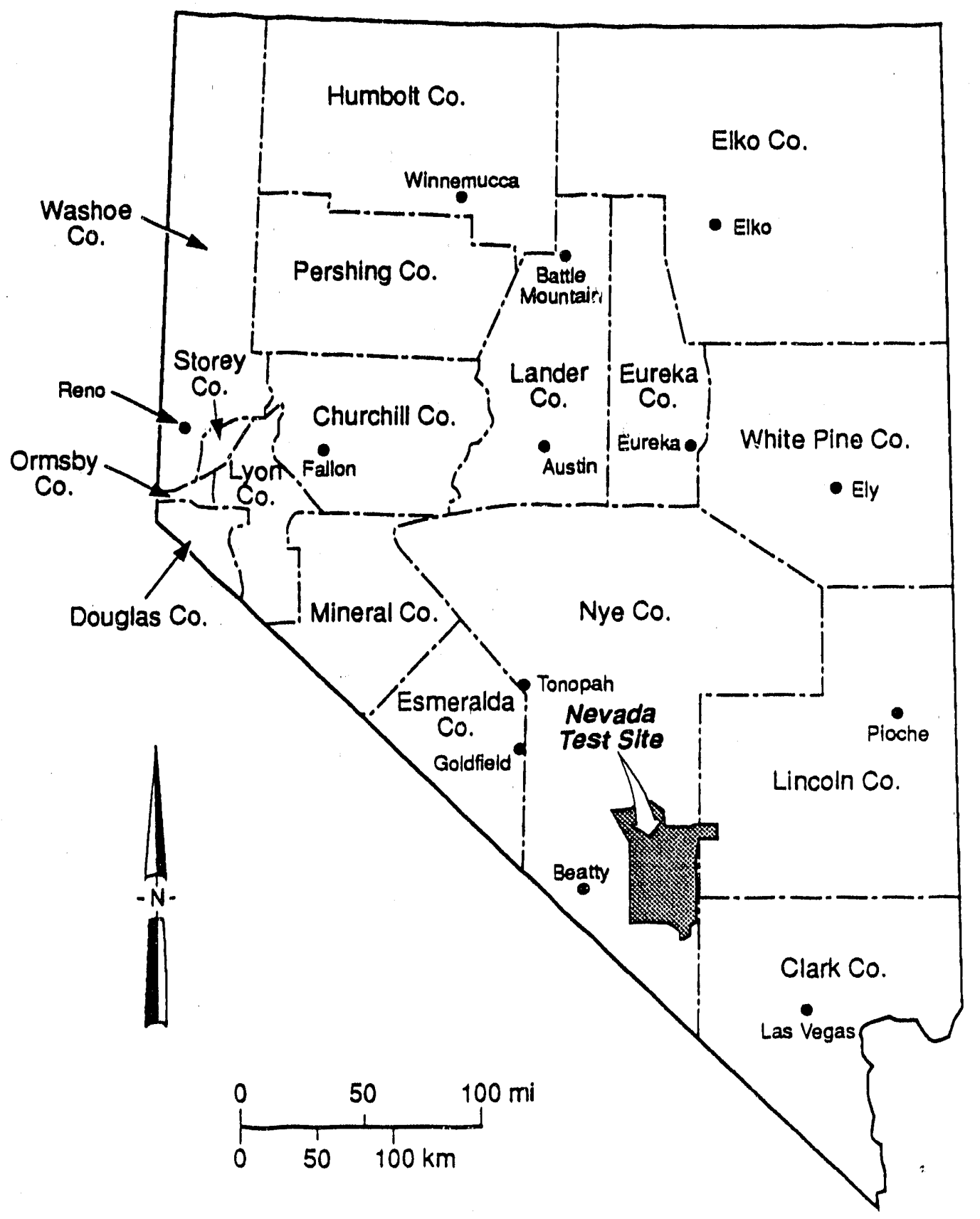

$\$ 9109049.4$

FIGURE 1. Location of the NTS 


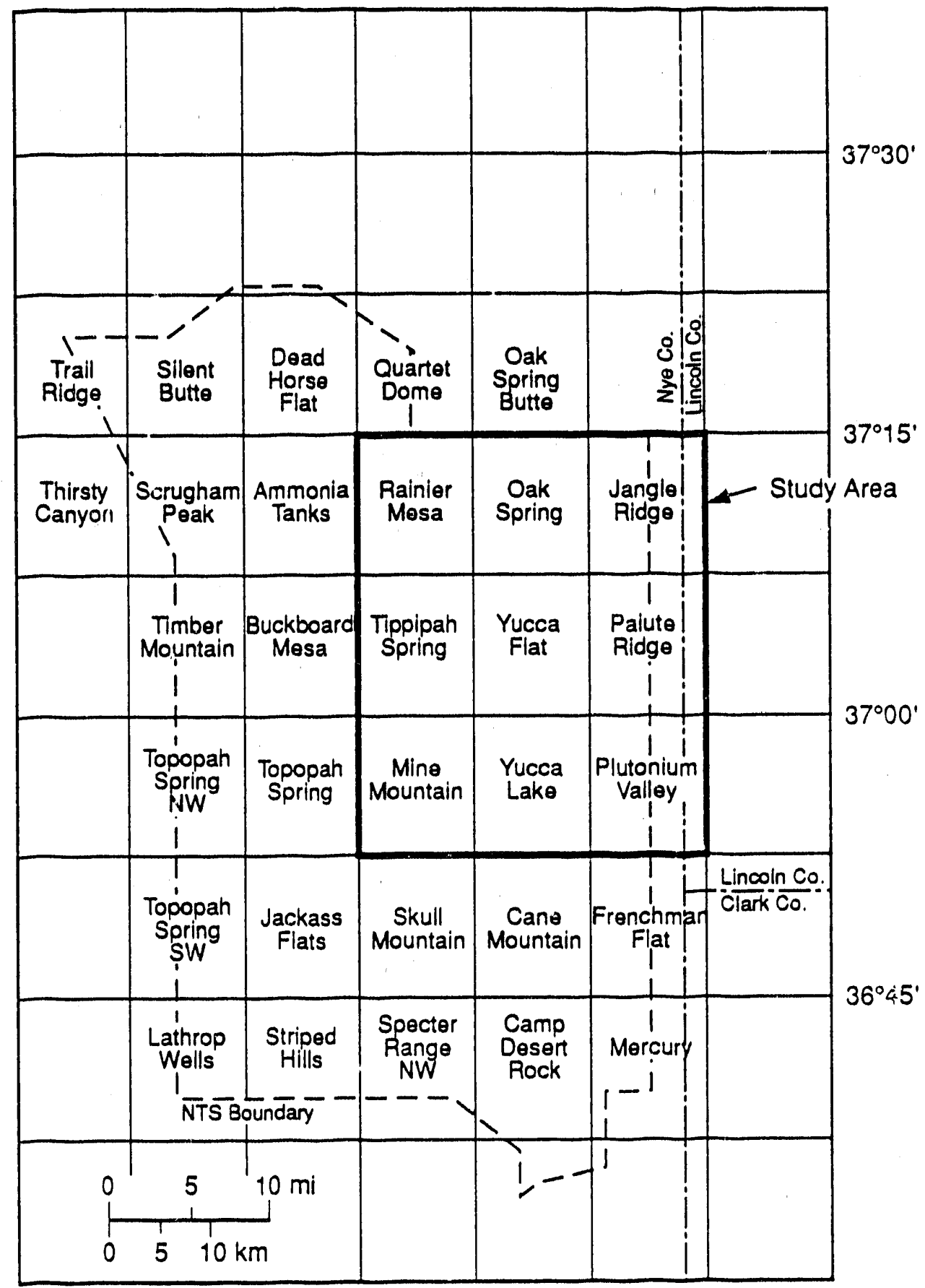

59109049.3

EIGURE 2. Nevada Test Site and Yucca Flat Study Area 


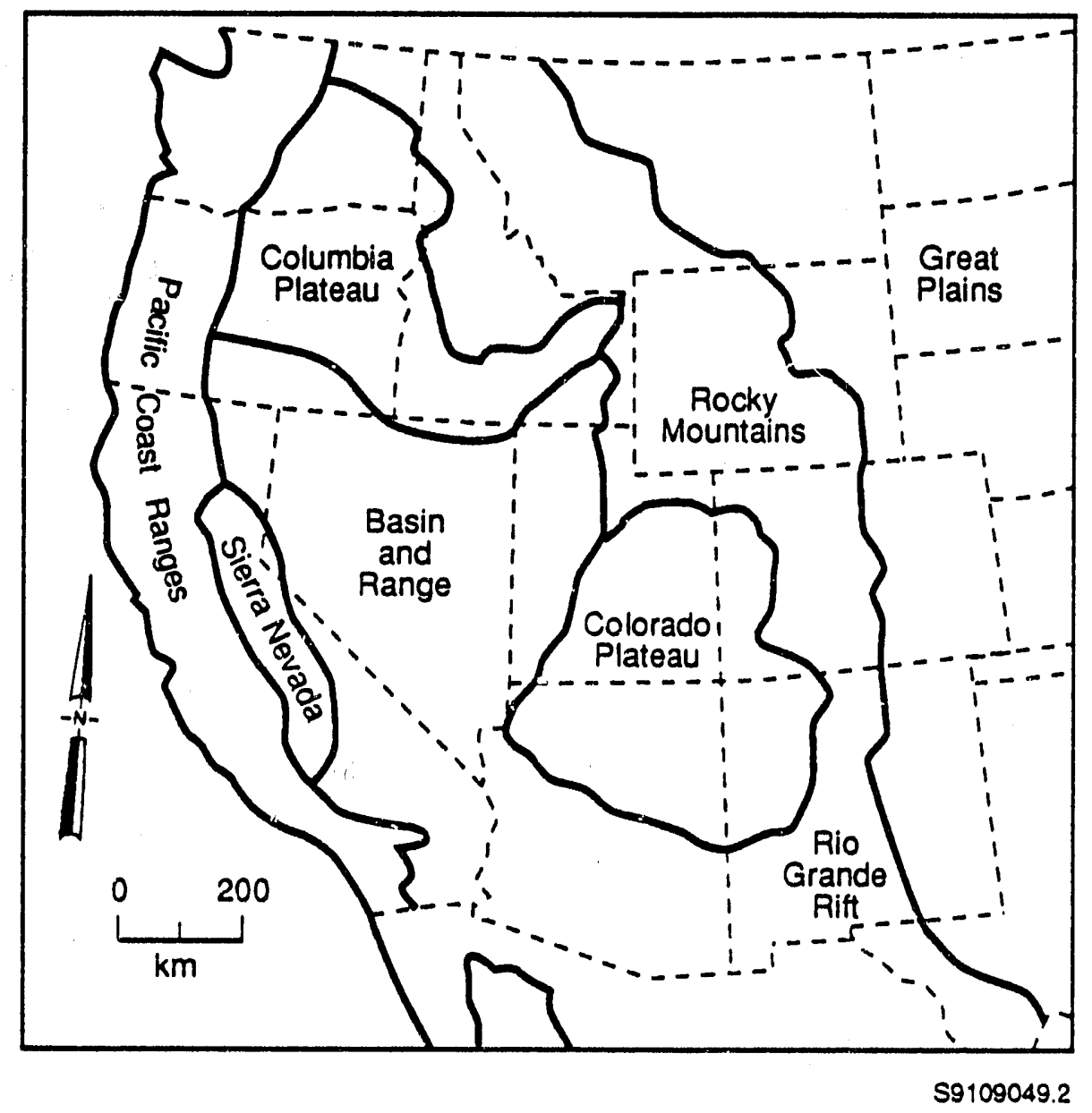

FIGURE 3. Physiographic Provinces of the Western United States 


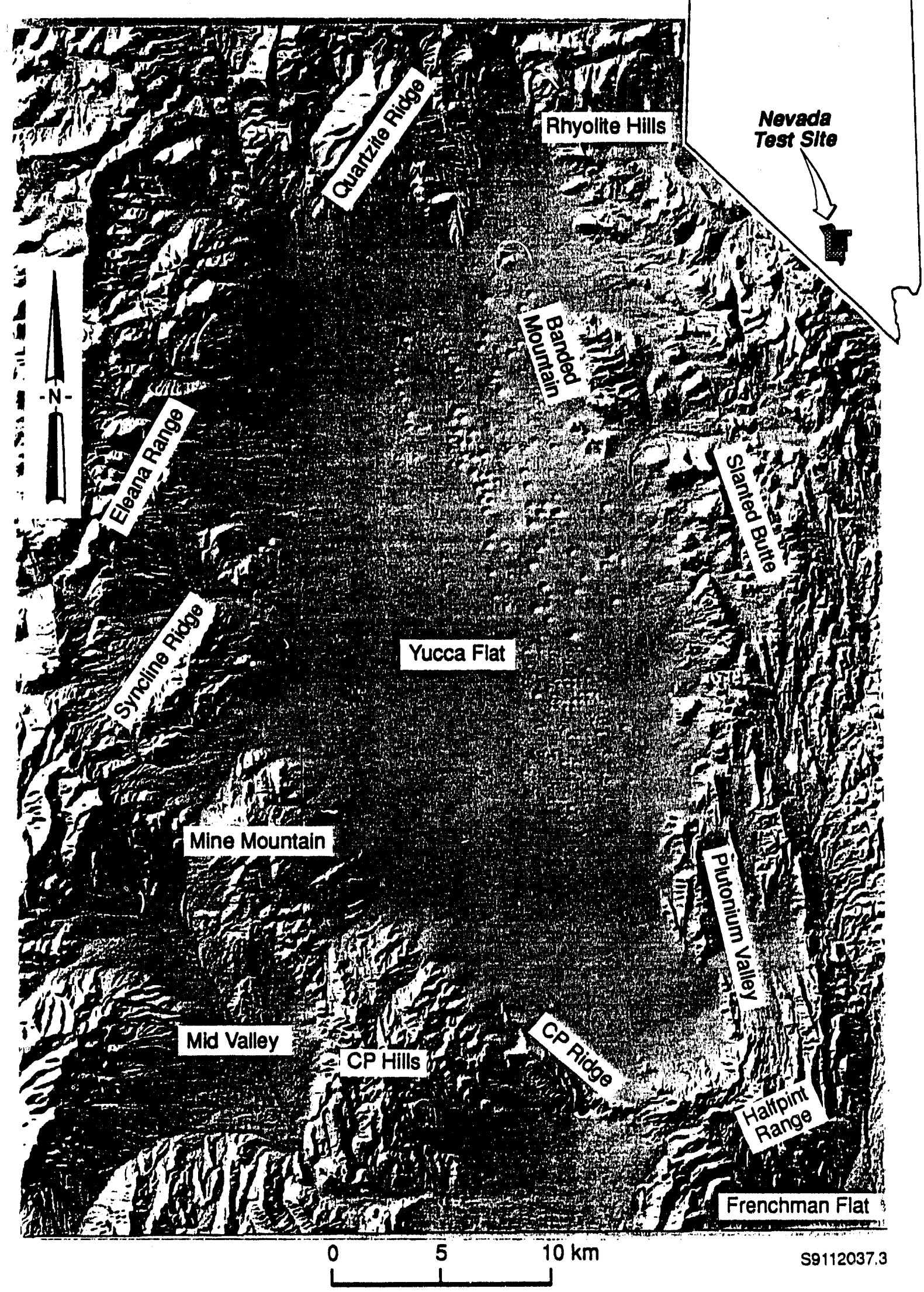

FIGURE 4. Physiographic Regions of the NTS Study Area 


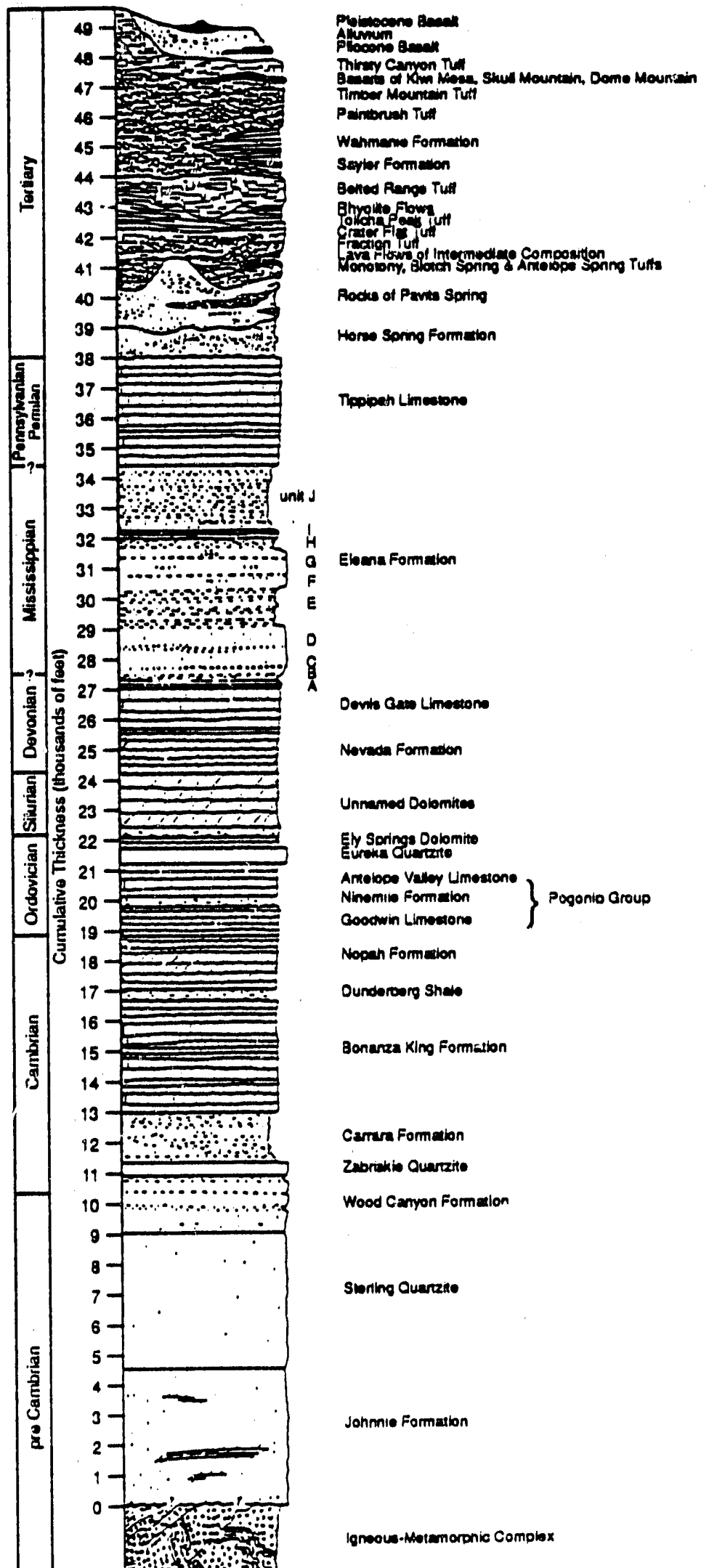

59109049.7

FIGURE 5. Stratigraphic Section of the NTS Study Area 


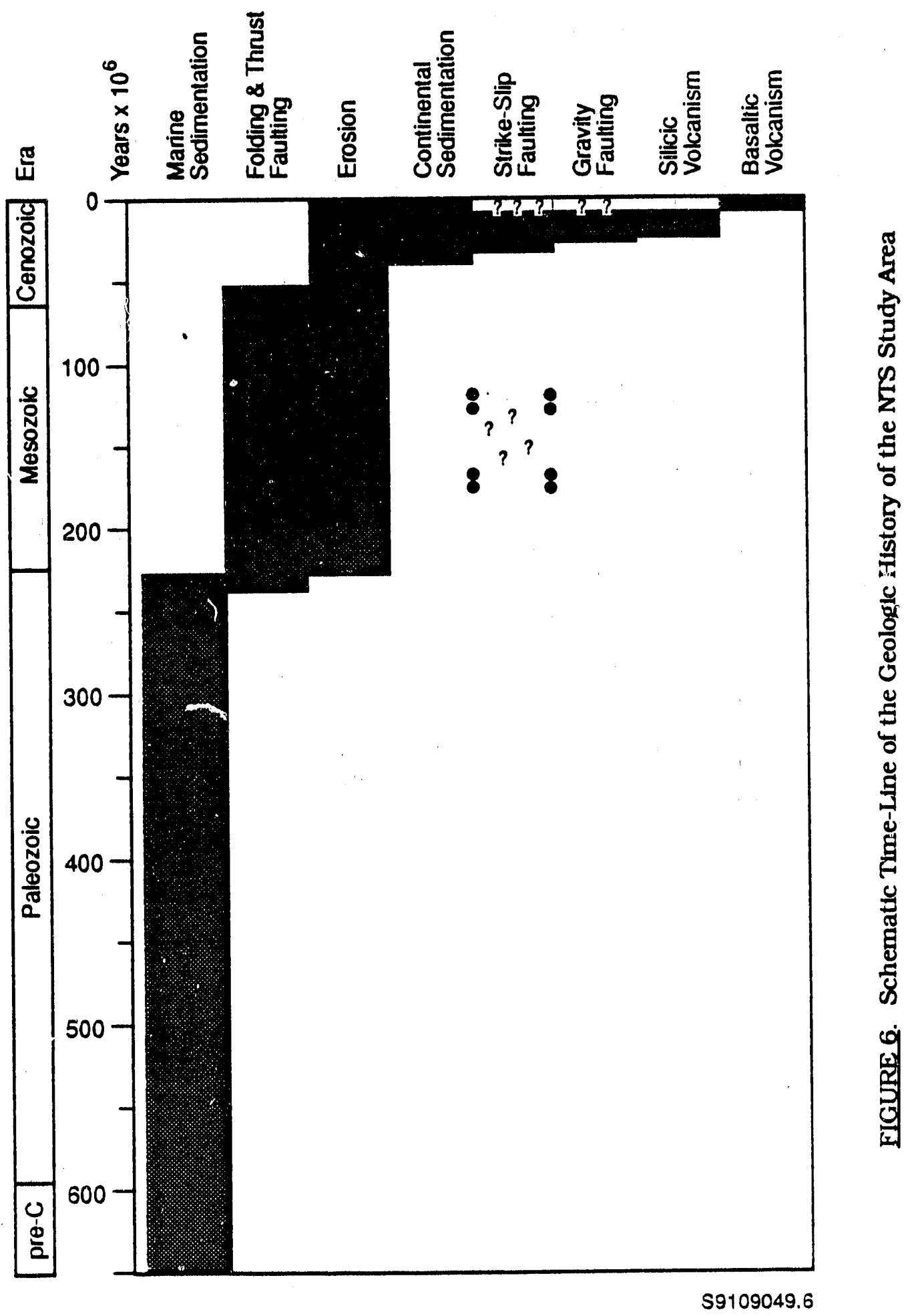


vironment. Overlying the Pogonip Group is the Eureka Quartzite, which marks the regression of the sea and the end of the Sauk Sequence. The seas returned later in Eureka time, reworked the earlier sands, and deposited the transgressive portion of the Eureka Quartzite. Deposition of more carbonates followed in the Ordovician Ely Springs Dolomite, unnamed Sllurian Dolomites, and the Nevada Formation, and Devil's Gate Limestone of the Devonian.

In central Nevada, the Antler Orogeny was a time of mountain building from the Devonian to the Mississippian, but only a small disconformity at the NTS represents this event. This orogeny created a land mass northwest of the NTS and a trough where the Eleana Formation was deposited. The Eleana Formation consists mostly of argillites with carbonates, quartzite, and conglomerates also present (Sinnock 1982). The conglomerates could be the result of the emsion of the Devil's Gate Limestone (Poole. Houser, and Orkuld 1961). Following an early Pennsylvanian hiatus, deposition of the Tippipah Limestone continued into the Permian. The Tippipah Limestone is the last recognized marine depositional unit in the NTS area: its deposition was followed by intense regional compression beginning in the late Paleozolc and lasting through the early Cenozolc (Sinnock 1982).

The compressional tectonics in the NTS resulted in extenstve folding and thrust faulting during the Mesozolc. Initial thrust faulting and folding are thought to have begun during the Nevadan Orogeny from the middle Triassic to early Jurassic (Burchflel, Pelton, and Sutter 1970). Fold axes and thrust faults from this orogeny trend north to northeast, suggesting a compressional direction from the northwest to west (Sinnock 1982; Speed 1978). The Sevier Orogeny in the late Mesozolc probably caused little new deformation at the NTS, but it likely produced renewed movement along existing thrusts and folds. Small granitic intrusions were also emplaced during the Mesozolc. These intrusions include the Climax, Gold Meadows, and Twin Ridge Stocks. Emplacement of the Gold Meadows Stock occurred near the Jurassic-Cretaceous boundary, but timing of the other two stocks is uncertain (Gibbons et al. 1963). East of the NTS, the Sevier Orogeny ended in the late Cretaceous, although mountain bullding continued in the Rocky Mountains and is referred to as the Laramide Orogeny (Sinnock 1982).

The Cenozoic Era at the NTS is characterized by widespread volcanism, formation of the Basin and Range, and the development of strike-slip faulting. Before the onset of volcanism, deposition of the Horse Springs Formation took place, resulting in interbedded siltstone, claystone, conglomerate, limestone, tuffaceous sandstone, and minor tuff. Silicic volcanism began about 29 m.y. ago, during Horse Springs time. This activity resulted in widespread deposition of tuffs, as well as extrusion of rhyolite lavas (Sinnock 1982). The volcanism was probably controlled by concurrent extension of the entire area, possibly caused by back-arc spreading. The volcanism was not directly derived from subduction of the Farallon Plate (Anderson 1989; Stewart 1978; Eaton et al. 1978). Interbedded with these silicic tuffs and rhyolites are minor deposits of basalt, andesite, tuffaceous alluvium, and breccia. Most of these mid-Miocene erupttve centers occurred to the west of our study area and include the Sleeping Butte, Silent Canyon. Claim Canyon, Oasis Valley, and Timber Mountain Calderas, which overlap each other in the western part of the NTS (Figure 7).

About 6 to $8 \mathrm{~m} . y$. ago, silicic volcanism ceased and basaltic volcanisnı bagan (Sinnock 1982). These basalt flows were much less extensive than their silicic predecessors. They generally oc- 


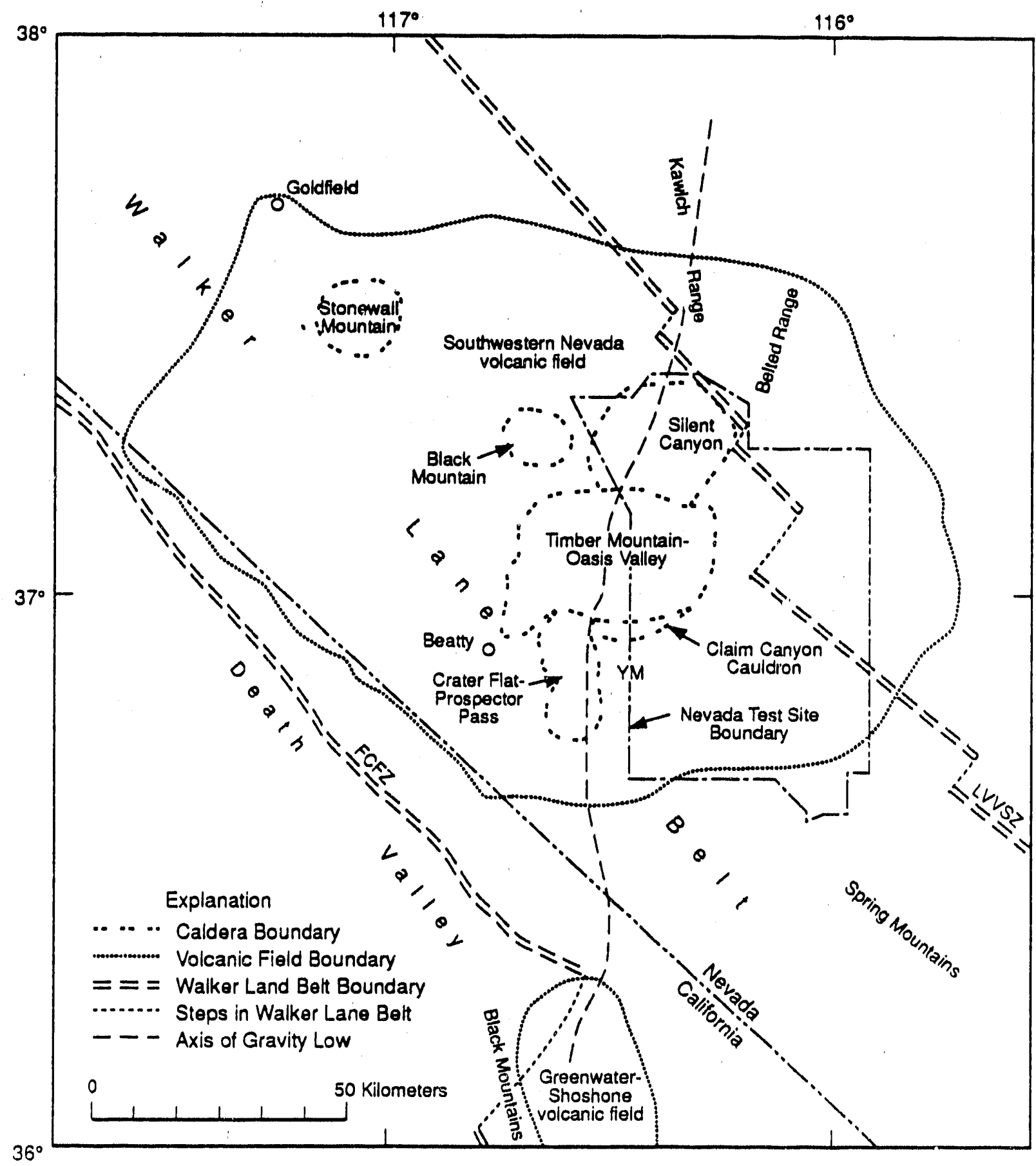

S9109049.1

EIGURE 7. Location of the Walker Lane Belt and Calderas of the Greenwater-Shoshone Volcanic Field in Relation to NTS. YM, Yucca Mountain; FCFZ, Furnace Creek Fault Zone; LVVSZ, Las Vegas Valley Shear Zone (Carr 1988) 
curred in the western half of the NTS and are located at Buckboard Mesa, Dome Mountain, KJw1 Mesa, Skull Mountain, and Little Skull Mountain. These basalts differ from earlier Miocene and Pliocene basalts in that the earlier basalts were "late-stage ... differentiates of the sillcic parent magma" (Sinnock 1982). The later basalts, hawalltes, seem to be the result of extreme lithospheric extension throughout the NTS at that time (Sinnock 1982).

Basin and Range extension seems to have hegun at about the same time as silicic volcanism. about 20 to $35 \mathrm{~m} . y$. ago, and is possibly the result of back-arc spreading, mentioned earller. However, the present basins and ranges probably did not form untll later than 15 to 20 m.y. ago and follow the trends of earlier deformation (Ekren et al. 1968; Stewart 1978). Determination of the timing of specific fault trend activity is unresolved. Ekren et al. (1968) state that inactive normal faults trend northeast and northwest, with the younger and perhaps still active set trending north. Carr (1974) however, thinks the north trending faults in the NTS are inactive, and the northeast trending faults are currently active. Carr supports this with evidence suggesting an extension direction of $5^{\circ} 0^{\circ} \mathrm{W}$ at the NTS, which is also supported by Ander's research (1984).

Strike-slip faulting and shearing also occurred at the NTS during the Cenozolc. Northeasttrending, left-lateral strike-slip faults occurred in the central portion of the NTS along the Cane Spring, Mine Mountain, and Rock Valley Faults (southern NTS). An east-trending, left-lateral strike-slip fault occurred to the south of Syncline Ridge and right-lateral movement occurred along a northwest-trending fault to the north of Syncline Ridge. Right-lateral movement also occurred along the Walker Lane/Las Vegas Valley Shear Zone (see Figure 7), which trends northwest through the NTS (Hoover and Morrison 1980; Carr et al. 1974; Sinnock 1982). Age of movement along this zone is uncertain. Albers (1967) believes that movement began in the early Jurassic and in some areas lasted until the Middle Tertiary. Noting that range topography is bent in some areas. Carr (1974) thinks that movement took place after the present ranges were formed. Ekren et al. (1968) believe that most movement along this zone took place in the last 17 m.y. Carr (1974) also suggests that the left-lateral faults are really oblique slip and were formed simultaneously with the Las Vegas Valley Shear Zone. He also thinks that activity along both has decreased since 11 m.y. ago, with little activity at present, and that the left-lateral faulting is complementary to right-lateral shearing. Others think that the left-lateral faulting is related to the currently active Garlock Fault in Calfornia, which could mean that left-lateral faults at the NTS are currently active (Suppe, Powell, and Berry 1975).

Deposition of alluvium at the NTS began 17 to $14 \mathrm{~m}$.y. ago during the last phases of sllicic volcanism when current basins and ranges were being formed (Ekren et al. 1968; Sinnock 1982). Depusition has continued to the present day and can reach depths of over $1,000 \mathrm{ft}$. in some of the larger basins (Sinnock 1982; McKeown, Healey, and Miller 1976; Colton and McKay 1966).

\section{STRUCTURAL GEOLOGY}

The overall structural geology of the study area consists of variously orlented normal, thrust. and strike-slip faults with folds and joint sets usually following nearby fault trends (Figure 8). The structural geology of the study area will be examined region by region.

Yucca Flat is an alluvium-filled basin, elongate north-south, with two major normal faults running almost its entire length. These two faults, the Carpetbag and Yucca faults, define the edges of a burled horst and graben structure (Sinnock 1982). Both faults join the northeast 


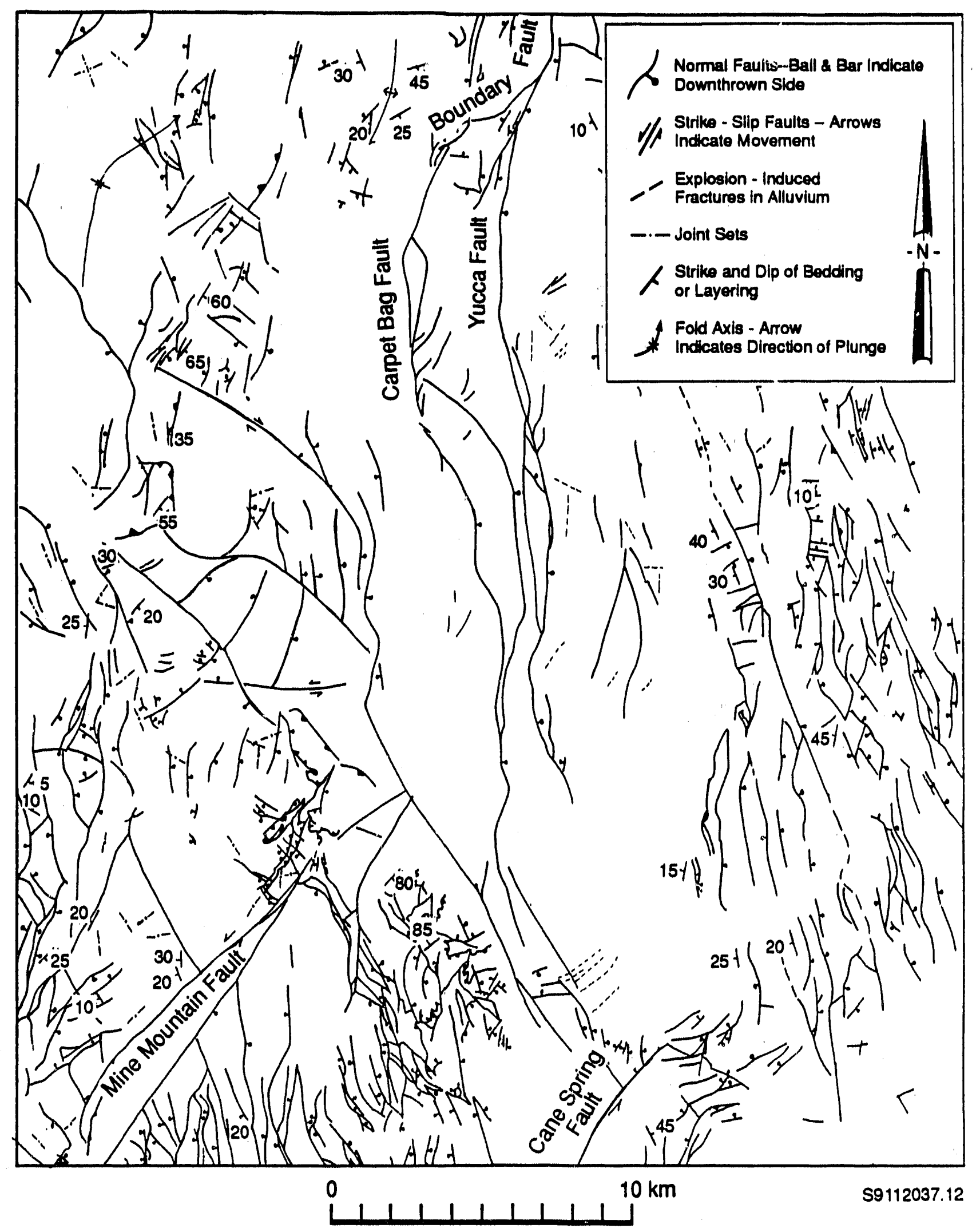

FIGURE 8. Mapped Structures of the Yucca Flat Study Area (primarlly Frizzell and Shulters 1990) 
trending Boundary fault at the northern edge of Yucca Flat, and possibly join the Cane Spring fault to the south (Frizzell and Shulters 1990; Carr 1974). Nuclear blasts beneath Yucca Flat have caused movement along the Carpetbag and Yucca faults and have also created fractures in the alluvium in Yucca Flat (Barosh 1968; Sinnock 1982). Some of these fractures are radial or concentric and are centered around ground zero. Others, however, follow one of the dominant structural trends of this area (Barosh 1968; USGS 1977). A long system of faults at the western edge of Yucca Flat begins as a northwest trending, right-lateral, strike-slip fault and continues southward toward CP Ridge as a normal fault (Cornwall 1972).

The Halfpint Range is characterized by northwest trending normal faults and folds; many of these faults define valleys. A set of normal faults trend northeast in the Banded Mountain and Paiute Ridge areas and several small folds occur both in tuffs and in the Sterling Quartzite in the northeastern part of this region. These folds tend to be subparallel to nearby faults and joints. Joint sets in the north of this region mainly trend northwest or northeast, with a northerly and an easterly trend in the Rhyolite Hills (Barosh 1968). Joint information regarding the southern section of this region is sparse, but bedding generally strikes northeast and dips at moderate $\left(15^{\circ}\right.$ to $45^{\circ}$; angles to the west (Barnes, Christiansen, and Byers 1965; Hinrichs and McKay 1965; Byers and Barnes 1967; Frizzell and Shulters 1990).

Structurally, the CP Ridge area is very complex. Generally, normal faults trend northwest with some tending to define valleys; a number of low-angle thrust faults occur in the western portion of this region. The Cane Spring Fault, a northeast trending, left-lateral, strike-slip fault, cuts the CP Ridge in the eastern segment of this area and continues to the southwest. The Carpetbag Fault is thought to join the Cane Spring Fault in the area of CP Ridge. Attitudes of bedding in this region are varied and show no overall trend (Orkdld 1968; McKeown, Healey, and Miller 1976).

The Mid Valley region is also structurally complex. In the south, ranges trend north-south, and normal faults tend to parallel these trends. In the north, the Mine Mountain Fault, a northeast-trending, left-lateral, strike-slip fault, cuts through the Mid Valley and part of Mine Mountain. About $1.5 \mathrm{~km}$ southeast, a normal fault runs subparallel to the Mine Mountain Fault and intersects it near Mine Mountain. The Mine Mountain Thrust Fault separates the eastern edge of Mine Mountain from Yucca Flat. In the rest of this region, most fault trends vary from northwest to northeast, and in some instances the faults define valleys. Joints in this region tend to follow the trends of nearby faults and are mostly near-vertical. Attitudes of beds vary widely, and there are no pervasive trends (Frizzell and Shulters 1990; Orkild 1963, 1968).

The Eleana Range region contains three dominant structural trends: northwest, north, and northeast. There is no overall trend for ranges as there is in the Halfpint Range, but fault-controlled valleys trend north and northeast. In the southeastern portion, Syncline Ridge trends northeast, as do two basins, one north and one south. A normal fault runs the length of Syncline Ridge and is cut by short normal faults that trend west and northwest. On its northeastern end. Syncline Ridge is cut by a northwest trending normal fault. As mentioned eariler, a northwest trending, right-lateral, strike-slip fault enters Yucca Flat north of Syncline Ridge. There are also north-trending thrust faults and north-to-northeast trending normal faults. Folds in this area, including Syncline Ridge and synclines in the northern part of this region, generally trend northeast. Joint trends are varied and do not necessarlly reflect the trends of nearby faults. Attitudes 
of bedding are also varled, but strikes tend to follow the trends of nearby faults (Frizzell and Shulters 1990; Robinson 1985; Orkild 1963, 1968; Gibbons et al. 1963; Hoover and Morrison 1980).

The Quartzite Ridge region is not as heavlly faulted as other regions in the study area. Most normal faults trend north, with a few west and northwest trends also present. The major fault in this area is the northeast-trending Boundary Fault, which joins with the Carpetbag and Yucca faults on the northern edge of Yucca Flat. A fold is also present in this area-an anticline in Quartzite Ridge. The axds of this anticline plunges in a south-southwesterly direction. In the eastern part of the region, a joint set trends in the same general direction. Attitudes of bedding vary widely (Frizzell and Shulters 1990; Barnes, Houser, and Poole 1963).

There is a possibility that faults and joints lie beneath the alluvium of linear washes at the NTS. Scott et al. (1984) showed that burled faults do indeed exist under the alluvium of some washes at Yucca Mouritain. The exdstence of similar features in our study area has not been proven, but buried faults or joints could control the topography of some washes. 


\section{REMOTE GEOLOGIC STRUCTURAL ANALYSIS}

In the DEMs of the Yucca Flat study area, we used the RGA geomorphic pattern-recognition and statistical hierarchical cluster analysis to identify zones of topography with anomalously high concentrations of coplanar valley segments. This automated approach is a logical outgrowth of conventional geomorphic analysis; however, it produces "features" that cannot necessarly be identified or confirmed using conventional field or remote sensing methods. For this reason we took considerable care to ensure identified plane sets were not serendipitous associations of unrelated valleys. Whether the identified features are also correlative with geologic structures will be discussed in a later section.

Our analysis consisted of three parts. The first part was a geomorphic pattern-recognition analysis in which we applied a valley-finder algorithm, a vector-fitting algorithm, and coplanar analysis to the entire Yucca Flat DEM to identify coplanar valley segments that may be evidence of erosional control by planar fracture zones. In the second part, we used statistical cluster analysis to locate zones of coplanar valley segments that were of anomalously high density (compared with random associations), which were the final output of the remote analysis. In the third part, we compared output of the remote analysis with topographic, geologic, and geophysical features to evaluate structural significance. The following section describes the first two parts of our analysis; the next section describes the third.

\section{COPLANAR ANALYSIS}

Our RGA geomorphic analysis of Yucca Flat used Eliason's (1984) hypothesis that segments of erosional valleys lying along approxdmately planar fault or fracture zones will be coplanar. The automated RGA pattern-recognition approach 1) identified all points in the DEM that were lower in elevation than their neighbors on both sides, 2) segregated those that formed contiguous strings (valley bottoms), and 3) fitted vectors to collnear segments of the strings. The analysis then compared every valley-segment vector with every other one to find those that are coplanar and calculated the location and orientation of the resulting planes.

This approach assumed that of all the stream valleys in a landscape, the parts of interest were those lying along planar zones of fracturing or shearing that enhance erosion. We further assumed, by using vectors fitted to segments of the valleys, that stream-valley segments of interest for identifying planar shear zones are linear. These assumptions are reasonable because most stream longitudinal profles are only slightly curved, and a shear-zone-defined valley is by deflnition almost straight in map view. There will be other linear valley segments in topography that are not related to enhanced erosion along faults or fractures, but we assumed that the patternrecognition analysis for planes would eliminate most of these uncorrelated vectors.

\section{Digital Elevation Model}

The Yucca Flat study area of the NTS comprises nine 1:24,000-scale U.S. Geological Survey (USGS) quadrangles (see Figure 2). Early USGS DEMs were unsuitable for application of RGA because the manual-profiling method used to generate them introduced east-west, linear-valley artifacts that RGA was capable of detecting. During 1989, the USGS made avallable a new series of 1:24,000-scale DEMs based on scanning and digitization of map contours, thus eliminating 
the linear artifacts produced by manual profling. We obtained contour-to-grid DEMs for six of the nine quadrangles of our study area: DEMs for the remaining quadrangles were prepared by Markhurd Corporation, a company that routinely produces contour-to-grid DEMs for the USGS.

The resulting Yucca Flat DEM (Figure 9) was composed of 1131 pixels east-west by 1404 pixels north-south, with a node spacing of $30 \mathrm{~m}(98.425 \mathrm{ft}$.). Apparently, the DEMs from the USGS and Markhurd are of equal quality; slight elevation mismatches at the edges are the result of quadrangle-by-quadrangle interpolation of contour lines. Some edge "tears" are the result of missing pixels in the USGS DEMs. Rather than attempt to repair these edge features, thereby potentially introducing systematic errors into the data set, we ignored the vertical, north-south or east-west planes detected along the edges.

\section{Valleys}

The valley finder identified low points in the digital topographic array by using a $7 \times 7$ node detector lsernal (Figure 10). The kernal checked whether the center pixel was lower in elevation than the end-point pixels in one or more of the 16 independent directions possible in the $7 \times 7$ node array. To qualify as a "low point," the center pixnl had to be lower than the end-point pixels by a "smoothing factor." The analyst specifled the smoothing factor after trials to select a value that minimized noise while still producing detalled valley networks. The high quality of the Yucca Flat DEMs allowed us to use a smoothing factor of $3.05 \mathrm{~m}$ (10 ft.). Adjacent individual low points were then strung into continuous valley bottoms with minimum lengths above a predetermined threshold; isolated low-point pixels and strings shorter than the threshold were eliminated. To accomplish the elimination, the valley finder ised a $3 \times 3$ kernal centered on subsequent adjacent low points to continue the strings along the maximum gradient. In this manner, 73,750 valley string points were identifled for the Yucca Flat area (Figure 11).

\section{Vectors}

The vector-fitting algorithm then broke the valley strings into linear segments by adding adjacent string pixels to a growing vector if the adjacent pixels fell within a user-specified colinearity tolerance. Whe used tolerances on vector trend and plunge of $10^{\circ}$ for the Yucca Flat analysis; a new valley-botiom vector was started if subsequent adjacent pixels fell outside this tolerance. After the vectors were identified, we useci a linear least-squares fit to the pixels in each vector to produce the final vector (represented by the fitted vector's two end points) in order to reduce the influence of the DEM grid to this extent possible by allowing vector end points to lie off the grid. The 73,750 valley strings prod iced from Yucca Flat topography yielded 6,446 vectors (Figure 12).

\section{Planes}

For the coplanar analysis, the program examined each pair of vectors in three-dimensional space to determine if all four vector end points lay within a single plane. Each possible plane contained three of the four end points; for each pair of vectors, then, four possible planes were calculated. We ridd not expect that real valley vectors related to erosion along a fault would be mathematically :oplanar. The coplanar analysis algorithm allows several user-specified parameters, including coplanar and colinear tolerances, the pole-magnitude ratio, and the dip limit. The coplanar tolerance was the maximum absolute angle between the poles (1.e., normals) to the planes defined by each group of three vector end points. For analysis of Yucca Flat vectors, the 


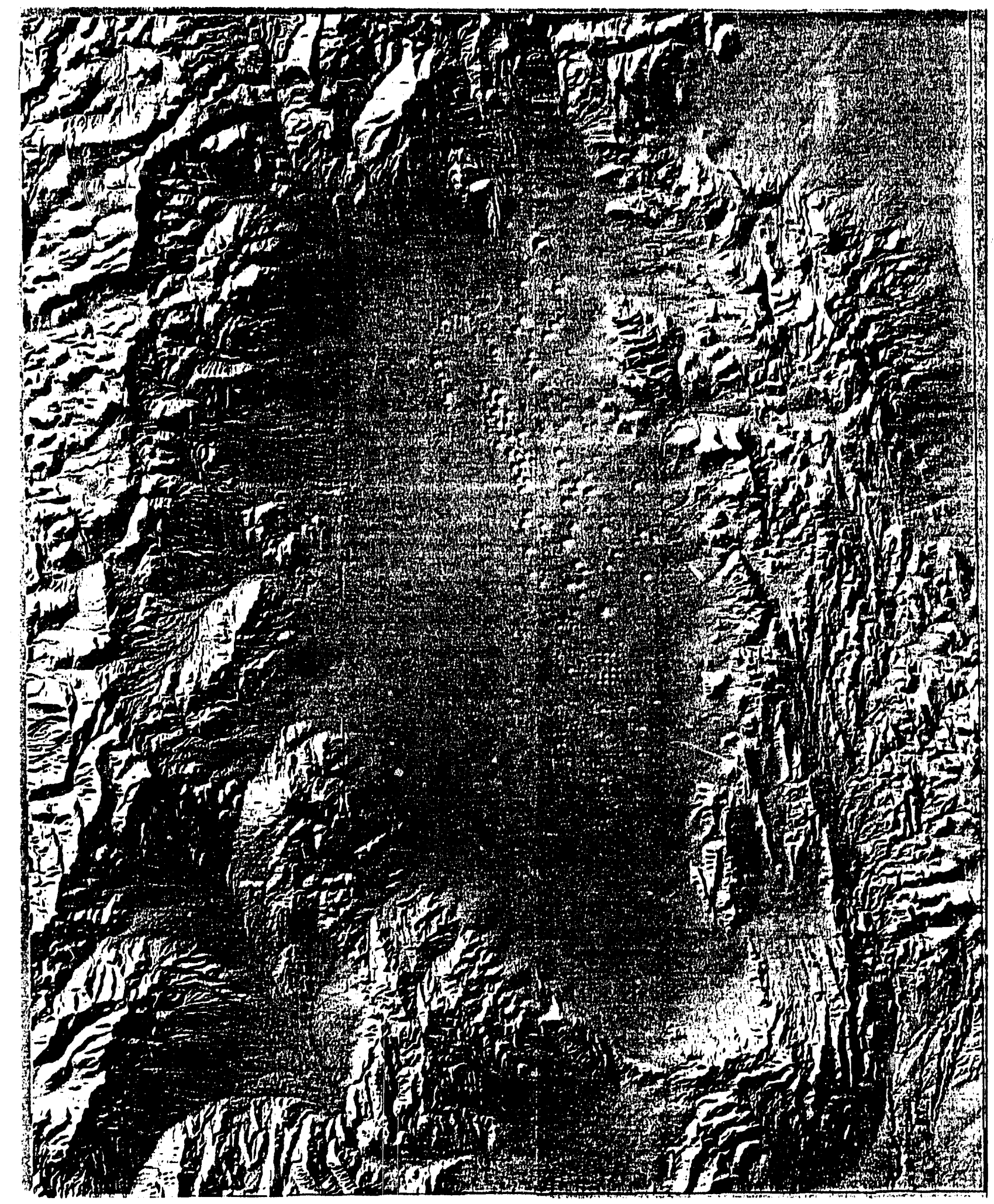

FIGURE 9. Digital Elevation Model for the Yucca Flat Study Area 

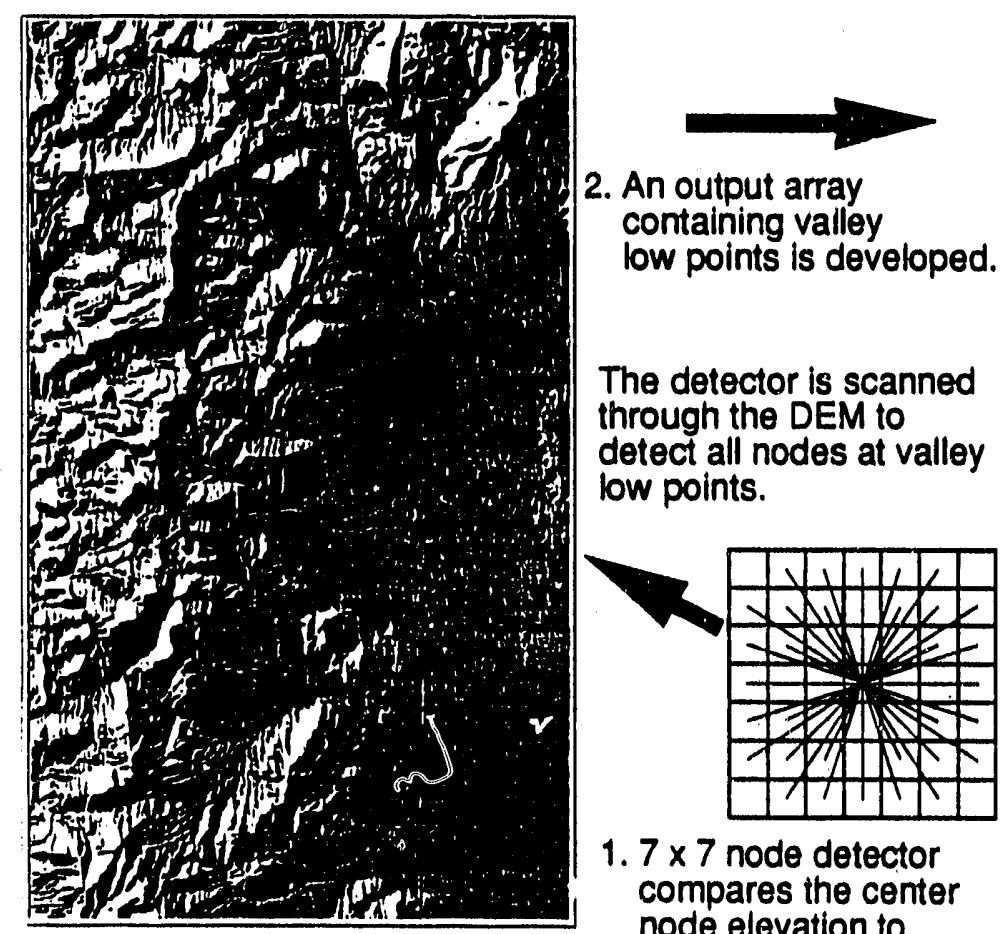

The detector is scanned through the DEM to detect all nodes at valley low points.

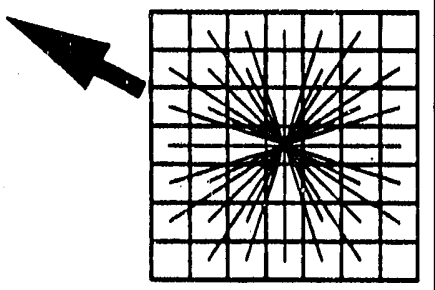

1. $7 \times 7$ node detector compares the center node elevation to elevations in each

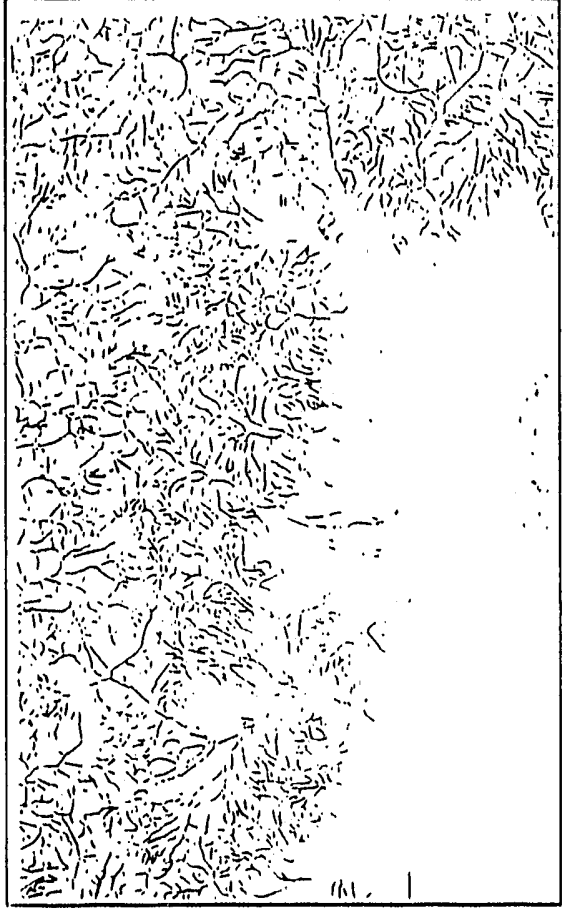
of 16 directions.

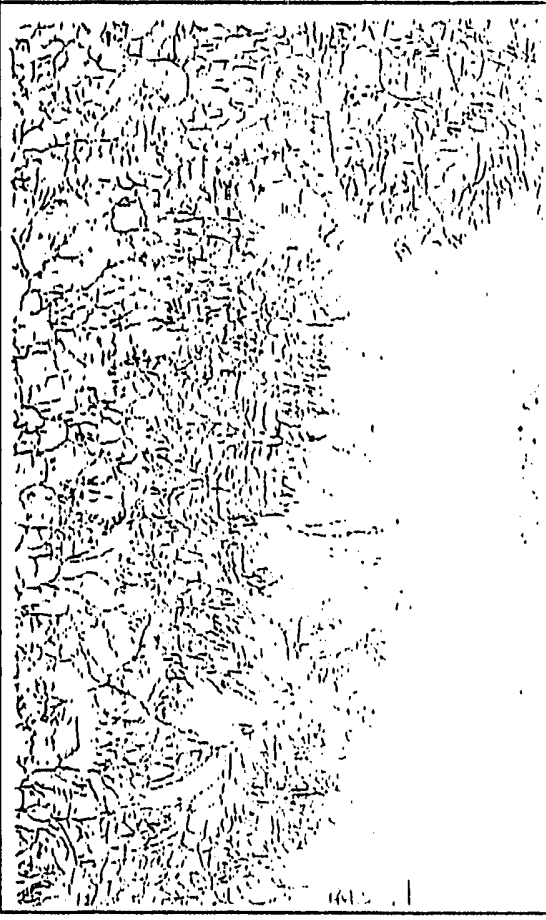

4. Vectors longer than user-specified minimum are output for coplanar analysis.

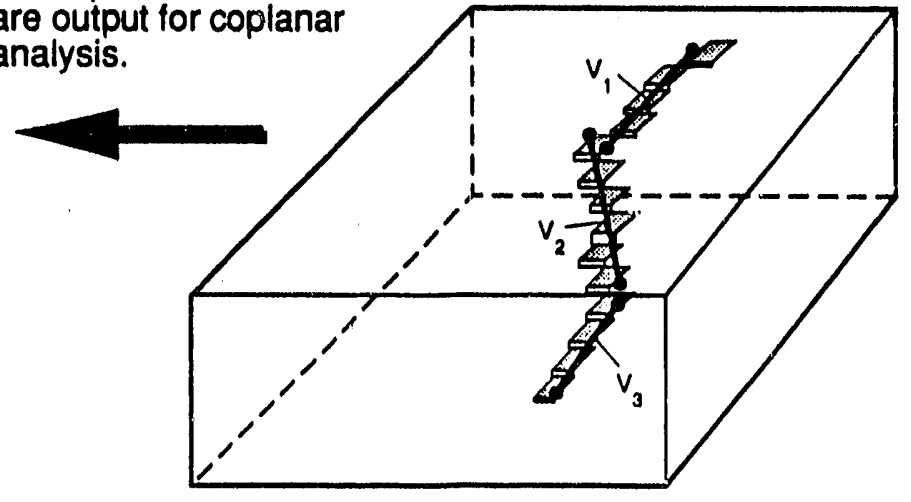

S9112037.13

FIGURE 10. Locating Low Points in a Digital Elevation Model and Fitting Vectors to Strings of Low Points 


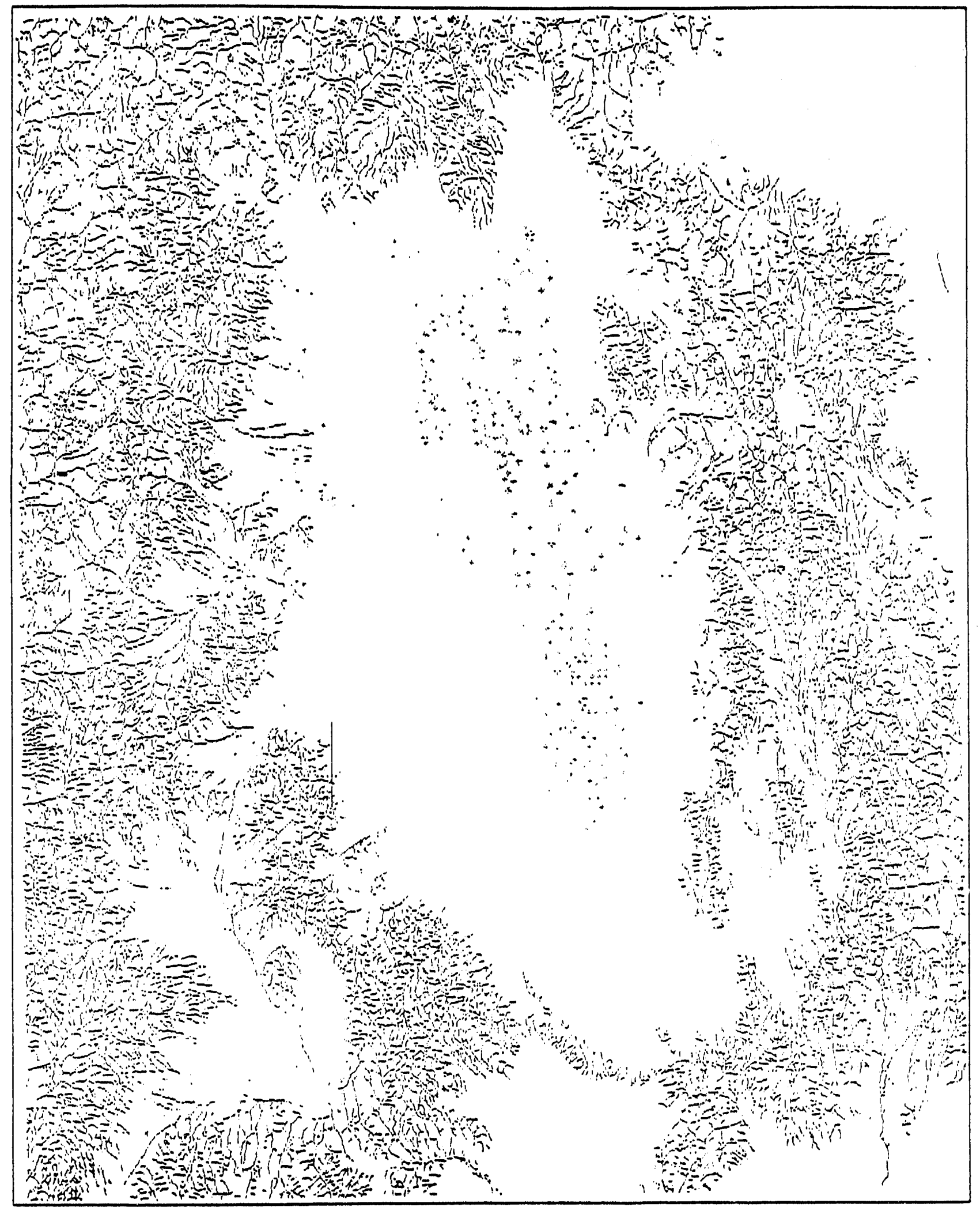

FIGURE 11. Low-Point Strings Detected in the Yucca Flat Study Area DEM by the RGA Valley Algorithm 


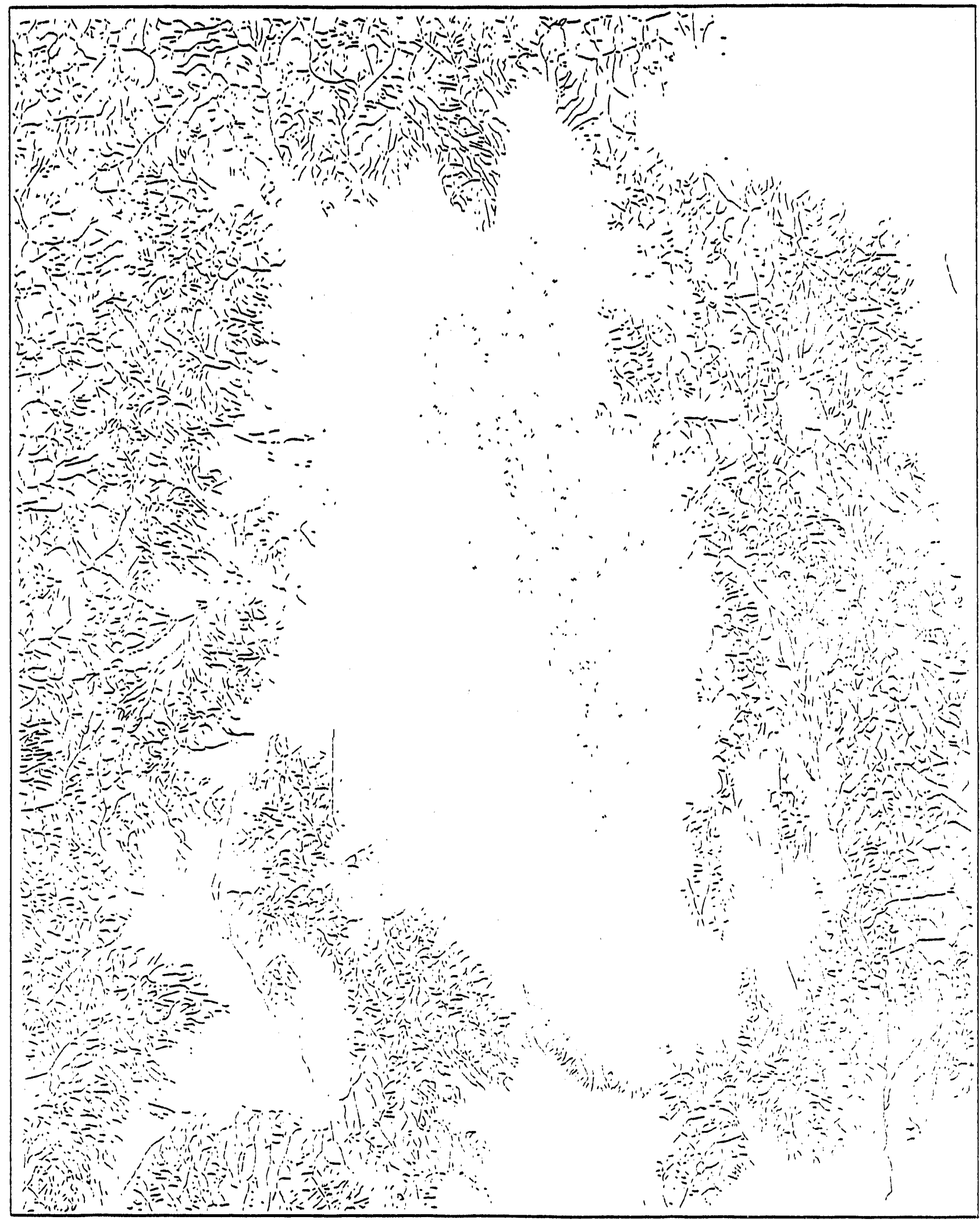

FIGURE 12. Valley Vectors Produced for the Yucca Flat Study Area DEM by the RGA Vector Algorithm 
value was $7^{\circ}$; planes with poles deviating from one another at angles $>7^{\circ}$ were not considered coplanar. A colinear tolerance, which represents the minimum allowable angle between vectors, was necessary because coplanar analyses cannot be conducted on absolutely colinear vectors. For this study, the collnear tolerance was set at $2^{\circ}$.

The pole-magnitude ratio was a tolerance specified with respect to the location, size, and orientation of each pair of vectors. The ratio was calculated from the relative lengths and orientations of the two vectors being tested. Consideration of these quantities was necessary because testing for coplanarity from a long vector to a short vector had a good chance of finding both planes coplanar; the reverse was not necessarlly true. For example, Figure 13 illustrates the four planes (A, B, C, D) that can be fit to two obviously non-coplanar vectors (1-2 and 3-4). If vector 3-4 is substantially shorter than 1-2, it is possible that planes A and B would be coplanar within the allowed tolerance while $C$ and $D$ would not. The cutoff pole-magnitude ratio we used for the NTS analysis was 15 , a value that worked well and had been determined by trial and error during previous analyses.

The final parameter set for the Yucca Flat coplanar analyses was the dip limit. This limit is the lowest dip for which a plane will be calculated from coplanar vectors, an important consideration because coplanar detections with higher dips are more likely to correspond to real geologic structures. Planes with dips $<30^{\circ}$ tended to be random hits between gently plunging valley-bottom vectors, and as such, should be ignored in coplanar analyses directed toward determining relevant geologic structures. We used a dip limit of $40^{\circ}$ for Yucca Flat coplanar analyses.

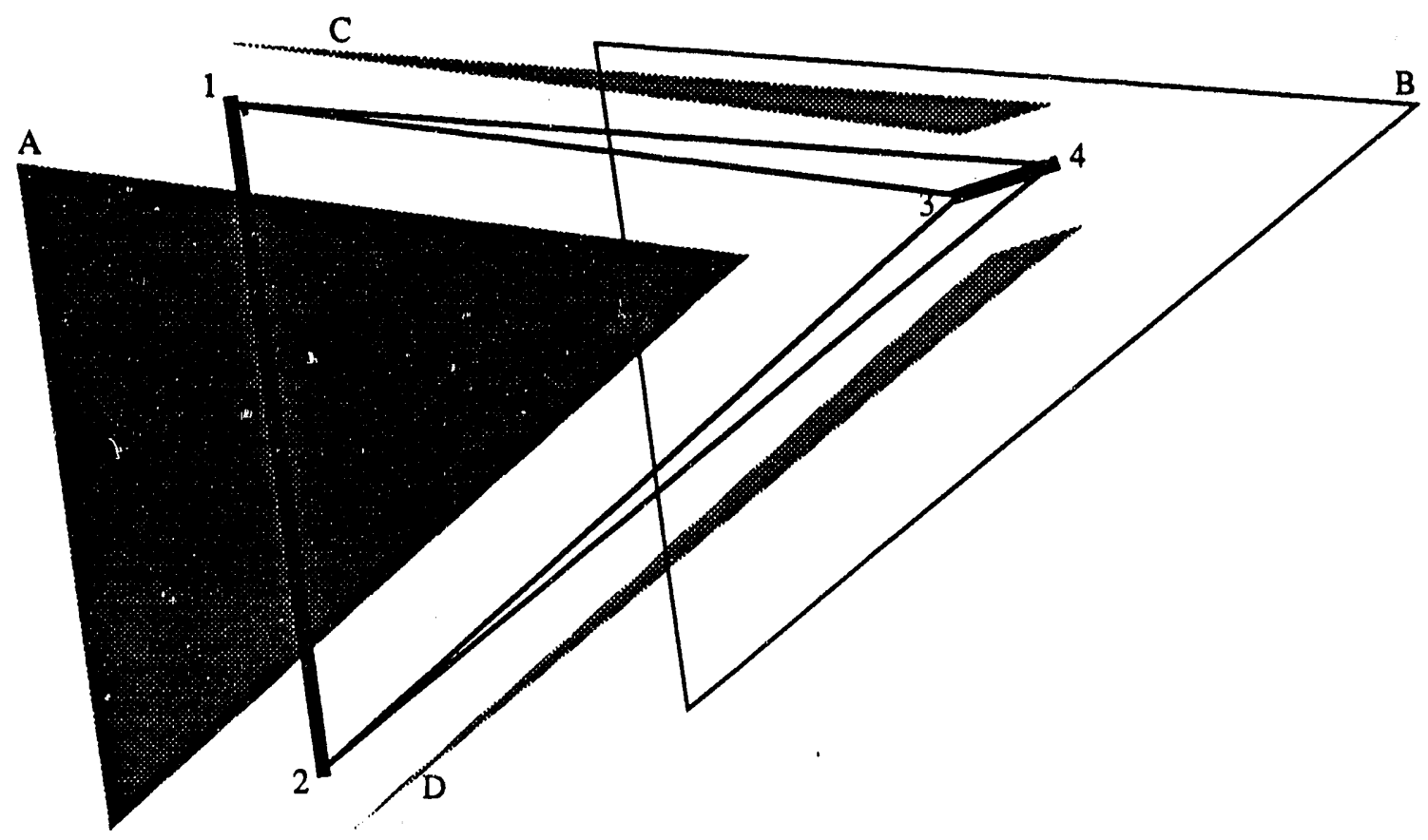

FIGURE 13. Illustration of the Need for the Pole-Magnitude Ratio in RGA Cluster Analysis 


\section{CLUSTER ANALYSIS}

The RGA algorthms generated 26.473 planes for the Yucca Flat area of the NTS. The necessary use of tolerances for both mechanistic and analytical reasons, however, increased the possibility of false planar correlations. Thus, to allow interpretation (1.e., to potentially identify real geologic structures), we needed to look for alignments of many closely spaced planes. Each plane would be defined by just two vectors, but as a group these closely spaced planes would delineate a distinct and relatively continuous zone of valley vectors representing members of nearly parallel planes.

Quantitative spatial screening and plane grouping were achieved by using cluster analysis, a statistical evaluation used to dertve meaningful plane sets (1.e., clusters) on the basis of their anomalous properties. To facilitate statistical manipulation of such a large data set, the Yucca Flat plane set was divided into two subsets solely on the basis of dip. The "inner" plane set comprised planes with dips ranging from $40^{\circ}$ to $63^{\circ}$ and was by far the larger subset, containing 19,308 planes. The "outer" data set, composed of $\$, 237$ planes ranging in dip from $60^{\circ}$ to $90^{\circ}$. slightly overlapped the inner set for continulty at the boundary. The pole to each plane was uniquely specified to permit quantitative evaluation of the distribution in three-dimensional space of the planes in these subsets. These poles were specified by using the polar coordinates of strike $(\theta), \operatorname{dip}(\varphi)$, and distance $(r)$ from a central reference joint. Because these coordinates do not define an equtvolume space (1.e., a truly random distribution would exhtbit a greater density in a portion of the $\theta-, \varphi$-, r-space), the variables were rescaled into Lambert space (see Appendix) so that random distributions would be uniformly spaced. Subsequent to rescaling, the inner and outer data sets were broken into plane clusters using a version of the S-Plus (Becker. Chambers, and Wilks 1988) Fastclust algorithm, a connected (single-linkage or minimum) cluster routine wherein two points (each uniquely specified in polar coordinates) are identifled as members of a cluster if their straight-line separation distance is less than a specified threshold (radius). In the present analysis, this radius was $2^{\circ}$ ( 0.035 radians) for $\theta$ and $\varphi$ and $1,666 \mathrm{ft}$ (508 $\mathrm{m})$ for $r$. These values were determined in previous, manual interpretations of RGA planes in much smaller data sets. In the manual interpretations, the plane clusters were about $1,000 \mathrm{~m}$ wide and contained planes with strikes and dips that varied about $5^{\circ}$. Using these criteria, we derived 1,494 clusters from the outer plane set. The largest cluster contained 178 planes; most clusters contained fewer than about 30 planes. As expected, more clusters were dertved from the inner plane set. The largest cluster contained 2,351 planes, the second largest cluster consisted of 858 planes, and the remainder contained fewer than 300 planes.

Clusters containing 20 or more planes were further divided tnto subclusters. Subclusters were determined using the S-plus (Becker, Chambers, and Wilks 1988) hierarchical cluster analysis algorithm applied to a Lambert metric in a compact or maxdmum clustering routine (see Appendix). The term metric refers to the means by which the distance between two points is measured; Lambert metric indicates that the variables were rescaled into Lambert space. The compact clustering method was used to calculate the maxdmum distance between any point in one cluster and any point in another cluster to determine if the two points belonged in a single cluster. For example, two clusters were one if the maximum distance between any two points was less than the threshold. The compact method produced compact clustering trees with distinct subcluster groups (Figure 14) based on complex combinatione ff strike, dip, and distance. 


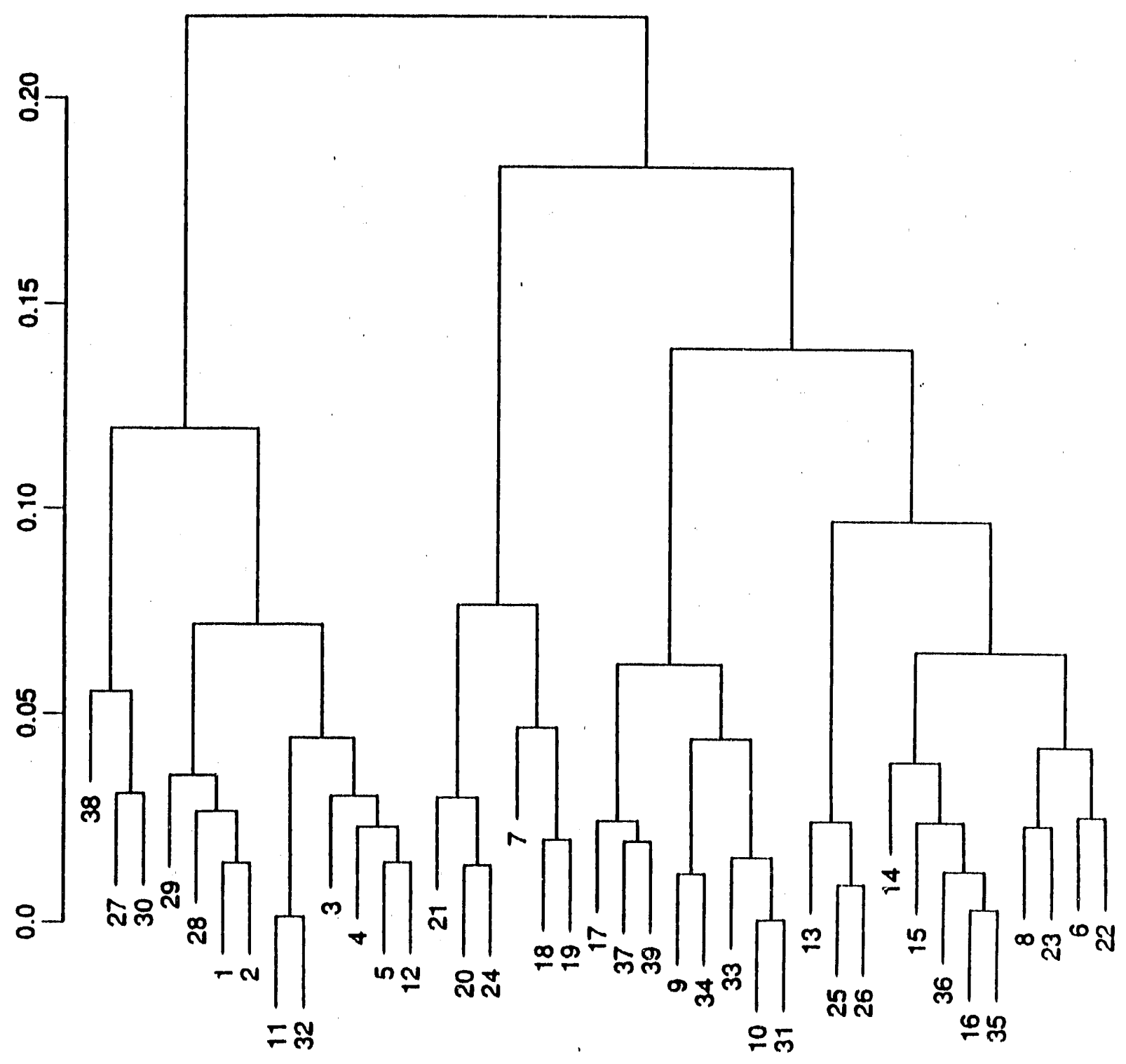

FIGURE 14. Representative Hierarchical Cluster Tree for RGA Plane Cluster 
These hierarchical clusters, in conjunction with a number of other important criteria, served as the basis for selecting meaningful plane clusters believed to correspond to real geologic phenomena. The additional criteria included identification of subcluster groups through viewing clusters and subclusters on Lambert stereoplots containing the entire Yucca Flat plane set and stereo-pair vlewing of the single clusters. The number of subclusters visible in Lambert stereoplots usually corresponded to the number of subclusters present at the 0.2 level of breakdown in the hierarchical tree. Below this threshold, subcluster groups were more tightly clustered, and further subdivision appeared unnecessary when considering comparison to real-world geologic structures.

Individual subclusters were selected for geologic ground-truth testing, and the traces of the planes that composed them were plotted at relevant scales for comparative purposes. Subclusters were selected if their average dips were $255^{\circ}$, if the average location (strike, dip, and distance) information they carried was not somewhat duplicated in another subcluster, and if they contained about 15 to 20 planes. Subclusters containing fewer planes were considered (structurally) less meaningful than larger subclusters. Using these guidelines, 13 subclusters from 10 clusters of the outer plane set and 12 subclusters from 11 clusters of the inner plane set were selected for analysis (Table 1, Figure 15). The geologic relevance of these plane clusters is discussed in the next section.

TABLE 1. Significant RGA Plane Clusters for the Yucca Flat Study Area

\begin{tabular}{|c|c|c|c|c|c|}
\hline $\begin{array}{c}\text { Cluster } \\
\text { No. } \\
\end{array}$ & $\begin{array}{l}\text { No. of } \\
\text { Planes } \\
\end{array}$ & $\begin{array}{c}\text { No. of } \\
\text { Subclusters } \\
\end{array}$ & $\begin{array}{c}\text { Average } \\
\text { Strike }\end{array}$ & $\begin{array}{c}\text { Average } \\
\text { Dip* }\end{array}$ & $\begin{array}{l}\text { Average } \\
\text { Distance }\end{array}$ \\
\hline 1425 & 178 & 5 & 8.7 & 64.6 & -34.637 \\
\hline 1477 & 40 & 2 & 40.6 & 64.1 & $-40,914$ \\
\hline 871 & 29 & 2 & 19.8 & 69.4 & $-26,446$ \\
\hline 1450 & 26 & 2 & 340.5 & 66.5 & $-20,876$ \\
\hline 1202 & 25 & 2 & 191.3 & 62.5 & 35.093 \\
\hline 1383 & 25 & 2 & 167.5 & 90.4 & 22,224 \\
\hline 1434 & 23 & 2 & 351.1 & 62.3 & 21,370 \\
\hline 1391 & 23 & 2 & 20.8 & 81.3 & $-40,478$ \\
\hline 425 & 21 & 2 & 281.4 & 61.4 & $-39,118$ \\
\hline 730 & 20 & 0 & 278.2 & 85.4 & $-24,397$ \\
\hline 884 & 165 & 4 & 282.3 & 58.0 & $-37,797$ \\
\hline 1840 & 113 & 5 & 274.4 & 57.1 & 30,355 \\
\hline 1073 & 57 & 3 & 276.2 & 61.5 & $-22,313$ \\
\hline 909 & 42 & 3 & 50.0 & 60.0 & 10,327 \\
\hline 2050 & 39 & 2 & 83.0 & 55.5 & $-51,752$ \\
\hline 2029 & 35 & 2 & 38.5 & 61.3 & $-39,512$ \\
\hline 935 & 35 & 2 & 44.1 & 59.9 & 1,462 \\
\hline 1407 & 30 & 2 & 350.3 & 56.0 & $-19,366$ \\
\hline 566 & 29 & 2 & 77.7 & 57.0 & 36,895 \\
\hline 1740 & 26 & 2 & 50.8 & 56.2 & $-9,040$ \\
\hline 1523 & 20 & 2 & 248.5 & 55.5 & 4,301 \\
\hline
\end{tabular}

- Dip in accordance with the right-hand rule, 1.c., when looking in the direction of strike, dip is to the right. 


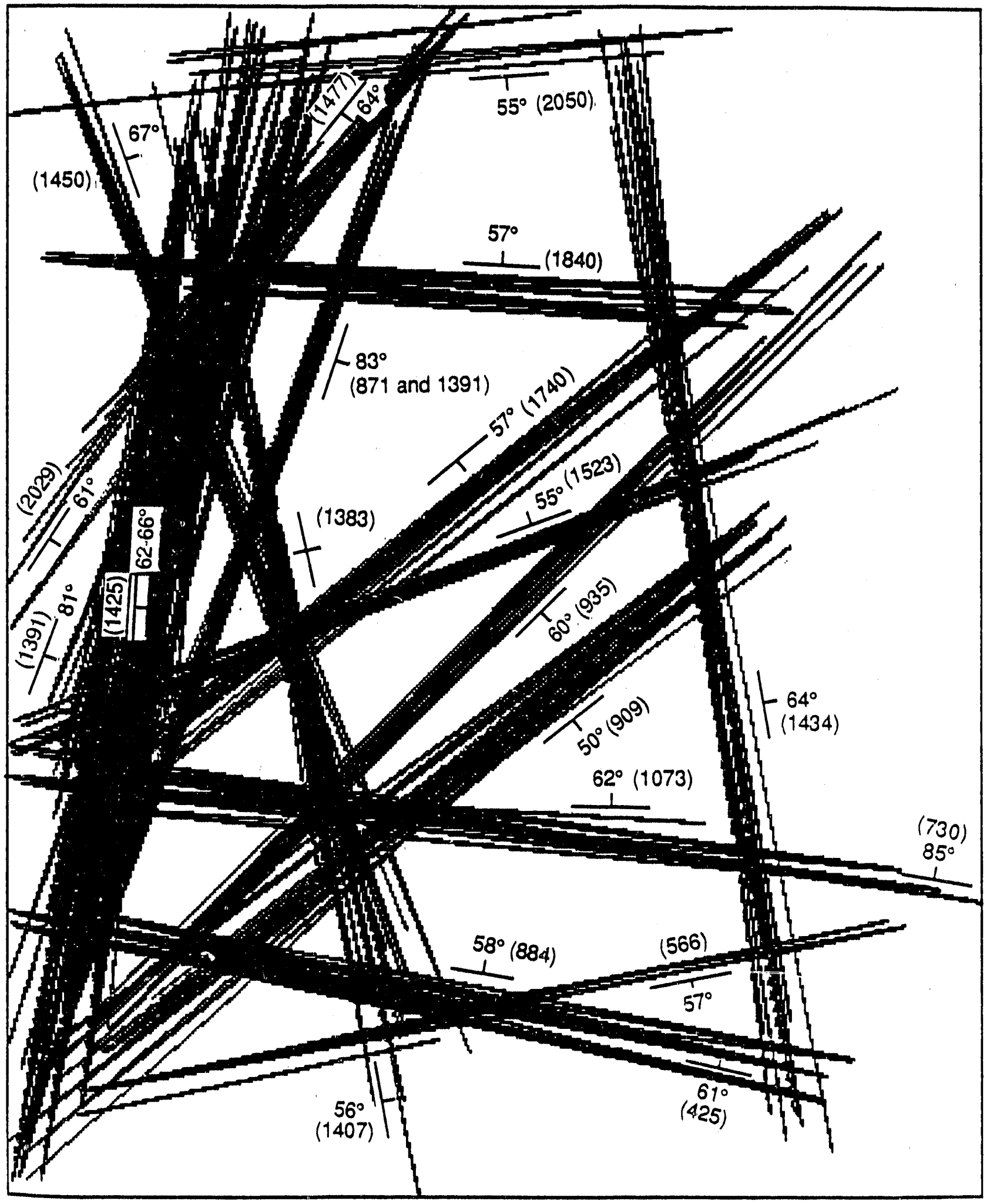

EIGURE 15. Significant RGA Plane Clusters for the Yucca Flat Study Area 


\section{CORRESPONDENCE OF PLANE.CLUSTER SURFACE TRACES TO TOPOGRAPHIC. GEOLOGIC. AND GEOPHYSICAL FEATURES}

To evaluate the RGA results for Yucca Flat, we compared the RGA-generated valleys with vectors to ensure they corresponded to actual topographic valleys. The only detectable anomalies in the RGA analysis were spurious "valleys" at the edges of the individual quadrangle DEMs where there were slight elevation mismatches or missing data.

As discussed in the previous section, 21 plane clusters met our significance criteria. Several of these clusters overlapped in strike and distance, but had different dips. Clusters $1383\left(89.6^{\circ}\right.$ dip), $1450\left(66.5^{\circ} \mathrm{dip}\right)$, and $1407\left(56.5^{\circ} \mathrm{dip}\right)$, which form one set and are indistinguishable in map view (e.g., Figure 15), have radically different dips. This is also true of clusters 730 (85.4 dip) and $1073\left(61.5^{\circ} \mathrm{dip}\right)$, and clusters $871\left(69.4^{\circ} \mathrm{dip}\right)$ and $1391\left(83.5^{\circ} \mathrm{dip}\right)$. However, clusters 425 and 884 , while mathematically distinguishable as separate clusters, have dips of $61.4^{\circ}$ and $58.0^{\circ}$ respectively, and are parts of the same cluster for practical geologic purposes.

In order to assess the geologic significance of these 15 clusters, pairs, and triplets, we compared the surface traces of the planes in each cluster with the following: topographic features, mapped geology and geologic structures, fractures activated during nuclear tests, lithostratigraphic isopach and structural contour maps, three gravity anomaly plots, a plot of basin-fill thickness modelled on the gravity anomalies, a magnetic anomaly map of northern Yucca Flat. manual lineament maps of the Palute Ridge quadrangle, and the shaded-rellef image of the DEM. Results of these comparisons are summarized in Table 2; detalls are discussed below.

\section{CORRELATION WITH TOPOGRAPHY AND MAPPED FAULTS}

We compared the surface traces of the 15 sets of clusters with the shaded-relief image of the DEM to identify correlations with topographic features. All of the clusters had a number of alignments with very small valleys, but several clusters, such as 1434 and 871/1391 appeared to coincide with major valleys. Linear ridges may have been created by resistant blocks of country rock left between parallel fault splays or as dip slopes in tilted, eroded layers of contrasting resistance to erosion. Clusters 730/1031, 909, 1425, and 1434 all appear to be examples of this behavior. Linear range fronts, which may be controlled by steeply dipping normal or reverse faults but would not be detected by the initial geomorphic pattern-recognition method implemented in RGA because they are not valleys, were consistent with several clusters. For example. the south end of cluster 871/1391 correlates with the front of Shoshone Mountain, 909 with the peak just south of Shoshone Mountain, 1383 and 1202 with the northeast side of Mine Mountain, and 1840 with the northern end of Banded Mountain.

\section{Cluster-by-Cluster Correlations}

By using the transparency of Figure 15 (in the inserted envelope), the 21 RGA plane clusters can be compared with a compilation of mapped faults in the Yucca Flat study area (Figure 8) and with other geologic and geophysical data (shown in following figures). Correlations are in Table 2.

\section{Plane Clusters 425 and 884}

Cluster 425 lies mostly to the south of Yucca Flat in the Mid Valley and CP Ridge regions. The strike of this cluster is approximately $281^{\circ}$ and does not seem to correspond to any dominant 
TABLE2. Summary Correlations for RGA-Determined Plane Clusters for Yucca Flat." Notes on following page.

\section{$425 \quad 730871 \quad 1450 \quad 1477$}

Clusters $884 \quad 56610731391909 \quad 9351202 \quad 14071425143420291523174018402050$

DIps NNE SSE NNE ESE SE SE WSW NE ESE NE SE NW SE NNE SSE

\begin{tabular}{|c|c|c|c|c|c|c|c|c|c|c|c|c|c|c|c|}
\hline Grav 1 & 1 & 0 & 0 & 0 & 1 & 1 & 0 & 1 & 0 & -1 & 1 & 0 & 0 & $1,-1$ & 0 \\
\hline Grav2 & 1 & 0 & 1 & 0 & 1 & 2 & 0 & 1 & -1 & -1 & $1,-1$ & 2 & 2 & $2,-3$ & 0 \\
\hline Grav3 & 1 & 0 & 2 & 0 & 3 & 1 & 0 & 1 & -1 & -1 & $1,-1$ & 2 & 1 & $3,-2$ & 0 \\
\hline G Reg & 1 & 0 & -1 & 0 & 0 & 0 & 0 & -1 & 2 & 0 & 0 & 0 & 0 & 0 & 0 \\
\hline G Mod & 1 & 0 & 0 & -1 & 0 & 0 & 0 & 1 & 0 & -1 & 1 & 1 & 1 & 1 & 0 \\
\hline Mag & $\mathbf{x}$ & $\mathbf{x}$ & $\mathbf{x}$ & 0 & 0 & 0 & 0 & 0 & 1 & 1 & 0 & 0 & 0 & $1 a$ & 0 \\
\hline M Det & $\mathbf{x}$ & $\mathbf{x}$ & $x$ & $\mathbf{x}$ & 0 & 0 & $\mathbf{x}$ & $\mathbf{x}$ & $\mathbf{x}$ & -1 & $\mathbf{x}$ & 0 & $\mathbf{x}$ & $\mathbf{x}$ & $\mathbf{x}$ \\
\hline Iso Old & $\mathbf{x}$ & $\mathbf{x}$ & $\mathbf{x}$ & $\mathbf{x}$ & 0 & -1 & $\mathbf{x}$ & $\mathbf{x}$ & $\mathbf{x}$ & -1 & $\mathbf{x}$ & 1 & 2 & 1 & $\mathbf{x}$ \\
\hline Iso GC & $\mathbf{x}$ & $\mathbf{x}$ & 0 & $\mathbf{x}$ & 0 & -1 & $\mathbf{x}$ & $\mathbf{x}$ & $\mathbf{x}$ & 0 & $\mathbf{x}$ & 2 & 2 & 1 & \\
\hline Iso PT & $\mathbf{x}$ & $\mathbf{x}$ & 1 & $\mathbf{x}$ & -1 & 1 & $\mathbf{x}$ & $\mathbf{x}$ & $\mathbf{x}$ & -1 & $\mathbf{x}$ & 1 & 1 & 1 & $x$ \\
\hline Iso RM & $\mathbf{x}$ & $\mathbf{x}$ & 1 & $\mathbf{x}$ & 1 & -1 & $\mathbf{x}$ & $\mathbf{x}$ & $\mathbf{x}$ & 0 & $\mathbf{x}$ & -2 & 1 & -1 & \\
\hline Iso All & $\mathbf{x}$ & $\mathbf{x}$ & 1 & 0 & 0 & 1 & $\mathbf{x}$ & $\mathbf{x}$ & $\mathbf{x}$ & 0 & $\mathbf{x}$ & 0 & 1 & -1 & \\
\hline SC GC & $\mathbf{x}$ & $\mathbf{x}$ & $\mathbf{x}$ & $\mathbf{x}$ & 0 & 1 & $\mathbf{x}$ & $\mathbf{x}$ & $\mathbf{x}$ & 0 & $\mathbf{x}$ & 1 & 1 & -1 & \\
\hline SC PT & $\mathbf{x}$ & $\mathbf{x}$ & $\mathbf{x}$ & $\mathbf{x}$ & 0 & 1 & $\mathbf{x}$ & $\mathbf{x}$ & $\mathbf{x}$ & 0 & $\mathbf{x}$ & 1 & 0 & 0 & \\
\hline SC RM & $\mathbf{x}$ & $\mathbf{x}$ & 0 & $\mathbf{x}$ & -1 & 1 & $\mathbf{x}$ & $\mathbf{x}$ & $\mathbf{x}$ & -1 & $\mathbf{x}$ & $1,-1$ & -1 & -1 & $\mathrm{x}$ \\
\hline SC AT & $x$ & $\mathbf{x}$ & $\mathbf{x}$ & $\mathbf{x}$ & -1 & 1 & $\mathbf{x}$ & $\mathbf{x}$ & $\mathbf{x}$ & 0 & $\mathbf{x}$ & 1 & -1 & -1 & $\mathrm{x}$ \\
\hline Orig & $\mathbf{x}$ & $\mathbf{x}$ & $\mathbf{x}$ & $\mathbf{x}$ & 7 & 2 & $\mathbf{x}$ & $\mathbf{x}$ & $\mathbf{x}$ & 3 & $\mathbf{x}$ & 2 & $\mathbf{x}$ & $\mathbf{x}$ & $\mathbf{x}$ \\
\hline Shad & $\mathbf{x}$ & $\mathbf{x}$ & $\mathbf{x}$ & $\mathbf{x}$ & 5 & 1 & $\mathbf{x}$ & $\mathbf{x}$ & $\mathbf{x}$ & 3 & $\mathbf{x}$ & 3 & $\mathbf{x}$ & $\mathbf{x}$ & $\mathbf{x}$ \\
\hline Corr & $\mathbf{x}$ & $\mathbf{x}$ & $\mathbf{x}$ & $\mathbf{x}$ & 3 & 1 & $\mathbf{x}$ & $\mathbf{x}$ & $\mathbf{x}$ & 5 & $x$ & 4 & $\mathbf{x}$ & $\mathbf{x}$ & $\mathbf{x}$ \\
\hline MCS & $\mathbf{x}$ & $\mathbf{x}$ & $\mathbf{x}$ & $\mathbf{x}$ & 4 & 3 & $\mathbf{x}$ & $\mathbf{x}$ & $\mathbf{x}$ & 5 & $\mathbf{x}$ & 5 & $\mathbf{x}$ & $\mathbf{x}$ & $\mathbf{x}$ \\
\hline Valleys & 9 & 9 & 13 & 8 & 16 & 11 & 14 & 8 & 21 & 14 & 17 & 17 & 15 & 12 & 10 \\
\hline Fronts & 0 & 0 & 0 & 1 & 1 & 0 & -2 & 1 & 3 & $3,-1$ & 2 & 0 & 1 & 1 & 0 \\
\hline Ridges & 0 & 0 & 1 & 0 & 1 & 0 & 0 & 0 & 1 & 1 & 0 & 0 & 0 & 0 & 0 \\
\hline Faults & 2 & 3 & 0 & 1 & 8 & 4 & 12 & 4 & 12 & 4 & 5 & 3 & 1 & 0 & 2 \\
\hline Offset & 0 & $1,-1$ & -1 & $2,-2$ & $5,-6$ & $3,-1$ & $8,-7$ & $5,-1$ & $14,-6$ & $5,-2$ & $2,-3$ & 0 & -2 & 0 & -2 \\
\hline Active & 0 & 0 & 0 & 0 & 0 & 1 & 1 & 0 & 1 & 0 & 0 & 0 & 0 & 0 & 0 \\
\hline
\end{tabular}

* Correlation of clusters with various geophysical, geologic, geomorphologic, and lineament features. Numbers indicate the number of times each feature is observed. A minus sign $(-)$ indicates the cluster correlates with a reverse-fault sense of offset for the calculated dip direction for that cluster. An $(x)$ signifies that the cluster falls outside the bounds of the map area for that particular feature. The map locations of several pairs (and one triplet) of clusters overlap, so each multiple cluster is evaluated as a single entity. 


\section{Notes for Table 2}

Grav1 Gravity gradient sense (Diment, Healey, and Roller 1960)

Grav2 Gravity gradient sense (Healey 1968)

Grav3 Gravity gradient sense (Ferguson et al. 1986)

G Reg Gravity gradient sense of the regional (Ferguson et al. 1986)

G Mod Depths to Tertiary-Paleozolc unconformity based on modelling of gravity data (Ferguson et al. 1986) (Yucca Flat only)

Mag Magnetic anomaly sense (Hinrichs 1968) (north part of Yucca Flat)

$M$ Det Magnetic anomaly sense (Hinrichs 1968) (detalled study area)

a Cluster 1840 has the wrong dip of magnetic basement, but thicker volcanics deposited to the north create this effect

Iso Old Isopach of tuffs older than Grouse Canyon Member (Ander 1984) (Yucca Flat only)

Iso GC Isopach of Grouse Canyon Member (Ander 1984) (Yucca Flat)

Iso PT Isopach of Paintbrush Tuff (Ander 1984) (Yucca Flat)

Iso RM Isopach of Rainier Mesa Member of the Timber Mountain Tuff (Ander 1984) (Yucca Flat)

Iso All Isopach of Tertlary-Quaternary alluvium (Ander 1984) (Yucca Flat)

SC GC. Structural contour map on base of Grouse Canyon Member (Ander 1984) (Yucca Flat)

SC PT Structural contour map on base of Palntbrush Member (Ander 1984) (Yucca Flat)

SC RM Structural contour map of Rainier Mesa Member, Tumber Mountain Tuff (Ander 1984) (Yucca Flat)

SC AT Structural contour map of Ammonia Tanks Member, Timber Mountain Tuff (Ander 1984) (Yucca Flat)

Orig Compilation lineaments (identified by at least 3 out of 5 interpreters) picked on an original thematic mapper (TM) image by Thlessen et al. (1986) (Paiute Ridge quadrangle only)

Shad Compllation lineaments based on shadow image generated from DEM (Thiessen et al. 1986) (Paiute Ridge quadrangle only)

Corr Compllation lineaments from a corrected TM, with shadowing removed (Thiessen et al. 1986) (Paiute Ridge quadrangle only)

MCS Compllation lineaments based on a stereopair of the corrected TM (Thiessen et al. 1986) (Palute Ridge quadrangle only)

Valleys Valleys visually identified on shaded relief image of study area prepared for the present study

Fronts Range fronts visually identified on shaded relief image

Ridges Linear ridges identified on shaded relief image

Faults Faults mapped on various geologic maps with no denoted offset sense, based on Frizzell and Shuiters (1990) and others

Offset Mapped faults with a designated sense of offset (- indicates observed offset is opposite to the one of the matching cluster) based on Frzzell and Shulters (1990) and others

Active Active faults (Figure 16, from Swadley and Hoover 1990) 


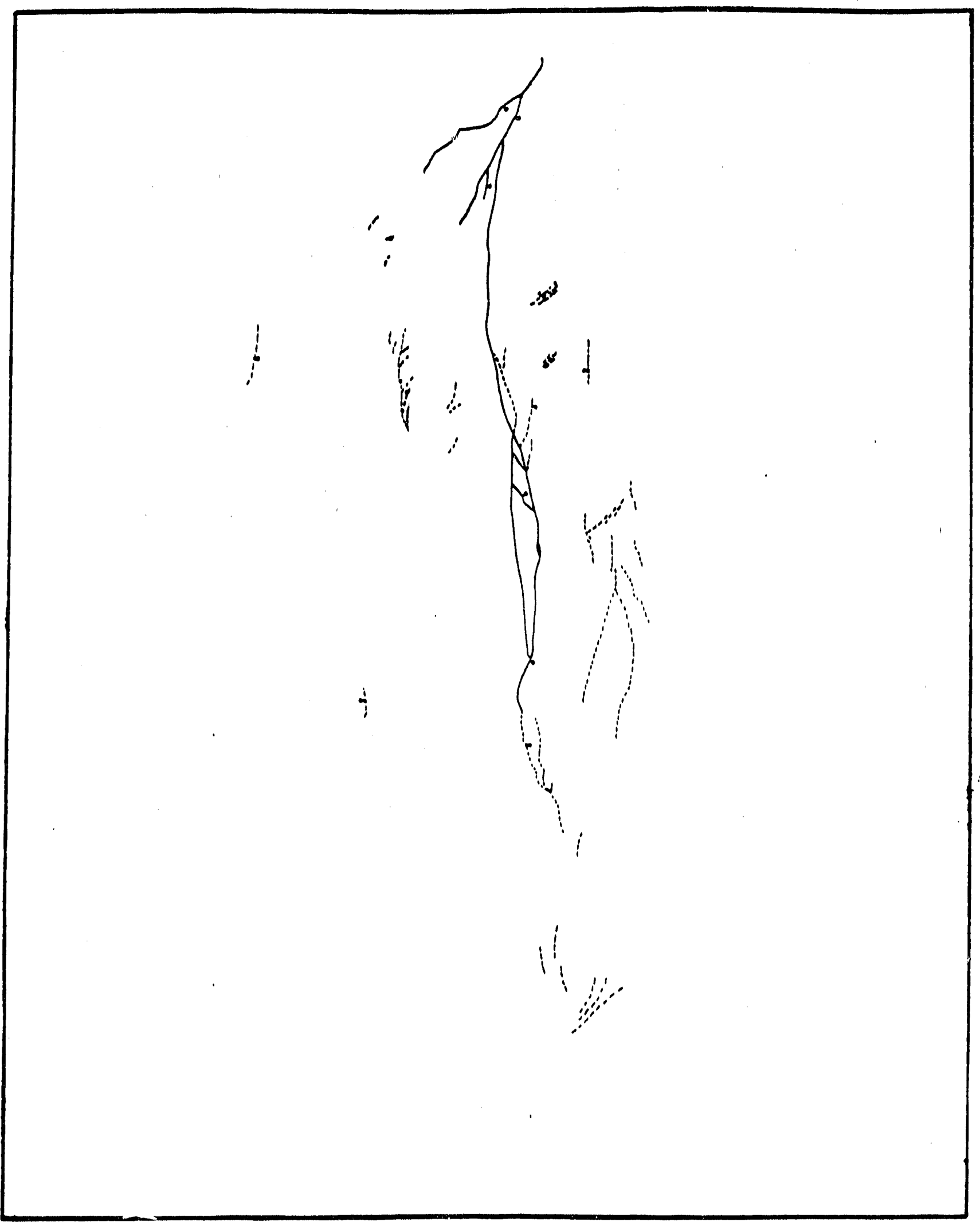

FIGURE 16. Active Faults in the Yucca Flat Study Area (from Swadley and Hoover 1990)

32 
structural trends. Its eastern vectors originate in small valleys south of Plutonium Valley in the Halfpint Range region. Cluster 425 crosses the southern tip of Yucca Flat and CP Ridge and runs into the CP Hills. Small valleys in the CP Hills with the same trend as Cluster 425 produce vectors in the middle of this cluster. The cluster then crosses Mid Valley and ends in valleys at the western edge of the study area. The only structural features that parallel Cluster 425 are scattered, small, west-northwest trending faults, and a foint set in the Halfpint Range, CP Ridge, and Mid Valley reglons. Cluster 425 is subparallel to clusters 730, 1840, 1073, and 884 (discussed below), which could represent an almost obscured, early structural trend (Frizzell and Shulters 1990; Hoover and Morrison 1980).

Cluster 884 begins in the southeastern part of the study area in the Halfpint Range and strikes $282^{\circ}$ across southern Yucca Flat, the CP Ridge and CP Hills, and Mid Valley, and ends in low hills west of Mid Valley. The valleys that generate the clusters do not contain mapped faults or joint trends. Near the southern end of Plutonium Valley and Yucca Flat, two normal faults lie within Cluster 884 and strike parallel to it. Another fault in the CP Hills also falls within the cluster and follows its strike. The remainder of faults and joint sets that parallel the cluster are distributed throughout the study area. Cluster 884 parallels clusters 425, 730, 1840, and 1073. Together, these clusters could represent a minor west-northwest structural trend in our study area (Frizzell and Shuiters 1990; USGS 1977; Orkdld 1963).

\section{Plane Cluster 566}

Cluster 566 begins in the southeastern portion of the study area in the Halfpint Range. It trends $258^{\circ}$ across Plutonium Valley, southern Yucca Flat, the CP Hills, and Mid Valley. The cluster ends in small valleys less than $1 \mathrm{~km}$ north of the Mine Mountain Fault. Although Cluster 566 does not parallel the Mine Mountain Fault, it parallels other faults and joint sets in the region, as well as faults in the southern part of the Halfpint Range. The cluster also parallels normal faults in Banded Mountain. Paiute Ridge, and Syncline Ridge. Cluster 566 is subparallel to Cluster 1523 and appears to represent the same structural trend (Frizzell and Shulters 1990; Orkdld 1963, 1968; Barosh 1968).

\section{Plane Clusters 730 and 1073}

Cluster 730 originates in valleys east of Plutonium Valley in the Halfpint Range and is subparallel to the trend of Cluster 425 . Cluster $73^{n}$ crosses Yucca Flat with a strike of $278^{\circ}$ and ends in valleys southwest of Syncline Ridge. The vectors that generate this cluster do not seem to correspond to valleys that are fault or joint controlled. Cluster 730 is subparallel to scattered faults in the vicinity of Mine Mountain and Syncline Ridge, as well as a joint set on Mine Mountain. This cluster is also subparallel to a strike-slip fault southeast of Syncline Ridge. It is possible that Cluster 730 represents an almost obscured west-northwest structural trend across the NTS (Frizzell and Shulters 1990; Hoover and Morrison 1980).

Cluster 1073 begins in the southeastern part of the study area in the Halfpint Range. The valleys tinat produced the vectors do not contain any mapped faults or joint sets. The cluster strikes $276^{\circ}$ across Plutonium Valley, southern Yucca Flat, Mine Mountain, and ends in valleys about $8 \mathrm{~km}$ west of Mine Mountain. These valleys do not contain mapped faults or joint sets. Cluster 1073 parallels very few structural trends except for a west-trending, left-lateral strike- 
slip fault about 1 to $2 \mathrm{~km}$ southeast of Syncline Ridge. The cluster is subparallel to a joint trend in this area and to a group of faults about $3 \mathrm{~km}$ east of Slanted Butte. Cluster 1073 also parallels explosion-induced fracture trends on Yucca Flat.

Cluster 730/1073 is subparallel to clusters 1840 and 425 and may represent the same structural trend (Frizzell and Shulters 1990; Hoover and Morrison 1980; USGS 1977).

\section{Plane Clusters 871 and 1391}

Cluster 871 begins in the extreme southwestern portion of the study area and strikes about $20^{\circ}$ past the western edge of Mid Valley. The cluster continues over Syncline Ridge, isolating Syncline Ridge from the rest of Eleana Mountain west of Yucca Flat, crosses the northwestern erige of Yucca Flat, and ends in valleys on the eastern slope of Quartzite Ridge. The valleys that produced the vectors do not appear to contain either mapped faults or jolnts. Cluster 871 parallels faults and joint sets in the Mid Valley, Eleana Range, Quartzite Ridge, and Yucca Flat areas and is also subparallel to the anticline in Quartzite Ridge.

Cluster 1391 originates in valleys about $2 \mathrm{~km}$ west of the southern end of Syncline Ridge. This cluster strikes $20^{\circ}$ and ends in valleys $4 \mathrm{~km}$ southwest and $2 \mathrm{~km}$ west of Quartzite Ridge. The southern vectors of Cluster 1391 appear to originate in fault-controlled valleys, but its northern vectors lie in valleys that do not contain mapped faults or joint sets. The cluster is parallel and subparallel to faults and joint trends in the Mid Valley, Eleana Range, Quartzite Ridge, and Yucca Flat regions. Cluster 1391 is also subparallel to the anticline in Quartzite Ridge.

Cluster $871 / 1391$ seems to represent a real northeast structural trend that is probably related to that of Cluster 1202 (Frizzell and Shulters 1990; Barosh 1968; Orkild 1963).

\section{Plane Cluster 909}

Cluster 909 begins in the Halfpint Range about $4 \mathrm{~km}$ east of Slanted Butte. Some of the valleys producing the vectors appear to be fault controlled. The cluster strikes between $230^{\circ}$ and $231^{\circ}$ across Yucca Flat, the southern part of Mine Mountain and parallels the Mine Muuntain Fault. Cluster 909 ends in the slopes surrounding Mid Valley. The Mine Mountain Fault, a leftlateral strike-slip fault, lies within this cluster for about $11 \mathrm{~km}$. Other faults and joints with trends that parallel Cluster 909 lie in the Mid Valley. Syncline Ridge, and Banded Mountain areas. Also, explosion-induced fractures, as well as faults, parallel this cluster on Yucca Flat. Cluster 909 is subparallel to clusters 1477, 935, and 1740 and appears to represerit the same northeast structural trend (Frizzell and Shulters 1990; USGS 1977; Barosh 1968; McKeown. Healey, and Miller 1976; Orkdld 1963, 1968).

\section{Plane Cluster 935}

Cluster 935 begins in the eastern portion of the Halfpint Range, strikes $225^{\circ}$ across Yucca Flat, and ends in valleys near the Mid Valley Fault, about $9 \mathrm{~km}$ southwest of Mine Mountain. Some of the valleys on the cluster's northeastern end that generated the vectors appear to be fault-controlled. The cluster itself parallels the Mine Mountain Fault and the ridge to the north of the fault, as well as other faults and joint trends in the area. Cluster 935 also parallels faults and joint sets in the Halfpint and northern Eleana Range, as well as faults and explosion-induced fractures in Yucca Flat. In the Halfpint Range, the northern extent of the cluster seems to orig- 
Inate in valleys related to northeast-trending folds and faults. Faults in the Banded Mountain and Paiute Ridge areas also parallel the cluster. Cluster 935 is subparallel to clusters 1477 and 1740, and seems to reflect a northeast structural trend in the study area (Frtzzell and Shulters 1990; USGS 1977; Barosh 1968; Orl illd 1963, 1968).

\section{Blane Cluster 1202}

Cluster 1202 begins in the extreme southwestern corner of the study area and strikes about $11^{\circ}$. This cluster runs northeast past the western edge of Mid Valley, about $2 \mathrm{~km}$ west of Syncline Ridge, then to the eastern portion of the Eleana Range (about $4 \mathrm{~km}$ southwest of Quartzite Ridge) where one set of subclusters terminates. The remainder of the cluster ends in a valley about 3 km west of Quartzite Ridge. Cluster 1202 parallels two large ridges on its southern end; both are about $6 \mathrm{~km}$ long. The cluster also parallels faults lying between these ridges; one of these faults coincides with the cluster. Cluster 1202 parallels other normal and thrust faults in the Eleana Range and Quartzite Ridge regions, as well as a fault on Yucca Flat. Joint trends in the vicinity of Mine Mountain also parallel Cluster 1202, as does the anticline in Quartzite Ridge. Cluster 1202 is subparallel to Cluster 1425 (discussed below). Cluster 1202 appears to reflect a northnortheast structural trend, possibly related to Mesozoic compression and subsequent Cenozoic extension along existing planes of deformation (Frizzell and Shulters 1990; Orkdld 1963, 1968).

\section{Plane Clusters 1383,1450 , and 1407}

Cluster 1383 generally lies on the western portion of Yucca Flat and trends approximately $167^{\circ}$ to $171^{\circ}$ subparallel to Cluster 1434 . The vectors defining the southern position originate in north-northwest-trending valleys in the CP Hills that appear to be fault controlled. The cluster crosses the very eastern portion of Mine Mountain, the western edge of Yucca Flat, passes to the east of Syncline Ridge, and crosses into the Eleana Range. The northern vectors of Cluster 1383 end in valleys about $6 \mathrm{~km}$ west of Quartzite Ridge. These valleys do not appear to be fault controlled. Structurally, the cluster is subparallel to small normal faults and joint trends in the CP Ridge, Eleana Kange, and Halfpint Range regions, and to normal faults east and northeast of Syncline Ridge. Cluster 1383 seems to reflect a north-northwest structural trend across the study area, as does cluster 1434 (Frizzell and Shulters 1990; USGS 1977).

The southern end of Cluster 1450 originates in northwest trending valleys in the CP Hills, two of which appear to be fault controlled. The cluster strikes about $341^{\circ}$, continues into the Eleana Range east cí Mine Mountain and Syncline Ridge, and ends in valleys $11 \mathrm{~km}$ west of Quartzite Ridge, near the Gold Meadows Stock. Cluster 1450 parallels a number of structural features both to the east and west of Yucca Flat. At its southern end, the cluster is subparallel to a number of normal faults in the CP Hills and CP Ridge area, to the extreme southern end of the Carpetbag Fault, and to a 5-km normal fault that lies about $2 \mathrm{~km}$ north of CP Ridge. Cluster 1450 is subparallel to a $13-\mathrm{km}$-long segment of the northwest trending normal fault that lies along the western edge of Yucca Flat. Cluster 1450 also parallels many northwest trending faults in the Halfpint Range and Yucca Flat. On Yucca Flat, the cluster parallels an explosion-induced fracture trend about $3 \mathrm{~km}$ west of Paiute Ridge. This cluster also parallels joint sets in the Mid Valley. Mine Mountain, and Syncline Rddge areas, as well as a jo, at set near the northern extent of the cluster near the Gold Meadows Stock. Cluster 1450 probably represents the same structural trend as clusters 1383 and 1434 (Frizzell and Shulters 1990; Cornwall 1972; USGS 1977). 
Cluster 1407 starts in the CP Hills area, strlkes $350^{\circ}$ along the western edge of Yucca Flat, and ends in the Eleana Range about $8 \mathrm{~km}$ west of Quartzite Ridge. The valleys that produced the vectors at the southern end appear to be fault controlled; those at the northern end do not. The cluster itself parallels many fault and joint sets across the entire study area, including the Yucca and Carpetbag faults, as well as faults and joints in the CP Ridge and Halfpint Range regions. Cluster 1407 , along with clusters 1383,1434 , and 1450 , seems to reflect the most prominent structural trend in the study area (Frizzell and Shulters 1990; Gibbons et al. 1963; Hinrichs and McKay 1965; Orkdld 1963, 1968).

\section{Plane Cluster 1425}

Cluster 1425 contains several planes with strikes ranging from about $9^{\circ}$ to $15^{\circ}$. This cluster begins in valleys west of Mid Valley, continues west of Syncline Ridge, and ends in valleys west of Quartzite Ridge. Only a few valleys that generated the vectors defining this cluster contain mapped faults or joint trends. However, the cluster as a whole does seem to represent an overall north-northeast structural trend to the west of Yucca Flat that includes faults, joint trends, and fold axc. A 9-km-long normal fault in the Eleana Range parallels this fault, is does the anticline in Quartzite Ridge and a portion of the syncline that lies $10 \mathrm{~km}$ southwest. Cluster $1425 \mathrm{is}$ subparallel to Cluster 1202 and probably reflects the same structural trend (Frizzell and Shulters 1990; Orkdld 1968).

\section{Plane Cluster 1434}

The surface trace of Cluster 1434 runs north-northivest in the Halfpint Range with a strike of $351^{\circ}$. The vectors that define the southern end of the cluster originate in north-northwest trending valleys south of Plutonium Valley, and the cluster aligns with Plutonium Valley in the south $(0.5 \mathrm{~km}$ wide). Cluster 1434 extends northwestward along the eastern edge of Yucca Flat and aligns with topographic breaks between the main mountains east of Yucca Flat and outliers such as Banded Mountain and Camera Station Butte. The cluster then continues to the east of Banded Butte and ends in the Rhyolite Hills. This ciuster is parallel and subparallel to the trend of most of the ranges in the Halfpint Range, particularly surrounding Plutonium Valley. Cluster 1434 parallels many of the high-angle normal faults in this range, especially those corresponding to valleys in the southern part of the range. Cluster 1434 dips northeast to match several mapped faults. The ridge associated with Cluster 1434 has a parallel fault mapped in the ridge. In various places, at least 8 small faults ( $<5 \mathrm{~km}$ long) run inside the trace of this cluster. Cluster 1434 parallels a joint set near Slanted Butte as well as two small folds on the northeastern edge of the Halfpint Range and a thrust fault near the center of the range. Outside the Halfpint Range, the cluster parallels the general trends of both the Carpetbag and Yucca faults, as well as many smaller faults throughout the rest of the study area. Cluster 1434 seems to reflect a north-northwest trending structural pattern that includes the Yucca and Carpetbag faults, which could be related to Mesozoic compression, and subsequently Cenozoic extension in the study area (Frizzell and Shulters 1990; USGS 1977).

\section{Plane Clusters 1477 and 2029}

Cluster 1477 begins in th.e Eleana Range about $7 \mathrm{~km}$ northwest of Syncline Ridge and strikes about $41^{\circ}$. It crosses Quartzite Ridge and ends about $2 \mathrm{~km}$ to the northeast. This cluster paral- 
lels clusters 935 and 909 , as well as the crest of Quartzite Ridge, and numerous small faults along the length of the cluster. Cluster 1477 also parallels both the Boundary and Mine Mountain Faults and explosion-induced fracture trends on Yucca Flat. This cluster seems to reflect a northeast structural trend that includes normal, strlke-slip, and thrust faults (Frizzell and Shulters 1990; USGS 1 177; Orkdld 1968).

Cluster 2029 begins northeast of Quartzite Ridge, strikes $218^{\circ}$ paralleling the ridge, and ends about $27 \mathrm{~km}$ away in the Eleana Range. A subcluster begins near the northern flank of Quartzite Ridge in a 4-km-long, northeast trending linear valley. This subcluster ends with the rest of the cluster in the Eleana Range. The valleys that produced the vectors do not contain mapped faults or joint sets. Cluster 2029 parallels other joint sets and faults throughout the study area, most notably the Mine Mountain and Cane Springs faults. It also parallels explosion-induced fracture trends on Yucca Flat, as well as both Quartzite and Syncline Ridges. Cluster 2029 is subparallel to clusters 935, 909, and 1740 and reflects the same northeast structural trend (Frizzell and Shulters 1990; USGS 1977; McKeown, Healey, and Muller 1976; Orkdld 1963, 1968).

\section{Plane Cluster 1523}

Cluster 1523 starts in the Halfpint Range and strikes $249^{\circ}$ across Yucca Flat to end in valleys $6 \mathrm{~km}$ southwest of Syncline Ridge. A subcluster begins in Syncline Ridge and also strikes $249^{\circ}$ for about $6 \mathrm{~km}$ where it ends with the remainder of the cluster. Most of the valleys that produced the vectors do not contain mapped faults or joint trends, but the cluster does parallel other fault and joint trends in the rest of the study area. Parallels to faults and joints mainly occur in line area of Paiute Ridge. Banded Mountain, and Syncline Ridge; some parallels also occur near Plutonium Valley. The faults and joint sets in the area of Syncline Ridge are actually in the cluster, as well as parallel to it. Cluster 1523 also parallels Cluster 566 and could possibly represent a northeast structural trend (Frizzell and Shulters 1990; Orkild 1963, 1968; Barosh 1968; Gibbons et al. 1963: McKeown, Healey, and Miller 1976).

\section{Plane Cluster 1740}

Cluster 1740 begins near the eastern edge of the Halfpint Range. It strlkes $231^{\circ}$ across Yucca Flat, runs south of Syncline Ridge, and ends in valleys $4 \mathrm{~km}$ south of Syncline Ridge. The valleys that produced the vectors do not contain mapped faults or joint trends. Cluster 1740 parallels faults and joint trends near Syncline Ridge, Mine Mountain, and in the Eleana and Halfpint Ranges; the Mine Mountain Fault, although this fault is about $10 \mathrm{~km}$ south of Cluster 1740; and small faults and explosion-induced fractures on Yucca Flat. Syncline Ridge itself also parallels the cluster, and the cluster passes through the valley that separates Syncline Ridge and Mine Mountain. Cluster 1740 is subparallel to Cluster 1477 and seems to reflect a similar structural trend (Frizzell and Shulters 1990; USGS 1977; Barosh 1968).

\section{Plane Cluster 1840}

Cluster 1840 begins in the Halfpint Range, strikes $274^{\circ}$ across Yucca Flat, and ends in the Eleana Range. The valleys that produced the vectors for this cluster do not appear to be fault or joint controlled, although small faults with a similar attitude occur in valleys near Cluster 1840 . 
Only one joint set is subparallel to Cluster 1840 on its western side, and it lies about $8 \mathrm{~km}$ south. There are only a few faults in the immediate area that parallel the cluster, but faults near Syncline Ridge and Paiute Ridge are subparallel. This cluster is subparallel to clusters 425 and 730 and is probably part of the same structural pattern (Frizzell and Shulters 1990; Hoover and Morrison 1980; Orkild 1963).

\section{Plane Cluster 2050}

Cluster 2050 lies north of Yucca Flat in the Eleana Range and Quartzite Ridge regions and strikes $83^{\circ}$. One subcluster begins in a west-trending valley about $2 \mathrm{~km}$ south of the Gold Meadows Stock; this valley does not contain mapped faults or joint sets. The subcluster ends on the eastern flank of Quartzite Ridge in a valley that does not appear to be fault or joint controlled. The remaining subclusters begin in valleys 4 to $5 \mathrm{~km}$ west of Quartzite Ridge and end near the northeastern corner of the study area. These valleys do not contain mapped faults or joint sets. Joints in the Gold Meadows Stock and a stock $8 \mathrm{~km}$ southeast of Quartzite Ridge are either parallel or subparallel to Cluster 2050, but there are few parallel faults in the cluster area itself. A 3-km-long east-northeast trending valley near the eastern end of the cluster is subparallel, but this valley does not contain mapped faults or joint sets. There are some faults and joint sets in the Halfpint Range and the Syncline Ridge area that are subparallel to this cluster, but relate better to other clusters further to the south.

\section{Correlation with Nuclear Test-Induced Fractures}

Barosh (1968) mapped fracture patterns that were activated during nuclear testing events (Figure 17). Cluster 1740 matched a whole family of northeast-oriented fractures that parallel bedrock joints and faults on Banded Mountain. Cluster 935 is parallel to this trend and also matches bedrock joints, but not explosion fractures. This is also true of Cluster 1434, which is oriented north-northwest. Cluster 1840 matches several east-west explosion-activated trends.

\section{Correlation with Field-Mapped Fractures}

In an earlier study, we mapped 7 faults, 20 open joints, 12 flled joints, and 133 plain joints in the western portions of the Paiute Ridge quadrangle study area. A contoured, lower-hemisphere Schmidt stereonet of poles to these fractures, with the average strike and dip of each cluster, is shown in Figure 18. One can see that a number of the peaks match or are close to poles to clusters. However, there is a general tendency for all field mappers to preferentially identify steep to vertical fractures, whereas our RGA geomorphic pattern-recognition method gtves equal weight to planes with shallower dips. As a result, several of the clusters map at gentler dips (towards the center of the stereonet) than the apparently correlative field data concentrations. The field data base includes only 172 data, which are not enough for statistical validity in identifying maxima.

\section{CORRELATION WITH SUBSURFACE AND GEOPHYSICAL DATA}

\section{Isopach and Structural-Contour Maps}

Ander (1984) used logs of over 300 drill holes to prepare a series of isopach and structural contour maps. Figure 19 is an isopach map of tuffs older than the Grouse Canyon Member of the Belted Range Tuff. This stratigraphic interval ranges in age from 30 to $13.8 \mathrm{~m}$.y. old. Most 


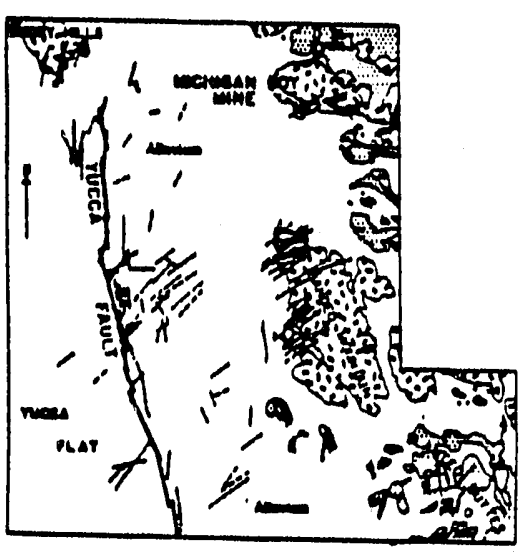

FIGURE 17. Correlation of RGA Plane Clusters with Fractures Induced by Nuclear Tests (after Barosh 1968) 


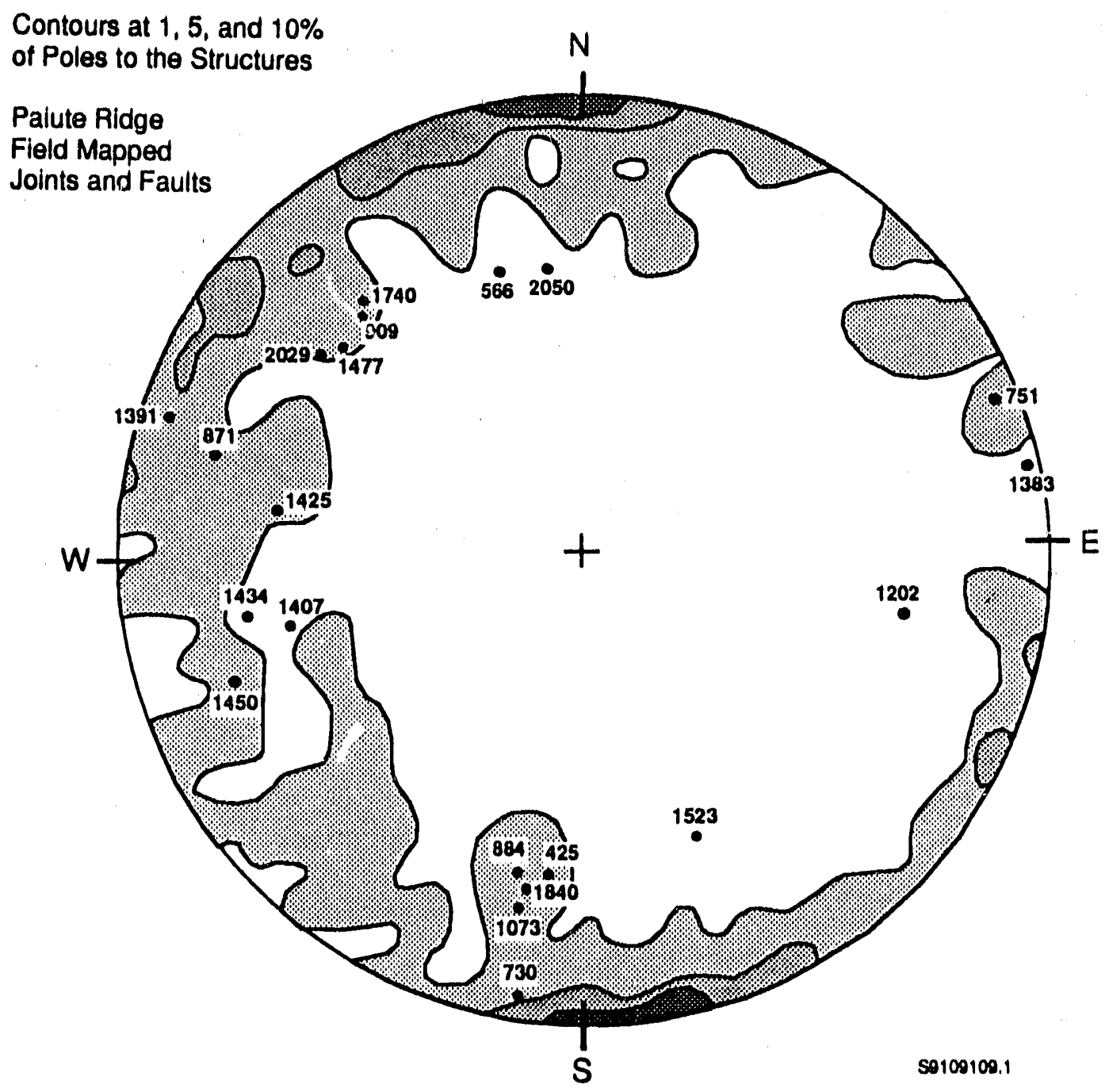

FIGURE 18. Equal-Area Stereonet Showing Poles of Field-Mapped Joints and Faults in Padute Rddge, Nevada Quadrangle and of Principal RGA Plane Clusters 


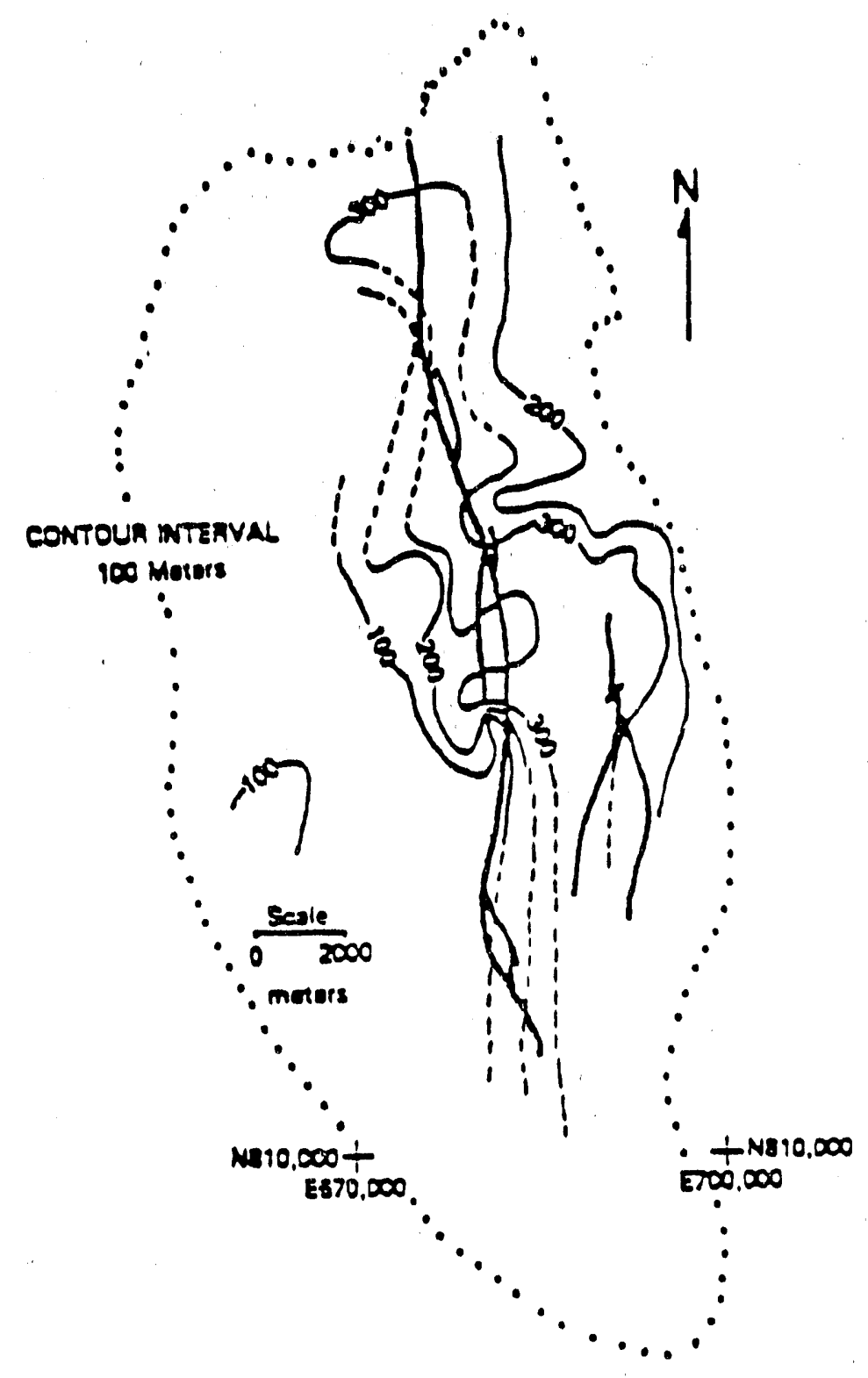

FIGURE 19. Isopach Map of Tuffs Older than the Grouse Canyon Member of the Belted Range Tuffs (Ander 1984). Thicknesses in meters; dotted line-Yucca Flat outline, heavy lines-mapped faults 
of the contours are dashed, indicating a lack of borehole control points in these deeper units. Yucca Fault is the north-south bold line through the center; other recently acttve faults are also mapped with heavy lines and include the Area 3 Fault in the eastern portion of the basin (Dickey 1968). Ander (1984) noted that deposition of this unit was not controlled by the Yucca or other faults. A thicker zone north of Cluster 1840 manifests a structure that controlled an early volcanic depocenter, as also indicated by the magnetic high in this region (see Figure 28 below). Clusters 1523 and 1740 align with northeast-orlented thickenings and thinnings of these units. Clusters 935 and 1434 are aligned along the east side of the flat.

The northern depositional center, possibly controlled by Cluster 1840 , was particularly well developed during deposition of the Grouse Canyon Member, a distinctive peralkaline tuff 13.8 m.y. old (Figure 20). Clusters 1740 and 1523 align with a northeast-oriented graben through the middle of Yucca Flat, as shown by thickening of the Grouse Canyon member. The clusters exhibit the proper dips for this structure.

Isopachs (Ander 1984) of the Paintbrush Tuff combined with three adjacent units (Figure 21) show that the northern depositional basin, aligned with Cluster 1840, was still partially active during the period 13.5 to $12.5 \mathrm{~m}$.y. ago, as enumerated in Table 2 . The central basin, between clusters 1523 and 1740, is nicely defined. Just south, Cluster 935 may be related to the northern edge of the thickest portion of the Paintbrush Tuff. The southern edge of this unit is located at the north-dipping Cluster 730/1073.

The northern depositional basin was no longer active during the deposition of the Rainier Mesa Member of the Timber Mountain Tuff, $11.1 \mathrm{~m}$.y. ago (Figure 22). The central basin, between clusters 1523 and 1740, has been replaced by a depocenter to the south, straddling Cluster 935. which may correlate with a fault-aligned valley system. Cluster 909 allgns with a gradient in the isopach map, but the southeast dip does not match the depocenter northwest of this feature. Cluster 730/1073 aligns with the southern edge of the depositional basin.

An isopach map (Ander 1984) of Tertiary through Quaternary alluvium (Figure 23) shows that Cluster 1840 aligns with the northern edge of the depositional basin, although it has a northward dip. Cluster 1740 dips into a central basin and aligns with deflected contours along the western part of the map. The thickest deposits are in the southern portion of Yucca Flat and may be partially controlled by Cluster 909 (south dip) and Cluster 730/1073 (north dip). Ander (1984) noticed the Yucca Fault and other north-south oriented faults appeared to be active only during the deposition of these units, during which time they controlled thick sequences of younger lithologies.

A structural contour map (Ander 1984) on the base of the Grouse Canyon Member (Figure 24) shows that this lithology is down-faulted into a graben between clusters 1740 and 1523, particularly west of Yucca Fault. Southeast-dipping Cluster 935 aligns with a down-drop in the unit to the southeast. Cluster 1840 aligns with the north end of the unit.

Figure 25 depicts Ander's (1984) structural contour map on the base of the Paintbrush Tuff. The small side graben in the Halfpint Range that has a good correlation with gravity values isee below) can be seen as a flexure in the contours between clusters 935 and 1523 .

An offset in the Rainier Mesa Member (Figure 26) aligns with clusters 1740 and 1523, which also appear to correlate with the boundaries of a small horst just west of Yucca Fault. Cluster 


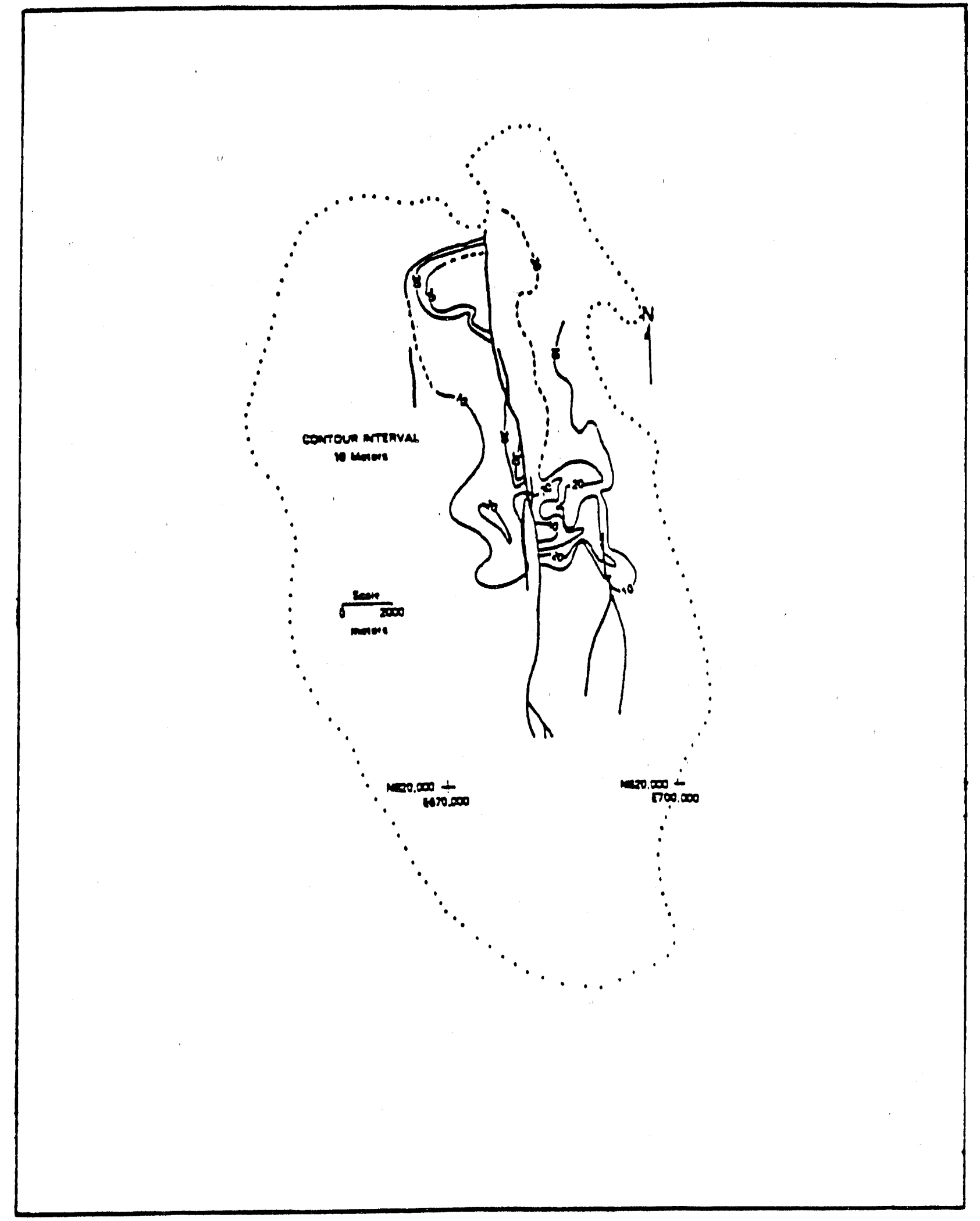

EIGURE 20. Isopach Map of Tuffs of the Grouse Canyon Member of the Belted Range Tuffs (Ander 1984). Thicknesses in meters; dotted line-Yucca Flat outline, heavy linesmapped faults 


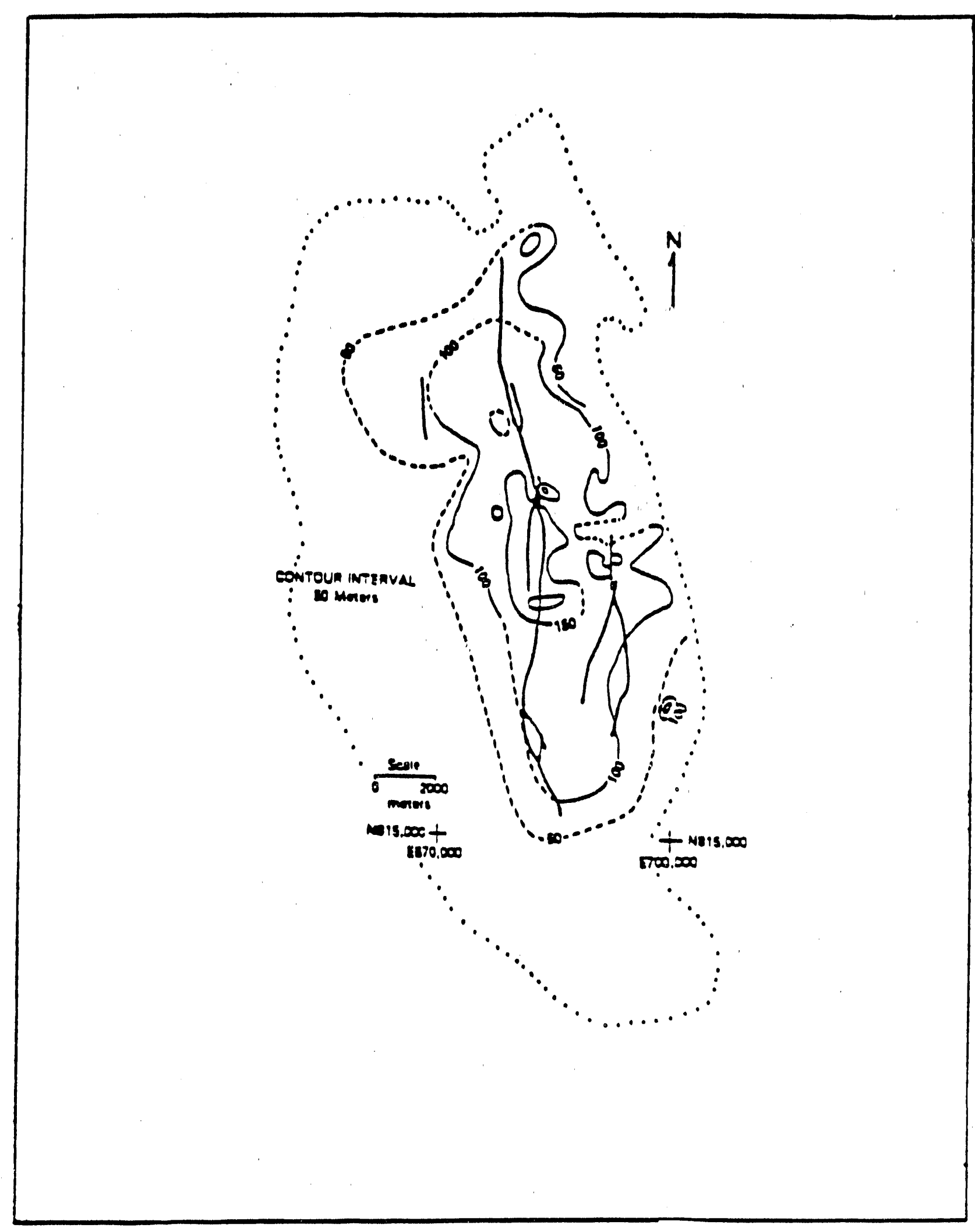

EIGURE 21. Isopach Map of Tuffs of the Paintbrush Tuff and Three Adjacent Units (Ander 1984). Thicknesses in meters; dotted line-Yucca Flat outline, heavy linesmapped faults 


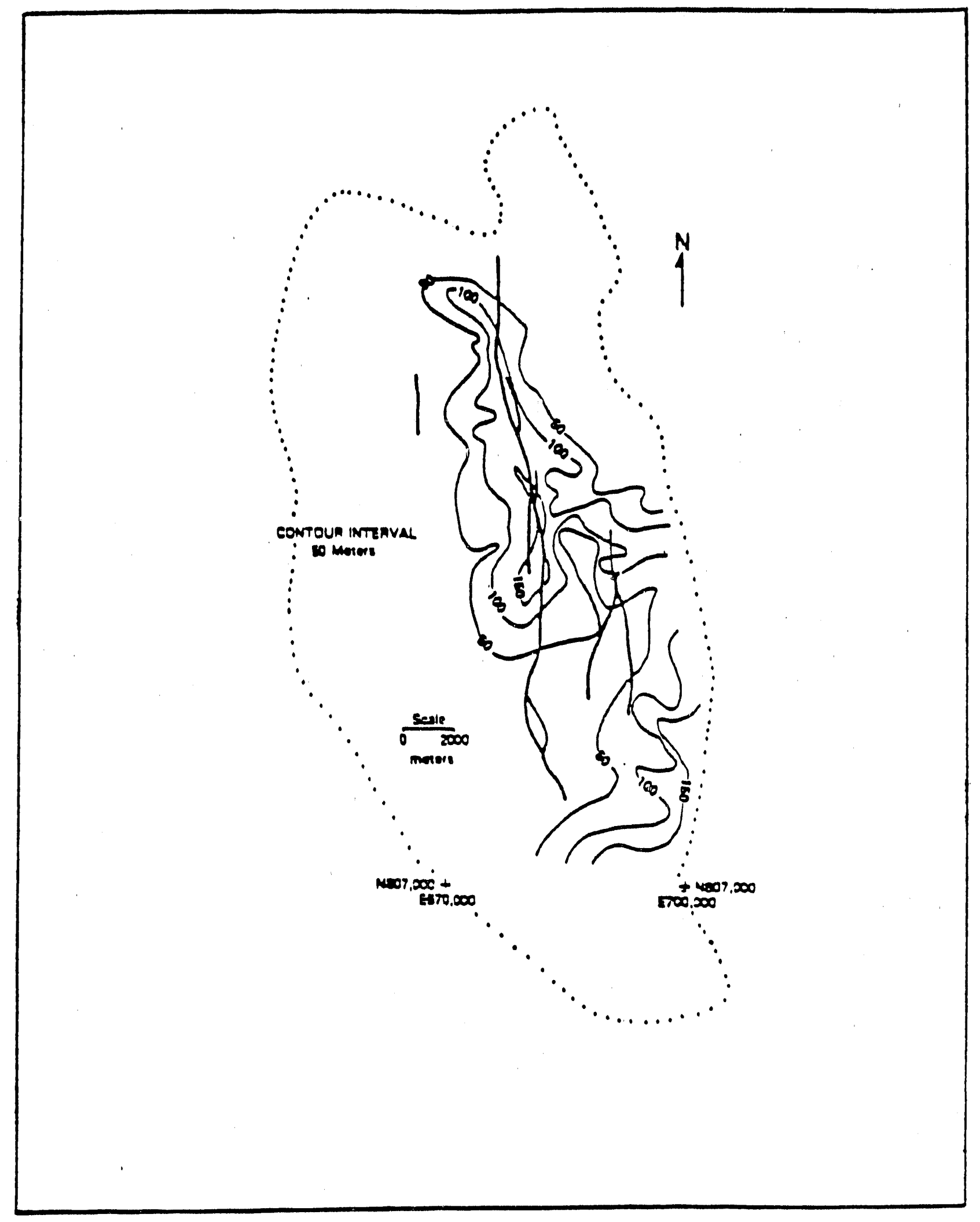

FIGURE 22. Isopach Map of the Rainier Mesa Member of the Timber Mountain Tuff (Ander 1984). Thicknesses in meters; dotted line-Yucca Flat outline, heavy linesmapped faults 


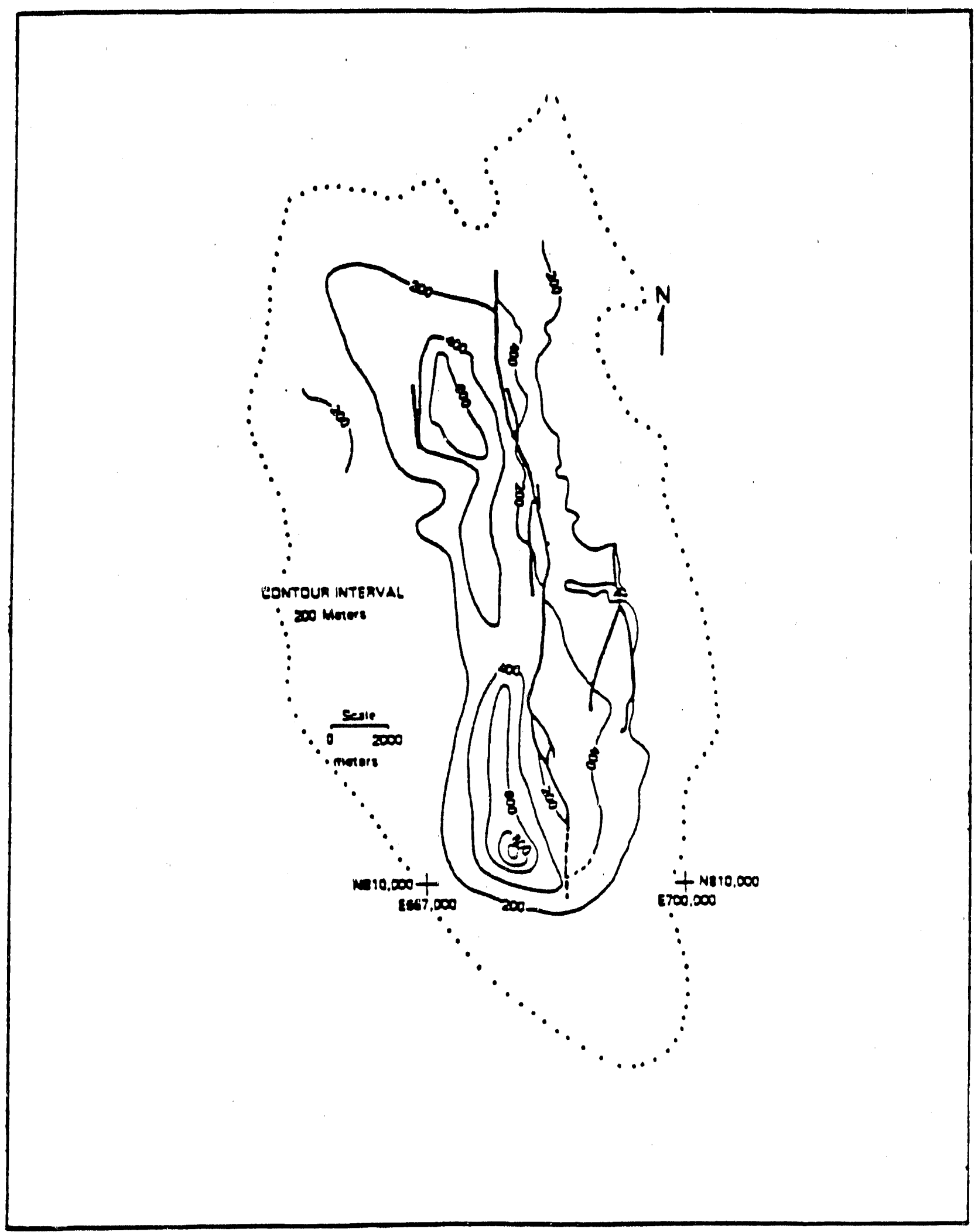

EIGURE 23. Isopach Map of Tertlary Through Quaternary Alluvium (Ander 1984). Thicknesses in meters; dotted line-Yucca Flat outline, heavy lines-mapped faults 


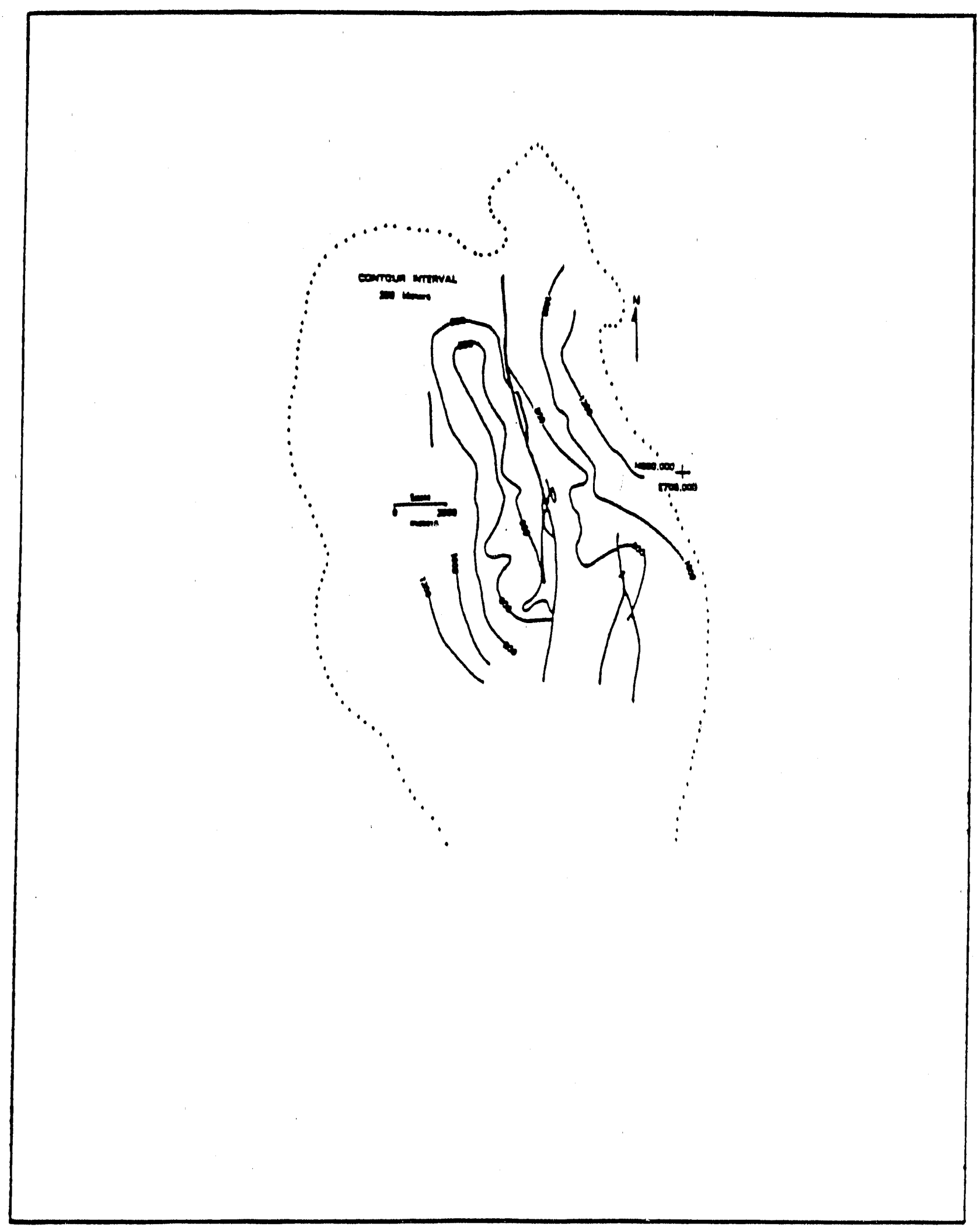

EIGURE 24. Structural Contour Map of the Base of the Grouse Canyon Member of the Belted Range Tuffs (Ander 1984). Elevations in meters; dotted line-Yucca Flat outline. heavy lines-mapped faults 


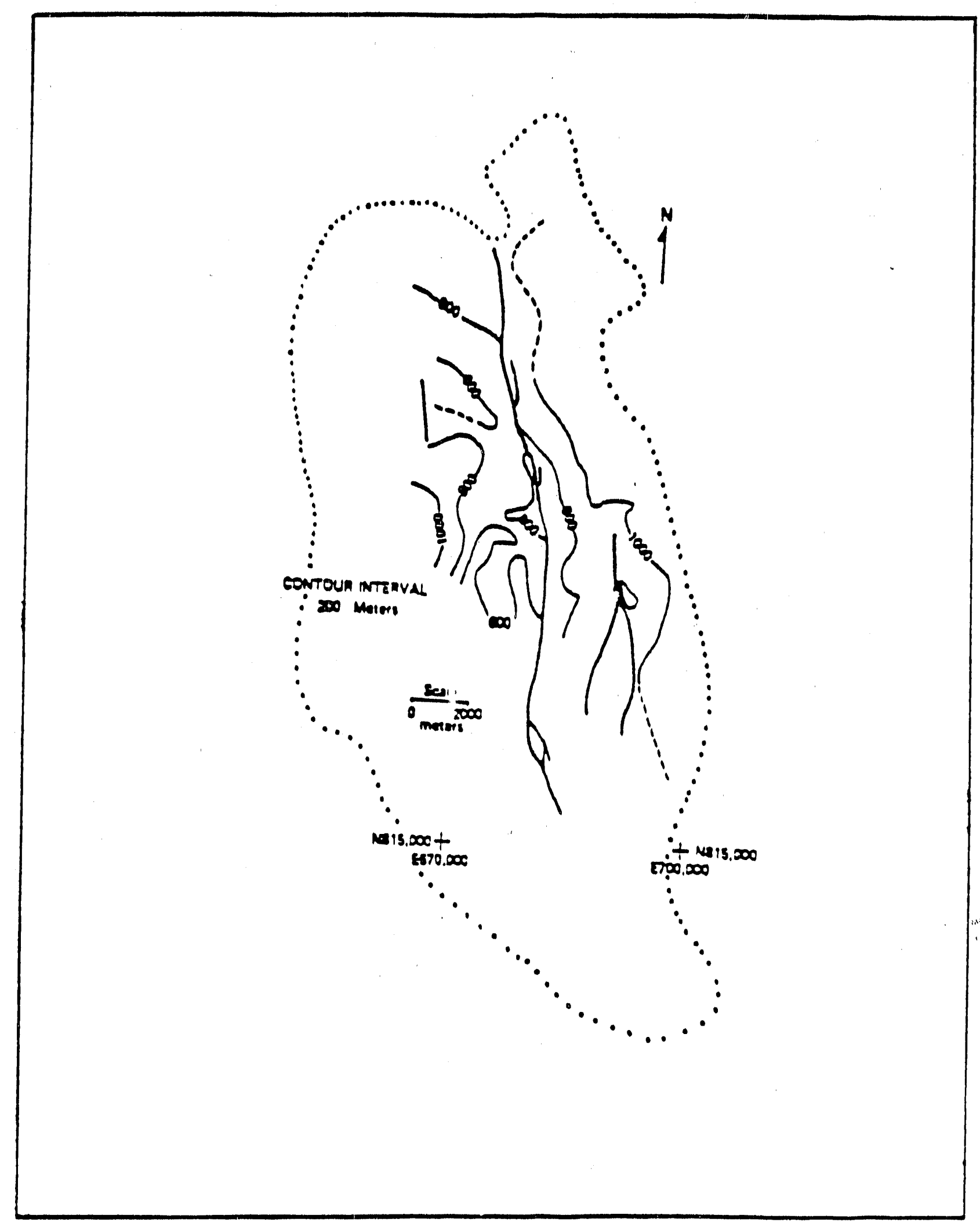

EIGURE 25. Structural Contour Map of the Base of the Paintbrush Tuff (Ander 1984). Elevations in meters; dotted line-Yucca Flat outline, heavy lines-mapped faults 


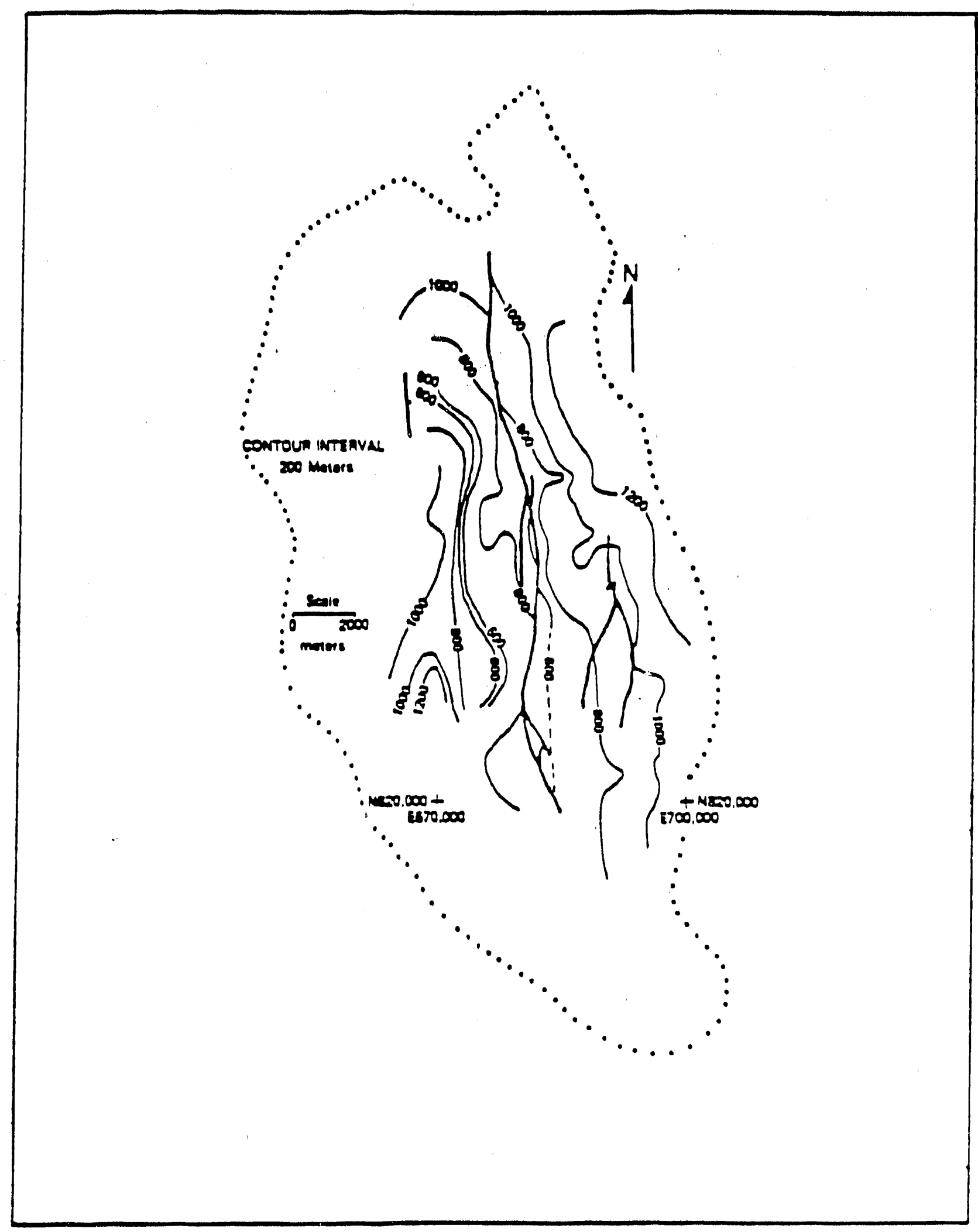

FIGURE 26. Structural Contour Map of the Base of the Rainier Mesa Member of the Timber Mountain Tuff (Ander 1984). Elevations in meters; dotted line-Yucca Flat outline. heavy lines-mapped faults 
935 matches a gradient along the east side of the Yucca Flat. Cluster 909 may be related to a reverse offset of the structural contours, although they are not extended into this area.

The structural contour map (Ander 1984) of the Ammonia Tanks Member of the Timber Mountain Tuff (Figure 27) shows a well-correlater down-dropping northwest of Cluster 1523 on the east side of Yucca Fault. Cluster 935 also shows a good correlation with a southeast down dropping. Clusters 909, 1740, and 1840 align with gradients in the contoured surface.

Ander (1984) observed that the Yucca Fault and related faults offset the four structural contour maps of the tuffs by approximately equal amounts. Therefore, all of these units were deposited prior to the time Yucca Fault became active. The Yucca, Area 3, and Carpetbag faults exhibit activity at the present time, particularly following a nuclear test in the vicinity (Dickey 1968).

\section{Gravity Anomalies}

A number of studies have examined the Bouguer gravity field of Yucca Flat and vicinity (Diment, Healey, and Roller 1960; Healey and Miller 1963; Healey 1966, 1968; Ferguson et al. 1986). Figure 28 lllustrates the reasonable distribution of gravity stations (circles) for the area. Most gravity data points were apparently collected along profiles. The mountains fringing Yucca Flat exhibit higher gravity values (-155 to -140 mgal) reflecting the denser nature of the bedrock composing them. The low gravity values $(-170 \mathrm{mgal})$ of Yucca Flat are due to the less dense basin fill. Cluster 1477 correlates with a gradient from -155 to $-160 \mathrm{mgal}$ in the northwest corner of Yucca Flat, as shown by the heavy black line. Cluster 1383/1450 aligns with a -140- to -165-mgal gradient along the southwest margin of the basin. Both of these clusters dip into the basin, correlating with the expected direction of the gravity gradients; they also match fronts of mountain ranges defined in the topography. In both cases, the cluster traces are displaced slightly away from Yucca Flat. The initial RGA geomorphic pattern-recognition approach finds stream valleys, and not range front scarps. Most likely, th' ${ }^{\prime}$.pproach finds manifestations of a large number of subparallel fracture systems that comprise part of the major range-front fault system. Because this method cannot effectively find valleys in the low topographic relief of Yucca Flat, these fractures are detected only in the surrounding mountains, and the main range-front faults must be inferred as lying parallel to and inboard (relattve to Yucca Flat) of the RGA clusters. Improved geomorphic pattern-recognition methods in development for our RGA system will be able to identify the range-front scarps directly and will eliminate this problem.

Cluster $425 / 884$ dips north and correlates with the southern termination of the gravity minimuni of Yucca Flat. Cluster 909 is aligned with the southeast side of Mine Mountain (where.it matches normal faults) and with a gravity feature. A major valley indenting the east side of Mine Mountain has a gravity flexure matching Cluster 935 . Cluster 1840 matches both the north end of a gravity maximum in Yucca Flat and a gradient from -165 to -170 mgal just to the east.

Cluster 1434 correlates with the southeastern edge of Yucca Flat in a similar range-front fault scenario (Figure 28, Table 2); however, it dips $62.3^{\circ}$ to the east. Several mapped faults have simllar orientations, as discussed in the previous section, and Cluster 1434 is probably related to them. In addition, the northern extension of Cluster 1434 aligns with a range-front fault sy ${ }^{\prime}$ cem defining the west side of Emigrant Valley to the north and has the proper dip. 


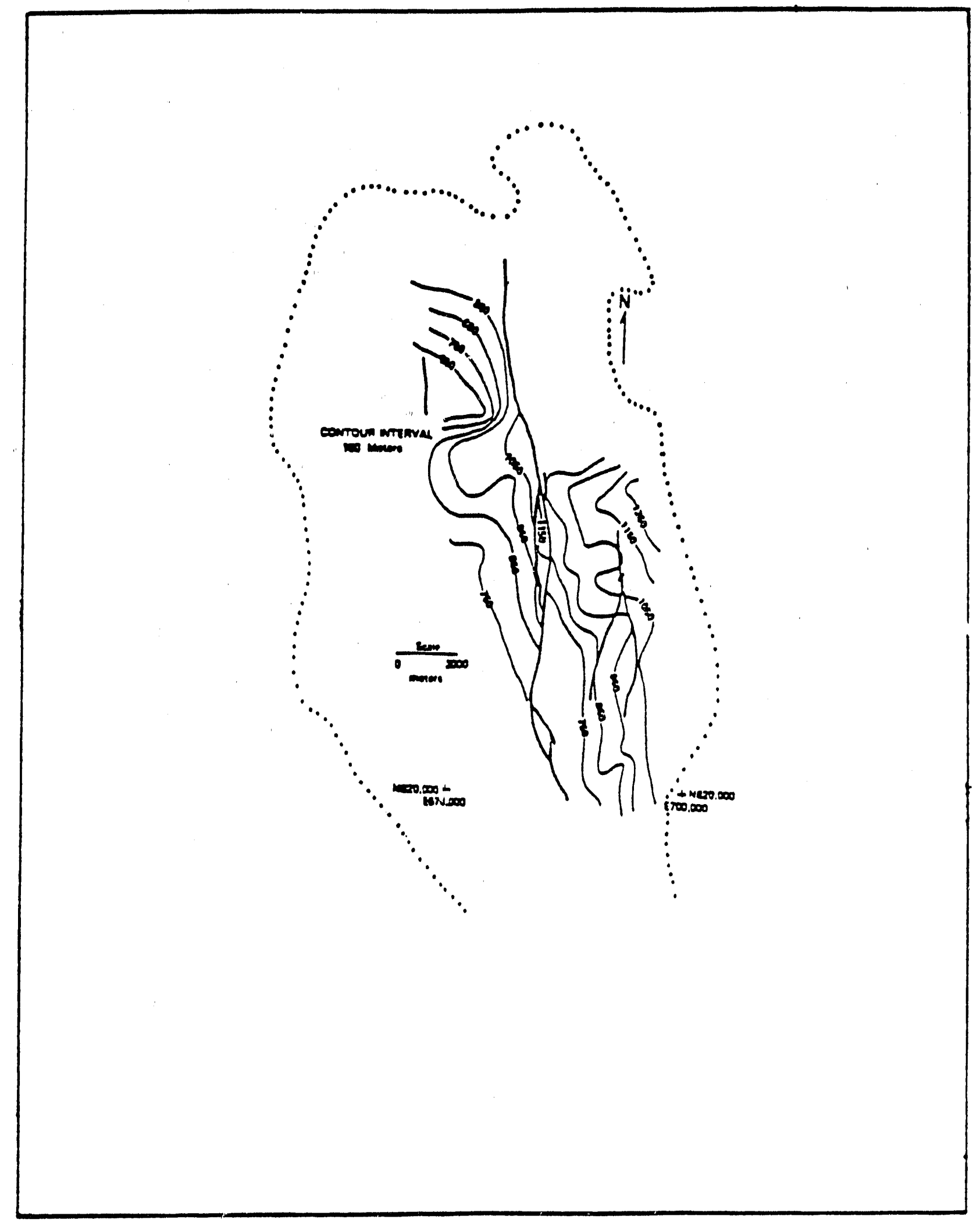

FIGURE 27. Structural Contour Map of the Base of the Ammonia Tanks Member of the Timber Mountain Tuff (Ander 1984). Elevations in meters; dotted line-Yucca Flat outline. heavy lines-mapped faults 


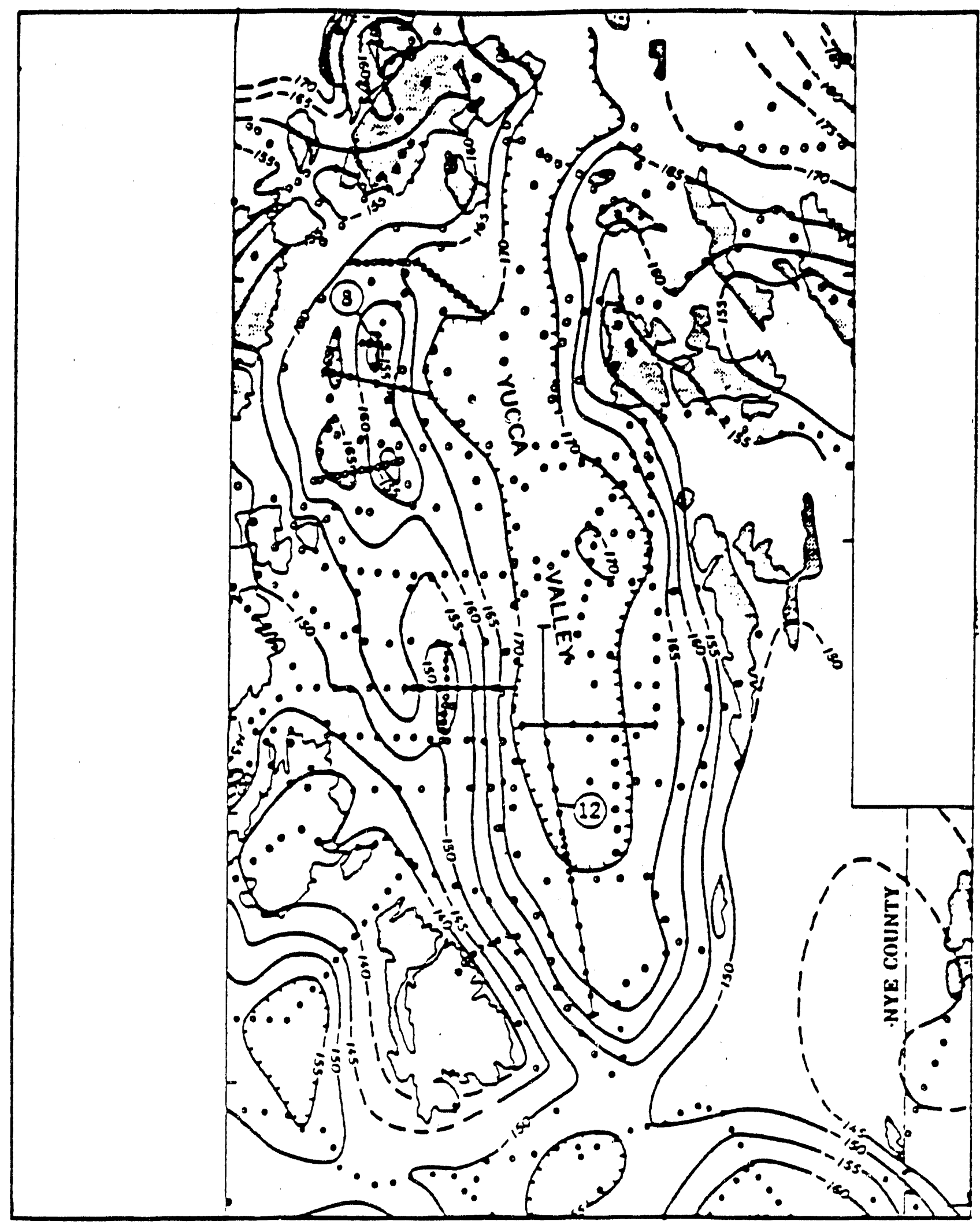

FIGURE 28. RGA Plane Clusters with Corresponding Bouguer Gravity Anomalies (mgal) after Diment, Healey, and Roller (1960) 
Figure 29, a more recent version of the complete Bouguer gravity field (Healey 1968), tllustrates all of the correlations seen on the earlier map and allows definition of smaller structures. Specifically, Yucca Flat's gravity minimum (diagonal patterning on Figure 30) is split by a northnorthwest-trending series of maxdma (dotted pattern), possibly relating to an interbasin horst structure. Clusters 1523 and 1740 bound a saddle in the gravity values along this horst. These clusters may correlate with a down-dropped block along the horst at this location. Similarly, on the east side of Yucca Flat, the Halfpint Range shows a gravity low corresponding to a possible graben and to clusters 935 and 1523. Truncation at the north end of the gravity maximum along Halfpint Range is aligned with Cluster 1840, with a northward dip. This same cluster correlates with the north end of the horst within Yucca Flat as well. Cluster 730/1073 correlates with a cross gradient at the southern end of the Halfpint Range. This map fills in the vold along the western side of the study area in Figure 28, and clusters 1477 and 1425 can both be seen to correlate with gradients on the west side of the Eleana Range.

Ferguson et al. (1986) used Bouguer gravity to model the depths of the Tertiary/Paleozolc contact under Yucca Flat. Figure 30 shows their updated version of the gravity, with essentially the same relationships that were seen on Healey's (1968) map (Figure 29). Ferguson et al. (1986) calculated a Fourier trend surface to the gravity values lying in the surrounding bedrock regions (Figure 31). Gradients in this trend surface show some correlation with Cluster 1425 (the cluster with the most planes) in the Eleana Range and Cluster 1383/1450/1407. Cluster 730/1073. which dips to the north, correlates to a southward decreasing gradient into a minimum under the southern portion of Yucca Flat. Cluster 425/884, also dipping to the north, coincides with the southern gradient of this same minimum.

Figure 32 (Ferguson et al. 1986) is a model of depths to the Tertiary/Paleozolc unconformity underlying Yucca Flat. This figure suggests the same relationships as the previous two Bouguer anomaly maps for the Yucca Flat itself. In addition, the northwest limit of the basin west of the horst correlates with Cluster 871/1391. The small features discussed in the Half Pint range are not included on this plot.

\section{Magnetic Anomalies}

A map of magnetic anomalies for the northern part of the Yucca Flat (Hinrichs 1968) appears as Figure 33. We would expect major fault and fracture systems to control magnetic gradients or low zones related to alteration and hydration. We would also expect volcanic rocks to show higher magnetism than either the Paleozolc basement or unconsolidated alluvium in Yucca Flat. The highest magnetizations appear to be due to the Mesozolc-aged Gold Meadows, Climax, and Twinridge stocks. Location of the Gold Meadows Stock correlates with the intersection of clusters 2050 and 1202. The Climax stock is close to the intersection of 1477 and 2050. Cluster 1434. with a northeast dip, correlates with a down-drop in the magnetic basement to the northeast, as shown by a decrease in magnetizations. Clusters 1425 and 1840 show similar correlation with offsets in the magnetic basement. Isopach maps discussed earlier indicate a depositional basin of Tertiary volcanics to the north of this offset, matching the observed magnetic anomaly. This correlation is designated with an "a" in Table 2.

The enclosed lows (hachured contours) in the northwest part of Figure 34 match an apparently reversely magnetized lava flow unit. The low in the south center corresponds to Yucca 


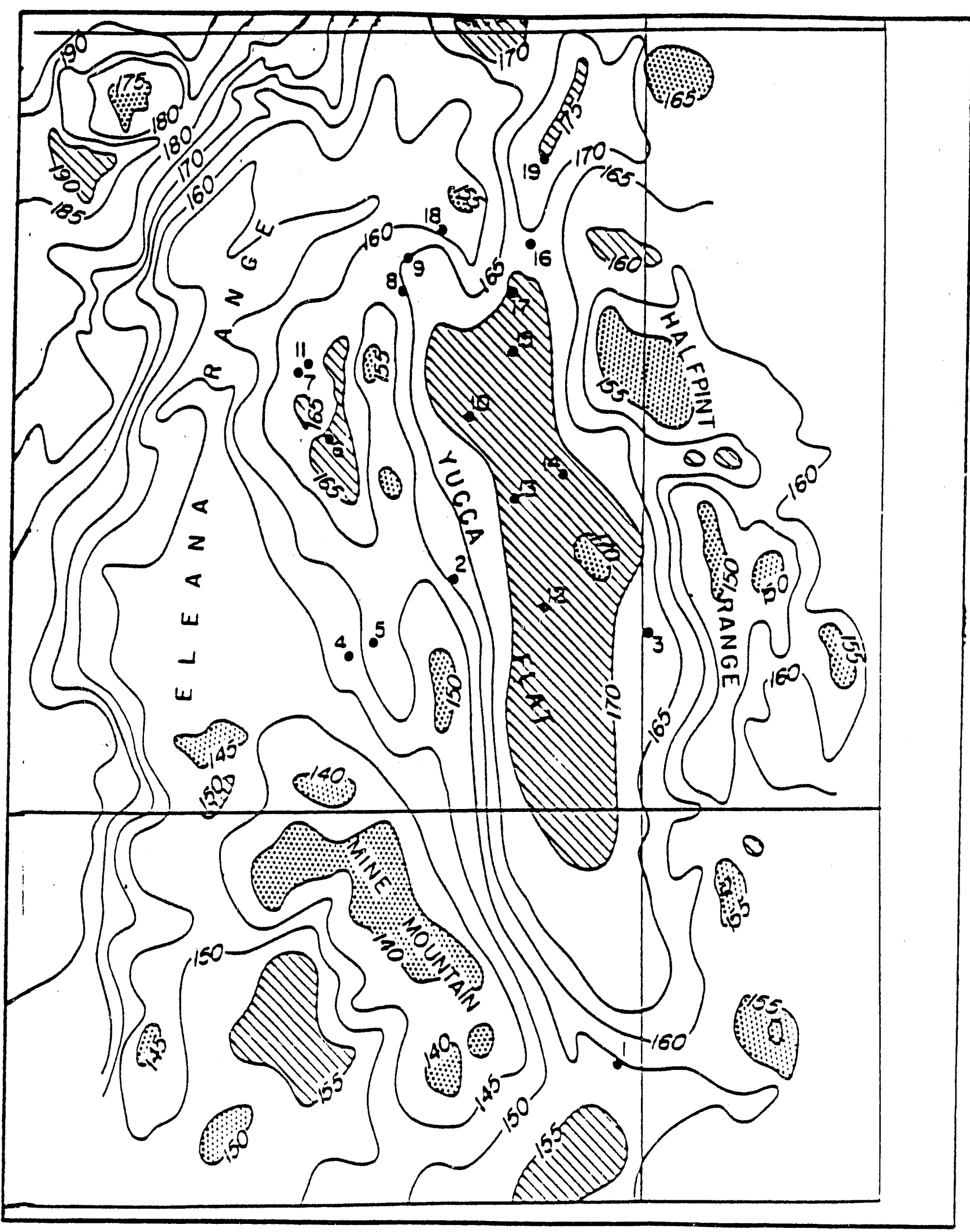

FIGURE 29. RGA Plane Clusters with Corresponding Bouguer Gravity Anomalies after Healy (1968). Dotted patterns-maxima, diagonal lines-minima, all values are negative (mgal) 


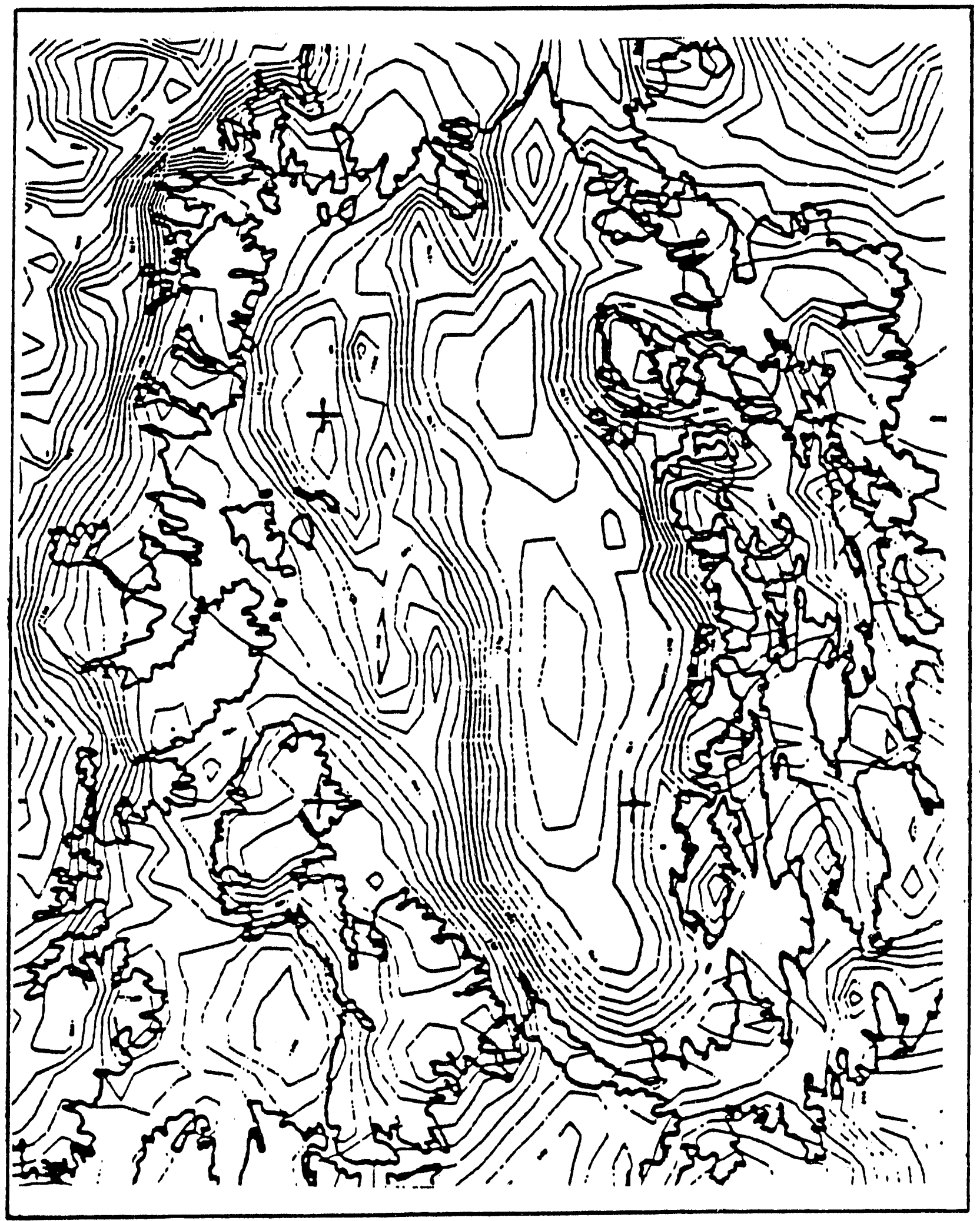

FIGURE 30. RGA Plane Clusters with Corresponding Bouguer Gravity Anomalies after Ferguson et al. (1986) 


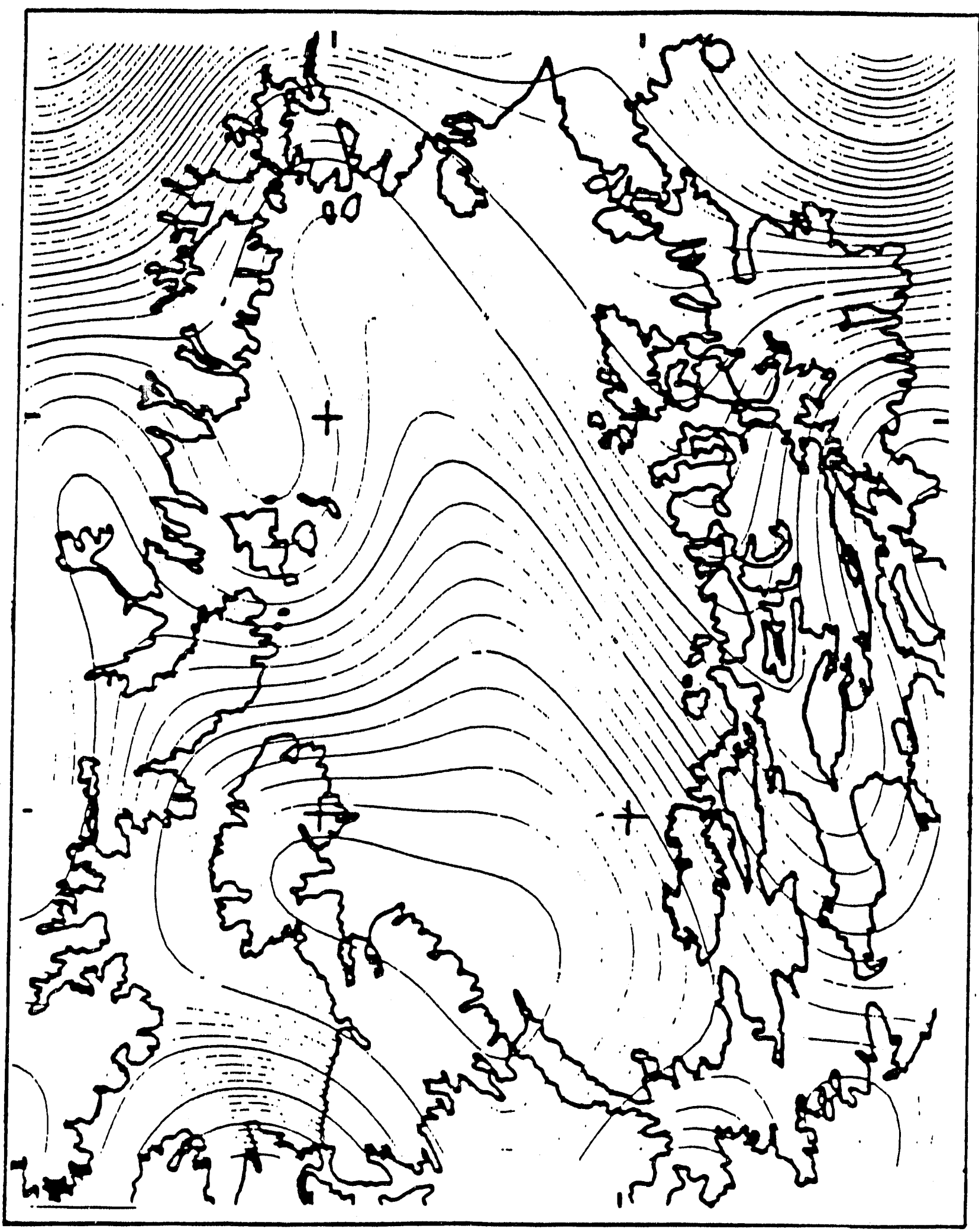

EIGURE 31. RGA Plane Clusters with Corresponding Regional Gravity Anomalles (Fourier trend surface after Ferguson et al. 1986) 


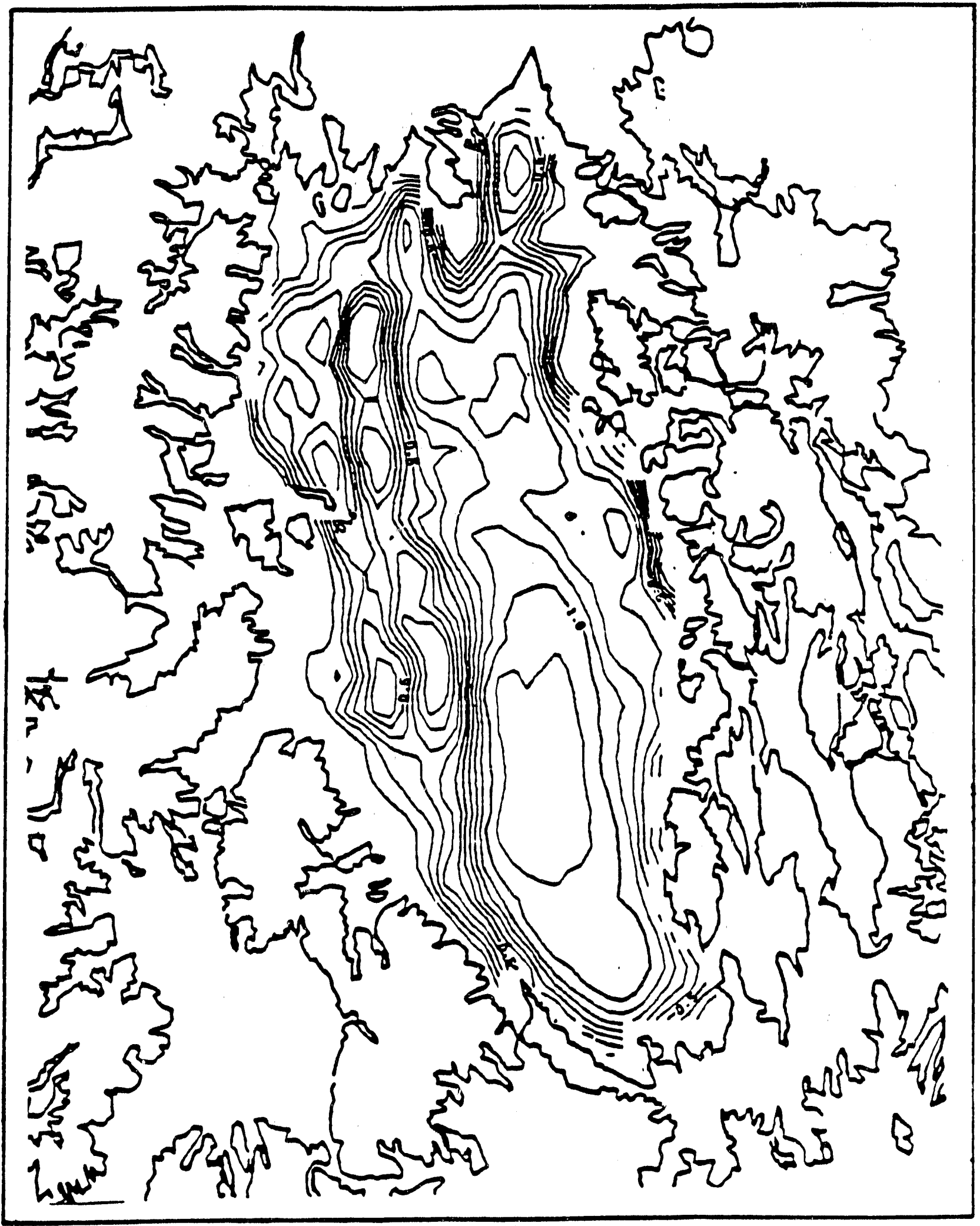

EIGURE 32. RGA Plane Clusters with Model of Depths to Tertiary/Paleozolc Unconformity (Ferguson et al. 1986) 


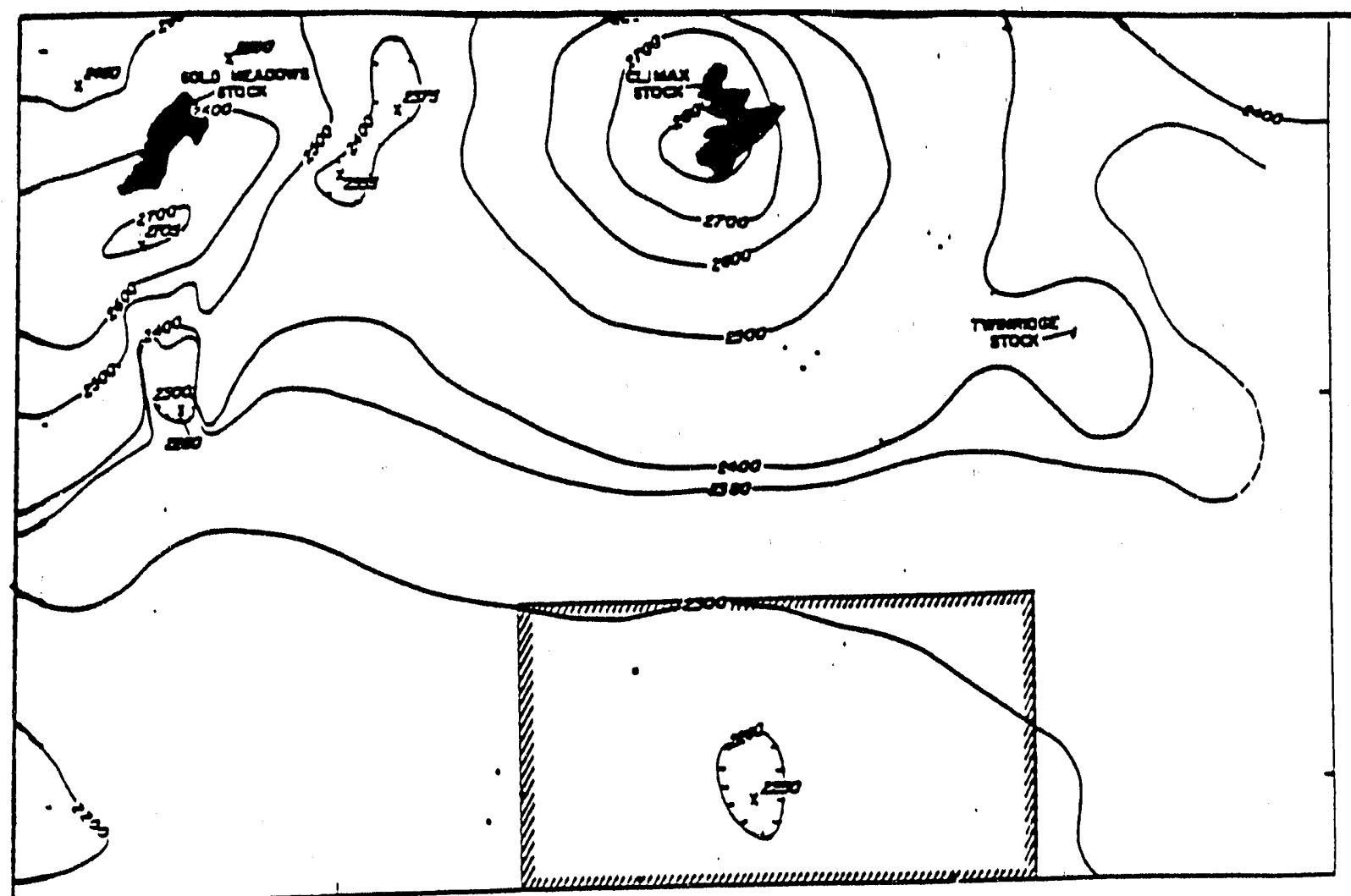

EIGURE 33. Magnetic Anomalies (in gammas) for the Northern Portion of Yucca Flat (Hinrichs 1968). Black zones are intrustve bodies, hachured boundary shows area of Figure 34. 


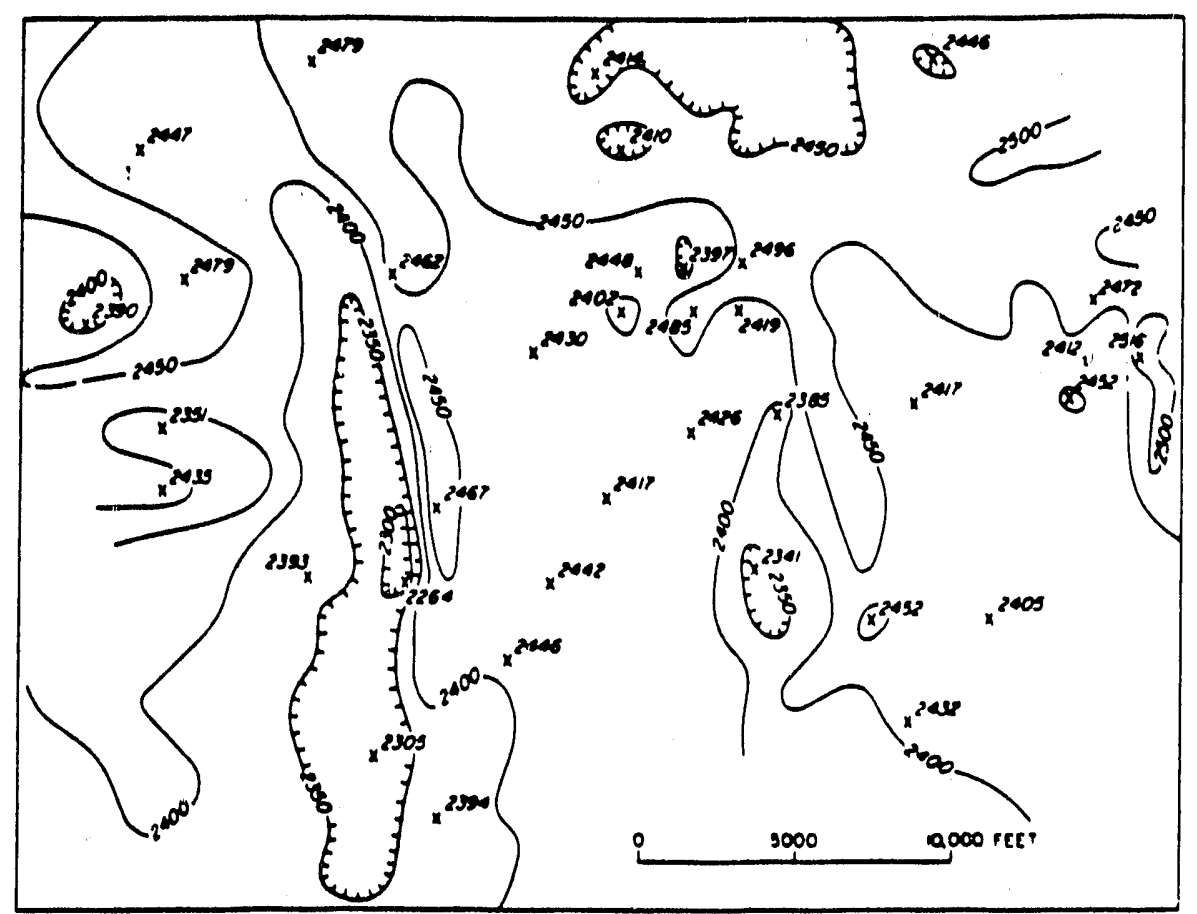

FIGURE 34. Detalled Magnetic Anomalies (in gammas) for Part of Yucca Flat (see Figure 33) 
Fault. A detalled study of the diagonally ruled area on these figures is shown in Figure 34. The Yucca Fault anomaly has been resolved into a north-south boundary between a low to the west and a high to the east. Cluster 1434 aligns with the north-northwest oriented anomaly right along the east side of this detalled study area; no other clusters cross this area.

\section{CORRELATION WITH YIELD RESIDUALS}

We compared the RGA plane clusters with a map (Figure 35) of yleld residuals for selsmic yleld-magnitude models of 160 nuclear-weapon tests at Yucca Flat (Elleen Vergino, written communication, 24 June 1991) to evaluate the abillty of RGA to partition the test area into blocks of systematically different behavior. This is a preliminary evaluation, because we have used these residuals without consideration of their source or dertvation, have not considered other factors such as proximity to the water table or Paleozoic basement that might also affect yield residuals, nor have we attempted to develop yleld-magnitude models assuming that the blocks may have systematic differences. Nevertheless, we can see in Figure 35 that the RGA plane clusters apparently do not divide the down-dropped block under Yucca Flat into sub-blocks that have distinguishably different model residuals. Rather, the RGA plane clusters apparently affect model residuals for tests conducted in the cluster "zones"; residual values there are in most cases signifIcantly different from those in the bodies of the sub-blocks away from the cluster "zones." However, at present we do not know enough about the derivation of the residuals to designate this a compelling correlation. Because this correlation is a direct approach to evaluating the relevance of our RGA pattern-recognition methods to seismic treaty verification, we recommend that future work to evaluate the correlation between RGA plane clusters and yield residuals begin with reevaluation of the residuals themselves as well as including the other geologic and geometric factors described above.

\section{CORRELATION WITH MAPPED LINEAMENTS}

Thiessen et al. (1986) prepared a number of remote sensing images of the Palute Ridge quadrangle, the central quadrangle along the east side of our nine quadrangle study area. Five different interpreters prepared lineament interpretations. Lineaments that were identified by at least three operators were considered high confidence features. Four different page-size images of this quadrangle were used, the original thematic mapper (TM) image acquired in March, a shadedrellef image based on a DEM of the quadrangle, the TM image with the shadows removed to correct for illumination effects, and the shadow-corrected image as a stereopair. Four of the clusters cross into the detalled lineament study area, with Cluster 935 intersecting only the northwest corner.

Figure 36 (also listed in Table 2) shows lineaments based on the original TM image of the Palute Ridge quadrangle. Cluster 1523 matches 2 high-confidence lineaments, 935 aligns with 2 , and 1434 with 3. Cluster 909 feeds into a series of 7 lineaments in the first ridge east of Yucca Flat. This ridge contains two mapped faults with the proper southeast dip.

High-confidence lineaments (picked by at least 3 of 5 interpreters) based on interpretation of a shaded-relief Image of the DEM are shown in Figure 37. Cluster 909 matches 5 features; 2 appear to be the coplanar valley bottoms that define some of the three-dimensional planes in this cluster. Clusters 1434 and 1523 both have 3 matches, and 935 has 1 . 


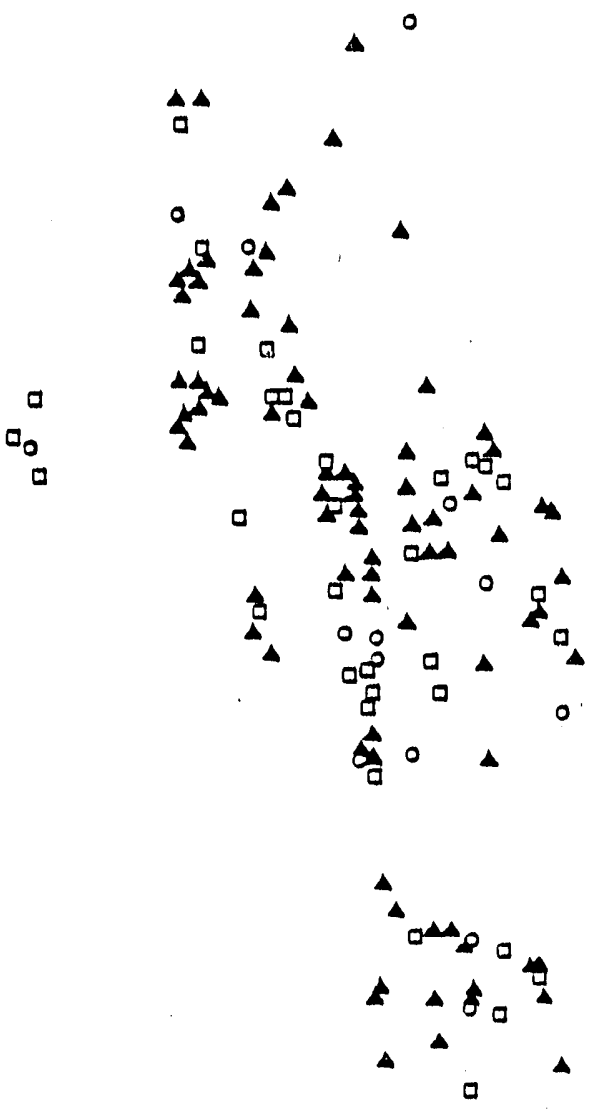

EIGURE 35. Yield Residuals for 160 Nuclear Weapons Tests at Yucca Flat (arbitrary scale; E1leen Vergino, written communication, 24 June 1991) 


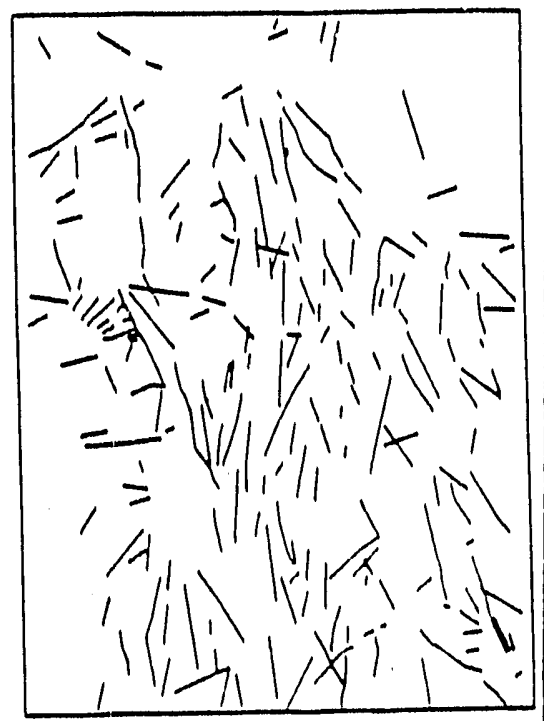

EIGURE 36. Lineament Map of the Palute Ridge Quadrangle, NTS, Based on Landsat TM Image (Thiessen et al. 1986) 


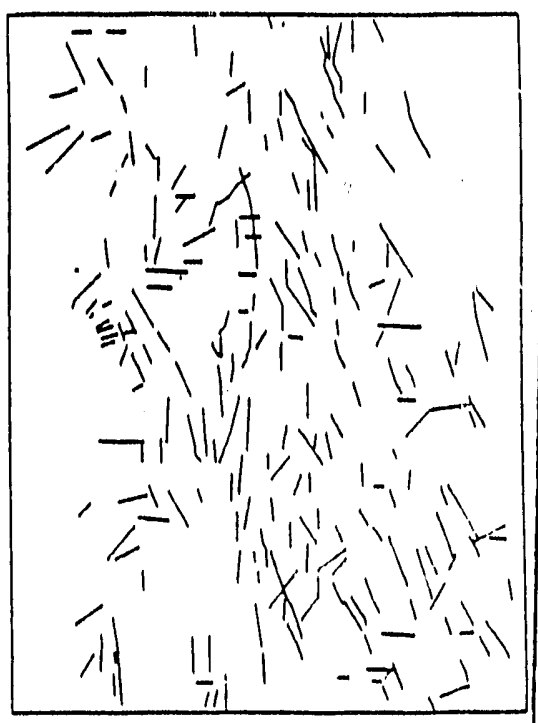

EIGURE 37. Lineament Map of the Paiute Ridge Guadrangle. NTS, Based on Shaded-Relief Image of DEM (Thiessen et al. 1986) 
Lineaments can be based on 2 major effects. The first of these is the tonal and color anomalies at a location due to soll, lithologic, and vegetation controls. The other effect is topographic (valleys, range fronts, ridges), which can be portrayed either as shadowing or a stereopair. Figure 37 shows the effects of a pure shaded-rellef (shadowed Lambert reflector) image. A purely color/ tonal image was produced in which the topographic shadowing effect was removed. Figure 38 suggests that 5 lineaments match Cluster 1434, 4 correspond to Cluster 1523, 3 correspond to Cluster 909, and 1 matches Cluster 935.

For the last lineament study, the corrected TM image was recalculated using the DEM to create a stereopair. Figure 39 presents features found by at least 3 of the 5 interpreters. Cluster 1434 matches 5 lineaments, Cluster 909 matches 4, Cluster 935 correlates with 3 lineaments. and Cluster 1523 with 5. Apparently, the corrected stereopair gives the highest number of matches to the high-confidence lineaments. These results agree with the Thiessen et al. (1986) observation that the corrected stereopair produces the best orientation plots (rose diagrams) with the least shadowing effect.

Several of the high-confidence lineaments were verified in the field. One of them, parallel to Cluster 1434, was actually one of a number of igneous dikes parallel to the fracture trends. This feature was detected 14 times of the possible 20 (5 interpreters of 4 images). Another of the lineaments parallel to Cluster 1434, found 16 times, was a change in stratigraphy. A well defined lineament, found 15 of 20 possible t'mes, is directly associated with the southeast-dipping Cluster 909. This lineament was examined in a pit in the field and found subparallel to several small northeast-oriented faults striking from $N 64^{\circ} \mathrm{E}$ to $\mathrm{N} 80^{\circ} \mathrm{E}$ with dips from vertical to $80^{\circ} \mathrm{SE}$. 


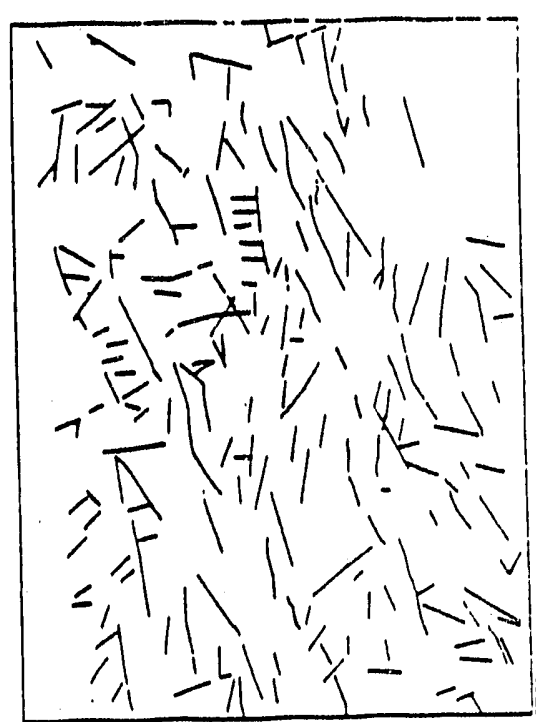

FIGURE 38. Lineament Map of the Paiute Ridge Quadrangle, NTS, Based on Shadow-Corrected Landsat TM Image (Thiessen et al. 1986) 


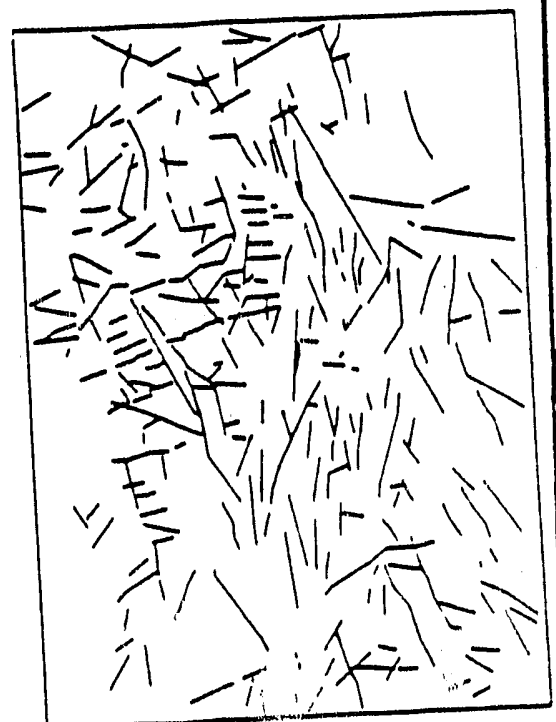

FIGURE 39. Lineament Map of the Palute Ridge Quadrangle, NTS, Based on Stereographic Projection of Shadow-Corrected Liandsat TM Image (Thiessen et al. 1986) 


\section{CONCLUSIONS}

The initial geomorphic pattern-recognition method implemented in our RGA system was designed to detect nearly linear zones in topography that have anomalously large numbers of coplanar valley segments. Our proof-of-principle analysis of the high-quality DEM of the Yucca Flat area of NTS demonstrated that this approach accurately detected valleys in the DEM, performed accurate coplanar correlations, and isolated statistically meaningful clusters of planes that could be ranked in order of signiflcance. It is not enough, however, to show that the geomorph'c pattern-recognition algorithms faithfully performed as designed; we must also evaluate the results in terms of their geologic significance and implications for seismic wave propagation relevant to veriflcation of arms-control treaties.

\section{GEOMORPHIC EVALUATION}

The current pattern-recognition method in our RGA analysis finds only stream valleys and not scarps, offset streams and terraces, or other manifestations of faulting; development of advanced RGA pattern-recognition algorithms for identifying these features is in progress. Because its current pattern-recognition analysis spatially integrates specific erosional features that are preferentially related to surficial fractures, it is most likely that RGA finds associations of large numbers of subparallel fractures in the upper few kdlometers of the earth's crust that manifest faults or folds at greater depth. The significant plane clusters found at Yucca Flat support this hypothesis; they are typically 1 to $2 \mathrm{~km}$ wide and contain dozens to hundreds of individual planes. If the clusters represent "flower structures" developed in the 2 to $5 \mathrm{~km}$ of crust overlying basement folds and faults, we would expect just such zones.

Previous methods of geomorphic analysis simply could not find such associations of valleys: they are not visible even to the trained geomorphologist. Lineament analysis, which is probably the closest predecessor approach, relies on associations of features that are colinear in map view. The RGA results are consistent with prevlous lineament studies of the Paiute Ridge Quadrangle at the eastern edge of the Yucca Flat study area, but make coplanar associations over much longer distances than the manual lineament analyses could reasonably attempt.

\section{GEOLOGIC EVALUATION}

Yucca Flat has been the subject of many detalled geologic and geophysical investigations, in part to support the nuclear-weapons testing conducted there. These investigations produced a wealth of useful data, which was the reason we chose Yucca Flat for our test application, despite its geologic complexity. We correlated RGA plane clusters with geologic and geophysical data for Yucca Flat, including mapped faults and joints, active faults and explosion-induced fractures, isopachs and structure-contour surfaces for rocks underlying Yucca Flat, gravity anomalles, and magnetic anomalies. We found strong correlations between plane clusters and apparent structures in the subsurface; nondetection or offset indications of structures mapped at the surface are explicable artifacts of the current RGA method of analysis.

- Not surprisingly, nuinerous strong plane clusters correlate with the range fronts facing Yucca Flat on the east and west. In both cases, the cluster traces are displaced slightly away from Yucca Flat. Because the initial pattern-recognition method used by RGA cannot 
effectively find valleys in the low topographic relief of Yucca Flat, these fractures are detected only in the surrounding mountains, and the main range-front faults must be inferred as lying parallel to and inboard (relative to Yucca Flat) of the RGA clusters. Pattern-recognition methods under development for RGA will eliminate this problem in future analyses.

- Also not surprisingly, no RGA clusters were found defining the Yucca Fault; its active scarp across Yucca Flat is visible in the shaded-relief image of the DEM, but it is not a valley and so is not detected by RGA. Pattern-recognition methods under development for RGA will eliminate this problem in future analyses.

- While segments of RGA plane clusters correlate with numerous mapped faults, including the Mine Mountain Fault, no single fault or assoctations of fault zones seem to correlate with a substantial length of the RGA plane clusters. In part, this is an artifact of the study area; the relief of Yucca Flat is too small for the initial RGA pattern-recognition method to detect any valleys. Its active scarp across Yucca Flat is visible in the shaded-relief image of the DEM, but it is not topographically expressed as a valley and, as such, is not detected. Overall, however, we think that significant RGA plane clusters manifest larger structures than those mapped at the surface in the area of Yucca Flat.

- This supposition is borne out by correlations of Yucca Flat-crossing RGA plane clusters with features found in isopach, structure-contour, gravity-anomaly, and magnetic-anomaly maps of Yucca Flat. All of the RGA plane clusters that cross Yucca Flat correlate with linear features, such as truncations, thinnings, or offsets, in these maps of subsurface features. Further, few features are found in the maps that are not associated with one of these clusters. The associations are compelling in the central part of Yucca Flat, less so at the northern and southern boundaries. Possibly, the smaller number of correlations north and south result from a relative lack of data.

We are confident that the RGA study of Yucca Flat identified significant fracture zones that, in addition to defining the obvious Basin-and-Ringe structural bounds of Yucca Flat, affect the down-thrown block underlying the basin and carry through into the bounding ranges. Because most of the Basin-and-Range bounding faults in this region are thought to be listric, we cannot project the apparent structures defined by the current RGA system to depths greater than 2 to 5 $\mathrm{km}$. Three-dimensional characterization and advanced studies based on deep crustal reflection and refraction seismology to constrain fault-surface geometry and enhanced RGA methods (for example, fitting of nonplanar surfaces to clusters) would be necessary for such a projection.

\section{SEISMIC EVALUATION}

We have been able to define planar zones that divide the down-dropped block underlying Yucca Flat into 5 or more sub-blocks using only topographic data, which can be determined by stereographic remote sensing for any similar-sized area of any planet for which we have high-resolution ( 10 to $30 \mathrm{~m}$ resolution) satellite imagery. Does this capabllity provide useful input for seismic studies related to verification of nuclear-testing treaties? Based on a preliminary correlation of RGA plane clusters with residuals from yield-magnitude models of weapons tests at Yucca Flat, we find

- The RGA plane clusters apparently do not divide the down-dropped block under Yucca Flat into sub-blocks that have distinguishably different model residuals.

- The RGA plane clusters apparently affect model residuals for tests conducted in the cluster "zones"; residual values within the cluster zones are in most cases significantly different from those in the bodies of the sub-blocks outside the zones. However, similar differences occur along the traces of the Yucca and Carpetbag faults. Because of the north-south dis- 
tribution of tests for which we have yield residuals, we cannot completely separate correlations between the residuals, the plane clusters, and the faults.

- At present, we know too little about the dertvation of the yleld residuals for this to be a compelling correlation.

\section{NEEDED WORK}

Our RGA study of Yucca Flat using the initial geomorphic pattern-recognition method is virtually complete. We do not think that further coplanar analysis is necessary, nor that future analyses with advanced RGA methods (e.g., detection of nonplanar features, scarps) will signiflcantly change the character of the significant plane clusters we identifled. Nevertheless, the value of the RGA system to the treaty-verification community can be enhanced by further investigations to improve

- the correlations of significant RGA plane clusters with geologic and geophysical data. A substantial data-compllation effort could be coupled with a synthesis of isopach and structure-contour surfaces and three-dimensional projection and visualization of these surfaces and RGA plane clusters.

- the apparent correlation with known nuclear-weapons test effects. The yield-magnitude models could be derived with explicit consideration that the RGA plane-cluster zones may have systematically different behavior, and RGA results could be correlated with resulting residuals distributions to include consideration of proximity to the water table and the top of the Paleozolc basement.

It is important to realize that these intense evaluations of the relationship between RGA plane clusters, geology, and yield residuals are based on a priort knowledge of subsurface information that will not be avallable at foreign test sites. While site data may increase our confidence in RGA as a predictive tool, we must also evaluate the efficacy of RGA for yleld estimation in the absence of all but remotely sensed data. This means that any refinements to RGA for application to inaccessible sites must not require site-specific data other than DEMs. However, this does not mean that we should eliminate the ability of RGA to use site data; improvements in that capability would be beneficial so long as they did not affect its primary use as a remote analysis tool. 


\section{REEERENCES}

Albers, J. P. 1967. "Belt of Sigmoldal Bending and Right Lateral Faulting in the Western Great Basin." Geological Society of America Bulletin 78:143-156.

Ander, H. D. 1984. Rotation of Late Cenozolc Extensional Stresses, Yucca Flat Region, Nevada Test Site, Nevada. Ph.D. Dissertation, Rice Untversity, Houston, Texas.

Anderson, R. E. 1989. Tectonic Evolution of the Intermontane Systern; Basin and Range, Colorado Plateau, and High Lava Plains." In Geophysical Framework of the Continental Untted States, eds. L. C. Pakdsee and W. D. Mooney.. Geological Society of America Memoirs 172:163176.

Barnes, H., R. L. Christiansen, and F. M. Byers, Jr. 1965. Geologic Map of the Jangle Ridge Quadrangle, Nye and Lincoln Countles, Nevada. U.S. Geological Survey Map GQ-363.

Barnes, H., F. N. Houser, and F. G. Poole. 1963. Geologic Map of the Oak Spring Quadrangle. Nye County. Nevada. U.S. Geological Survey Map GQ-214.

Barosh, P. J. 1968. "Relationships of Explosion-Produced Fracture Patterns to Geologic Structure in Yucca Flat, Nevada Test Site." In Nevada Test Site, ed. E. B. Eckel. Geological Society of America Memoirs 110:199-217.

Becker, R. A. J. M. Chambers, and A. R. Wilks. 1988. The New S Language: A Programming Envtronment for Data Analysis and Graphics. Wadsworth and Brooks/Cole, Pacific Grove, Callfornia.

Burchfiel, B. C., P. S. Pelton, and J. F. Sutter. 1970. "An Early Mesozolc Deformation Belt in South-Central Nevada-Southeastern California." Geological Soctety of America Bulletin 81:211215.

Byers, F. M., Jr., and H. Barnes. 1967. Geologic Map of the Patute Ridge Quadrangle, Nye and Lincoln Countles, Nevada. U.S. Geological Survey Map GQ-577.

Carr. W. J. 1974. Summary of Tectonic and Structural Evidence for Stress Orientation at the Nevada Test Site. U.S. Geological Survey Open File Report 74-176.

Carr, W. J. 1988. Volcano-tectonic Setting of Yucca Mountain and Crater Flat, Southwestern Nevada." In Geologic and Hydrologic Investigations of a Potential Nuclear Waste Disposal Site at Yucca Mountain, Southern Nevada, ed. M. D. Carr and J. C. Yount, U.S. Geological Survey Bulle$\operatorname{tin} 1790: 35-49$.

Carr, W. J., G. D. Bath, D. L. Healey, and R. M. Hazelwood. 1974. Geology of Northern Frenchman Flat, Nevada Test Site. U.S. Geological Survey Open File Report 74-216.

Colton, R. B., and E. J. McKay. 1966. Geologic Map of the Yucca Flat Quadrangle, Nye County, Nevada. U,S. Geological Survey Map GQ-582.

Cornwall, H. R. 1972. Geology and Mineral Deposits of Southern Nye County. Nevada. Bulletin 77. Nevada Bureau of Mines and Geology, Reno, Nevada. 
Dickey, D. D. 1968. "Fault Displacement as a Result of Underground Nuclear Explosions." In Nevada Test Site, ed. E. B. Eckel. Geological Soctety of America Memoirs 110:219-232.

Diment, W. H., D. L. Healey, and J. C. Roller. 1960. Gravtty and Selsmic Exploration at the Nevada Test Site. U.S. Geological Survey Professional Paper 400-B:B156-B160.

Eaton, G. P., R. Wahl, H. Prostka, D. Mabey, and M. D. Kleinhopf. 1978. "Reglonal Gravity and Tectonic Patterns: Their Relation to Late Cenozolc Epeirogeny and Lateral Spreading in the Western Cordillera." In Cenozoic Tectonics and Regional Ceophysics of the Western Cordillera, eds. $R$. B. Smith and G. P. Eaton. Geological Society of America Memoir 152:51-91.

Ekren, E. B., C. L. Rogers, R. E. Anderson, and P. P. Orkild. 1968. "Age of Basin and Range Normal Faults in the Nevada Test Site and Nellis Air Force Base, Nevada." In Nevada Test Site. ed. E. B. Eckel. Geological Soctety of America Memoir 110:247-250.

Eliason. J. R. 1984. A Techntque for Structural Geologic Analysis of Topography. Thesis, WashIngton State Untversity, Pullman, Washington.

Ferguson, J. F., R. N. Felch, C. L. V. Alken, J. S. Oldow, and H. Cockery. 1986. "Models of the Bouguer Gravity and Geologic Structure at Yucca Flat, Nevada." Geophysics 53(2):231-242.

Frizzell, V. A., and J. Shulters. 1990. Geologic Map of the Nevada Test Site, Southern Nevada. U.S. Geological Survey Map I-2046.

Gibbons, A. B., E. N. Hinrichs, W. R. Hansen, and R. W. Lemke. 1963. Geology of the Rainier Mesa Quadrangle, Nye County, Nevada. U.S. Geological Survey Map GQ-215.

Healey, D. L. 1966. "Gravity and Seismic Study of Yucca Flat, Nevada Test Site, Nye County, Nevada." Mining Geophysics 1:84-93.

Healey, D. L. 1968. "Application of Gravity Data to Geologic Problems at Nevada Test Site." In Nevada Test Site, ed. E. B. Eckel. Geological Society of America Memoir 110:147-156.

Healey, D. L., and C. H. Miller. 1963. Gravity Survey of the Gold Meadows Stock, Nevada Test Site, Nye County, Nevada. U.S. Geological Survey Professional Paper 475-B:B64-B66.

Hinrichs, E. N. 1968. "Geologic Structure of Yucca Flat Area, Nevada." In Nevada Test Site, ed. E. B. Eckel. Geological Society of America Memoir 110:239-246.

Hinrichs, E. N., and E. J. McKay. 1965. Geologic Map of the Plutonitum Valley Quadrangle, Nye and Lincoln Countles, Nevada. U.S. Geological Survey Map GQ-384.

Hoover, D. L., and J. N. Morrison. 1980. Geology of the Syncline Ridge Area Related to Nuclear Waste Disposal, Nevada Test Site. U.S. Geological Survey Open Flle Report 80-942.

McKeown, F. A., D. L. Healey, and C. H. Miller. 1976. Geologic Map of the Yucca Lake Quadrangle, Nye County, Nevada. U.S. Geological Survey Map GQ-1327.

Orkild, P. P. 1963. Geologic Map of the Tippipah Spring Quadrangle, Nye County, Nevada. U.S. Geological Survey Map GQ-213.

Orkild, P. P. 1968. Geologic Map of the Mine Mountain Quadrangle, Nye County, Nevada. U.S. Geological Survey Map GQ-746. 
Poole, F. G., F. N. Houser, and P. P. Orkdld. 1961. Eleana Formation of Nevada Test Stte and Vicinity, Nye County, Nevada. U.S. Geological Survey Proflle PPR 424-D, pp. D104-D111.

Robinson, G. D. 1985. Structure of Pre-Cenozolc Rocks in the Vicinity of Yucca Mountain. Nye County. Nevada: A Potential Nuclear Waste Disposal Site. U.S. Geological Survey Bulletin 1647.

Scott, R. B., G. D. Bath, V. J. Flanigan, D. B. Hoover, J. G. Rosenbaum, and R. W. Spengler. 1984. Geological and Geophysical Evidence of Structures in Northwest Trending Washes, Yucca Mountatn. Southern Nevada, and Their Possible Significance to a Nuclear Waste Repository in the Unsaturated Zone. U.S. Geological Survey Open Flle Report 84-567.

Sinnock. S. 1982. Geology of the Nevada Test Site and Nearby Areas, Southern Nevada. SAND82-2207, Sandia National Laboratory, Albuquerque. New Mexdco.

Speed, R. C. 1978. "Paleographic and Plate Tectonic Evolution of the Early Mesozolc Marine Province of the Western Great Basin." In Pactfic Coast Paleogeography Symposium 2-Mesozoic Paleography of the Western United States, eds. D. G. Howell and K. A. McDougall, pp. 253-270. Society of Economic and Paleontologic Mineralogists, Los Angeles.

Stewart. J. H. 1978. "Basin and Range Structure in Western North America: A Review." In Cenozoic Tectonics and Regional Geophysics of the Western Cordillera, eds. R. B. Smith and G. P. Eaton. Geological Society of America Memoir 152:1-31.

Suppe, J., C. Powell, and R. Berry. 1975. "Reglonal Topography, Selsmicity, Quaternary Volcanism, and the P. ssent Day Tectonics of the Western United States." American Journal of Sctence 275-A:346-397.

Swadley, W. C., and D. L. Hoover. 1990. Geologic Map of the Surficial Deposits of the Yucca Flat Area, Nye County, Neuada. U.S. Geological Survey Map I-2047.

Thiessen, R. L., L. K. Johnson, H. P. Foote, and J. R. Eliason. 1986. "Surface Reflectance Correction and Stereo Enhancement of Landsat Thematic Mapper Imagery for Structural Geologic Exploration." In Proceedings, Fyfth Thematic Conference, Remote Sensing for Exploration Ceology. pp. 763-773. Environmental Research Institute of Michigan, Ann Arbor, Michigan.

U.S. Geological Survey (USGS). 1977. Explosion-Induced Fractures of Selected Announced Underground Nuclear Tests, Yucca Flat. Nevada Test Site, Nevada, January through December 1975. Prepared by the U.S. Geological Survey for the Nevada Operations Office. U.S. Energy Research and Development Administration (NTS-239). 
APPENDIX

MATHEMATICAL AND STATISTICAL BACKGROUND 


\section{MATHEMATICALAND STATISTICAL BACKGROUND}

A quantitative evaluation of digital elevation maps requires the use of different coordinate systems, an introduction to the notion of error and variabllity, and a definition of the notion of clustering. In this section, we introduce the fundamental mathematical and statistical concepts needed to formulate and understand the fault plane problem in quantitative terms.

\section{COORDINATESSYSTEMS}

In this report, it will be necessary to describe fault planes and digital elevation maps in consistent coordinate systems. For the sake of clarity, these systems are defined in this section.

\section{Cartestan Coordinate System}

The DEM, valleys, and RGA planes are defined in terms of a Cartesian coordinate system $\left(x_{1}, x_{2}, x_{3}\right)$, with the origin of the coordinate system placed in the "middle" of the DEM map area. The coordinate $x_{1}$ points east, $x_{2}$ points north, and $x_{3}$ points up. All three coordinates are measured in consistent units.

\section{Polar Coordinate System}

The cartesian point $\left(x_{1}, x_{2}, x_{3}\right)$ can also be expressed in terms of polar coordinates $(\theta, \varphi, r)$ where the angles are in radians and $r$ is in units of length. The relationship between these polar coordinates and the Cartesian coordinates is given by the standard formulas:

$$
\begin{aligned}
& x_{1}=r \sin (\varphi) \cos (\theta), \\
& x_{2}=r \sin (\varphi) \sin (\theta), \text { and } \\
& x_{3}=r \cos (\varphi) .
\end{aligned}
$$

Therefore, $\varphi$ measures the angle between the coordinate axds $x_{3}$ and the vector $X$, whlle $\theta$ measures the angle between the coordinate axds $x_{1}$ and the projection of the vector $\boldsymbol{X}$ onto the $x_{1} \times x_{2}$ plane. As defined by the formulas, this representation is ambiguous; to obtain a unique polar coordinate, $\varphi$ is restricted to $0^{\circ}$ to $90^{\circ}$ and points below the $x_{1} \times x_{2}$ plane are represented with a negattve $r$ coordinate.

These coordinate systems are set up so that a plane's strike and dip are directly related to the $\theta$ and $\varphi$ coordinates of its normal vector (if we define the normal vector as the unit vector perpendicular to the plane that always points "up"). The strike of a plane is defined as the angle between the $x_{1}$ axds (north) and the intersection of the plane with horizontal. The strike is measured clockwise from north, so that the measured angle "includes" the projection of the normal vector. Given this definition, it can be shown that the $\theta$ coordinate of the normal equals -strike. Dip of a plane is defined as the angle the plane makes with the horizontal, measured so that dip is always between $0^{\circ}$ and $90^{\circ}$. Given this definition, it can be shown that the $\varphi$ coordinate of the normal vector equals dip. These conventions are equivalent to the right-hand rule for designating strike and dip in structural geology. 


\section{ANALYSIS OF POISSON PROCESSES}

A fundamental problem is that of identifying "clusters" of planes in 3-space. This problem is closely related to that of identifying lines or points in 3-space.

The notion of clusters has been defined in several different ways but one of the most useful definitions is probabilistic; clusters are "high" concentrations of planes (or lines or points) that occur very infrequently when the planes (or lines or points) are "randomly" distributed in Euclidlan space.

In this section, we spectfically define what it means for points to be "randomly" distributed in 3-space and how one might reasonably define the concept of "high concentration." The answers to these fundamental questions are relatively simple since the distribution of planes or lines in 3-space can be reduced to a problem involving points, which solves the more general problem.

\section{Point Processes}

Suppose we have a region $R$ in Euclidian (2- or 3-dimensional) space, in which points $X_{l}$. $l=1,2,3$... are distributed according to some probability model. We say that these points are randomly distributed if the following two properties hold:

1. If $A$ and $B$ represent two arbitrary, disjoint subsets of the region $R$ with the same volume ${ }^{*}$, then the chances of point $X_{l}$ falling into either are the same.

2. If $A$ and $B$ represent two arbitrary, disjoint subsets of the region $R$, then the number of points that fall into $A$ are independent of the number of points that fall into $B$.

It is an important fact that only one stochastic model has these two properties, a Poisson process. Thus, "randomly" distributed points in Euclidian space will be distributed according to one specific distribution, and this specific distribution can be used to define clusters.

If the points in the region $R$ have a Poisson distribution, this means that the number of points $N(A)$, within any subset will have a Poisson distribution. The specific form of this distribution is:

$$
\operatorname{Pr}(N(A)=K)=e^{-\lambda v(A)} \frac{(\lambda v(A))^{K}}{K !} .
$$

where $v(A)$ represents the volume of the subset $A$ and $\lambda$ is the rate parameter for the distribution: $\lambda$ represents the average number of points per unit volume.

This distribution can be used to define a "cluster." If $A$ represents a ball having a radius on the scale of interest. then a cluster may be defined as any sphere that contains an anomalously large number of points. Equation (A.2) can be used to define "anomalously large number of points." For example, if we chose $K$ so that $\operatorname{Pr}(N(A)>K)=5 \%$, then only $5 \%$ of the time woild we (incorrectly) find clusters in a Poisson process.

\section{Statistics for Identifying the Size of the Clusters}

We use two statistics to determine whether or not clusters exist in a prospective region. These statistics are also useful for determining on what scale non-Poisson clustering seems to be $\alpha$ curring. (Are the clusters $20 \mathrm{~m}$ in diameter or $2000 \mathrm{~m}$ in diameter, or both?)

- If the space is 2-dimensional, "volume" should be replaced with "area." Throughout this discussion, we will use the term "volume" even though it may be volume or area. 
The discussion above suggests one obvious statistic to use in the exploration for clusters, let

$$
K(t)=E(\text { number of points within distance } t \text { of an arbitrary point). }
$$

If the data points are Polsson. It can easlly be shown that $K(t)$ ought to be proportional to the volume defined by the distance $t$. More specitically, the relationship is

$$
K(t)=\lambda v(t) \text {. }
$$

Consequently, $K(t)$ should be proportional to $t^{n}$, where $n$ is the dimension of the Euclidian space. Therefore, a plot of $K(t)$ versus $t^{n}$ can be used to identify the "size" of clusters by looking for deviations in linearity in this plot.

Figures A. 1 through A.4 provide examples of this type of analysis. In Figures A.1 and A.2, a Polsson and clustered process have been simulated over a rectangle. Both processes have approximately $\lambda=75$ points per unit area, but in the clustered process, points occur in clusters of 5 , randomly distributed within a radius of 0.04 units of a center point.

Most observers would classify the points in Figure A.2 as obviously clustered. However, the Polsson process results, as lllustrated in Figure A.1, can be a bit ambiguous, at least to the untrained eye. Many people see "clusters" in Poisson data. For example, there seems to be a very interesting "circle" of points in the upper left-hand corner of Figure A.1, and there seem to be quite a few "non-uniform" blank spots in the plot. Most people would find clusters in the Poisson data, also. It is just this problem that these statistics can deal with.

$K(t)$ is plotted for the two processes in Figure A.3. Notice that the Poisson data produce an obviously linear $K(t)$. On the other hand, the cluster process produces a $K(t)$ with an obvious bend. This "bend" can be used to Identily the approxdmate radius of the clusters. From the figure, the "bend" in the cluster process $K(t)$ occurs at approxdmately $t^{2}=0.005$. In other words, for $t=0.07$. This is a reasonable rough estimate for the true cluster size "which is 0.04 .

Another statistic used to identify cluster size is called $G(t)$. This statistic is defined by:

$$
G(t)=P r(\text { Nearest Neighbor to an arbitrary point }<t)
$$

As with the curve $K(t)$, one can calculate its expected shape if the point data have a Poisson distribution. In this case, $G(t)$ has the following form:

$$
G(t)=1-e^{-\lambda(t)} \text {. }
$$

Thus, for this statistic, a plot of $\log (1-G(t))$ versus $t^{n}$ should be linear when the data are Poisson.

Figure A.4 shows plots of $G(t)$ for the two simulated processes llustrated in Figures A.1 and A.2. In general, $G(t)$ is less smooth than $K(t)$. particularly for larger values of $t$, however, the general pattern is still the same. The Poisson data exhibit a linear plot of $G(t)$, while the clustered process produces a bent curve. In this case, the bend occurs at $t^{2}=0.002$ or equivalently, $t=$ 0.04 , a very good agreement with actual cluster size.

Which statistic provides a more reliable estimate of cluster size? It depends on the nature of the clustering. The $K(t)$ statistic is sensitive to the outer dimension of the cluster, while the $G(t)$ statistic is sensitive to the density of the points in the clusters. For example, if clusters of the same general radius but different densities exist, then $G(t)$ will tend to identify two separate clus- 


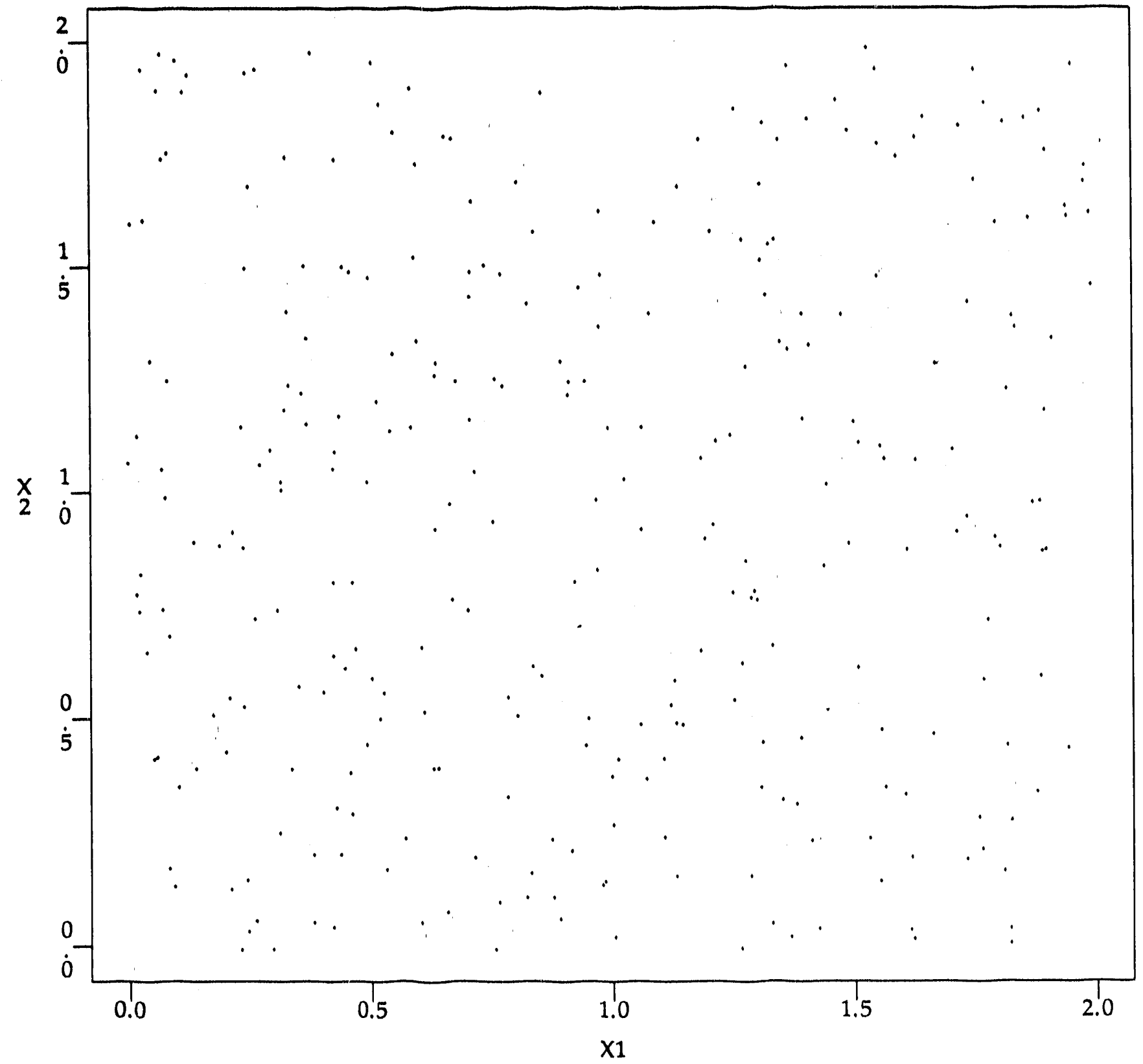

EIGUREA.1. Example of a Poisson Process 


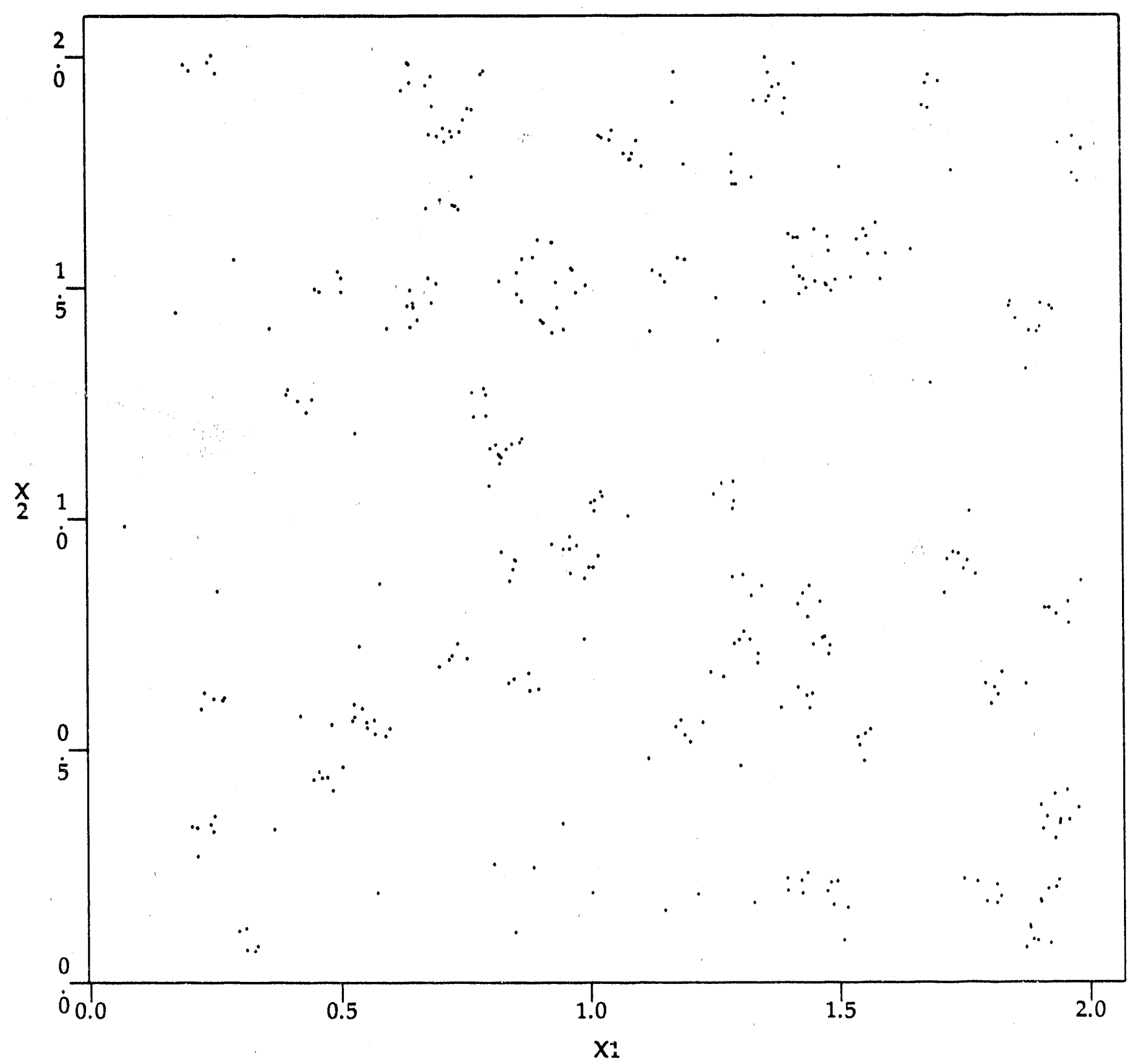

FIGURE A.2. Example of a Point Process with Clusters 


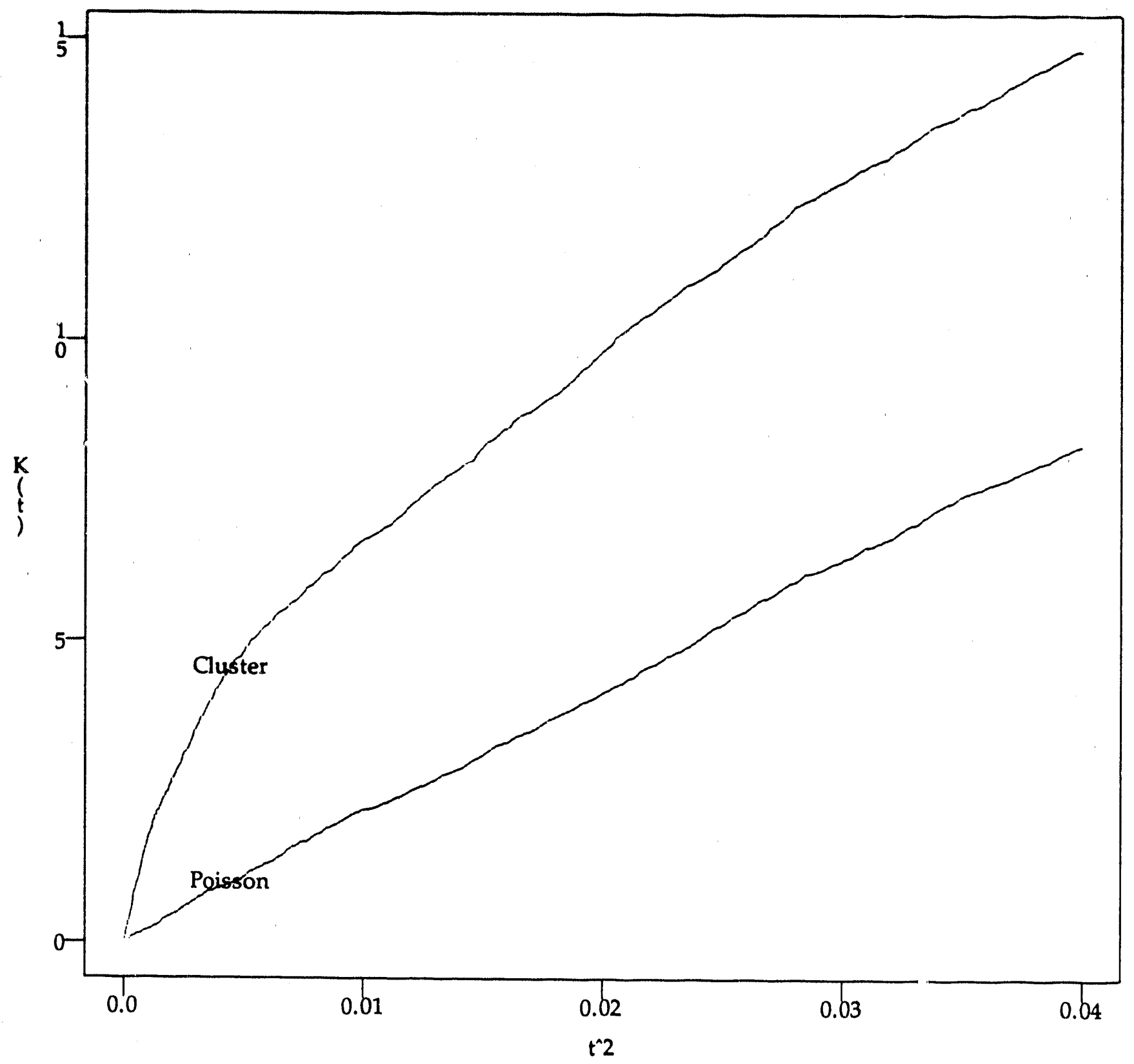

FIGURE A,3. $K(t)$ for the Poisson and Cluster Processes 


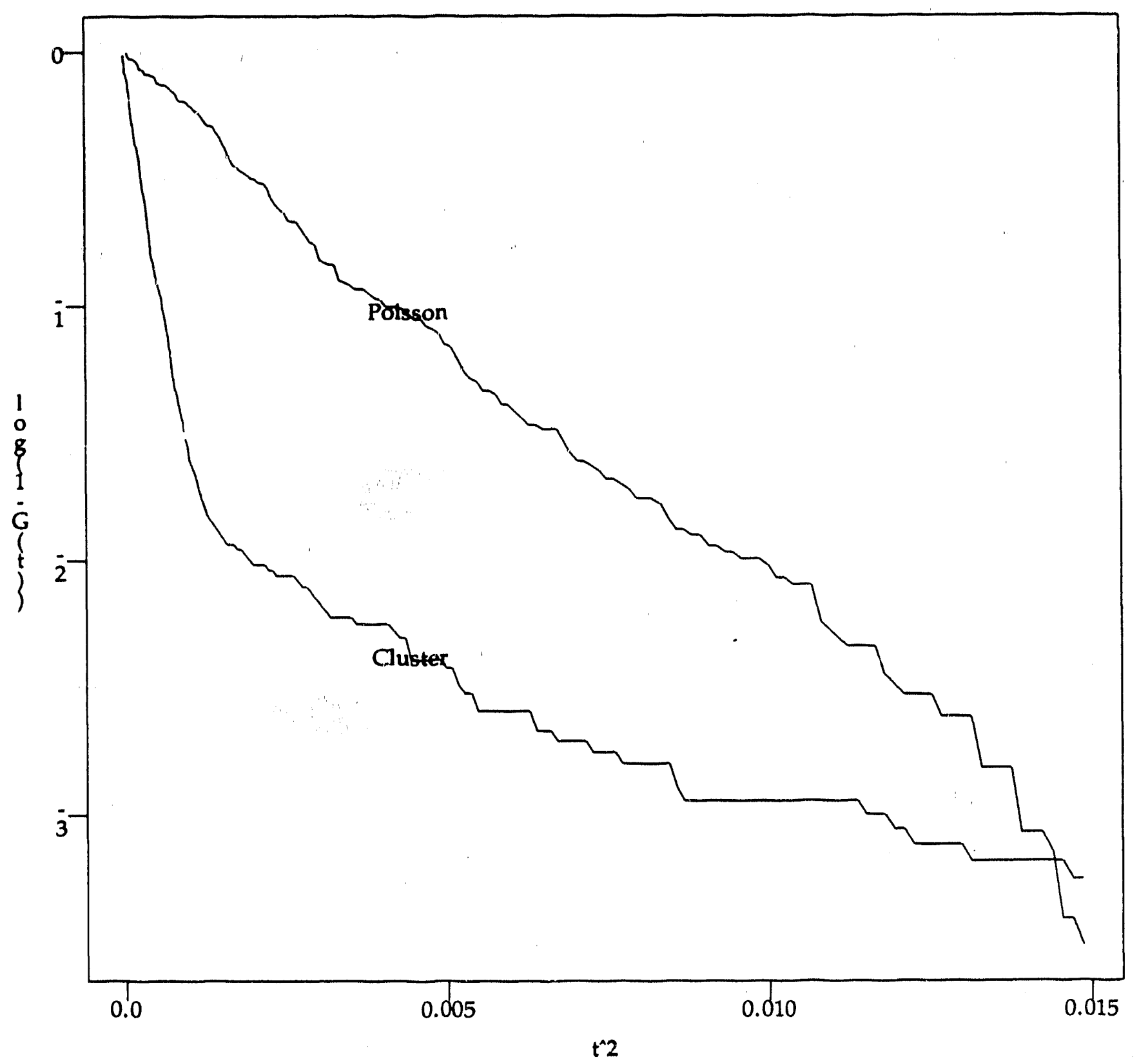

FIGURE A.4. $G(t)$ for the Poisson and Cluster Processes 
ters, but $K(t)$ will not. Also, if the clusters are not spherical, then $K(t)$ will tend to identify the major axds of the cluster, while $G(t)$ will tend to identify the minor axds.

\section{A Polsson Count Statistic to Identify Cluster Location}

A statistic derived from the Poisson process can also be used to identify the approxdmate locations of clusters. Once the approximate size of a cluster has been determined using either $K(t)$ or $G(t)$, the Foisson count is the obvious statistic for identifying clusters:

$N(x, T)=\#$ of points within radius $T$ of point $x$.

In the above statistic, the radius $T$ would be chosen via an analysis of $K(t)$ and $G(t)$. Now if there were no clustering, this statistic would have the Poisson distribution expressed in (A.2). Thus, any point $x$, where $N(x, T)$ is significantly higher than the value predicted by the Poisson distribution, is a good candidate for a cluster center. Figure A.5 lllustrates the idea for the cluster point process presented in Figure A.2.

Figure A.5 plots the distribution of $N(x, 1)$, assuming that it has a Poisson distribution (with $\lambda=360 / 4$ ) along with the observed distribution. As one would expect, the observed distribution has a heavier right-hand tall. In fact, this plot indicates that any ball of radius 0.04 containing more than 2 or 3 points contains "too many" points for a Poisson process.

Therefore, from Figure A.5, one would classify any point with more than 2 neighbors within 0.04 units as a member of a cluster. Figure A. 6 displays these identified "cluster points" superimposed on the original point process. As one can see from the plot, almost all the clusters have been found.

Although $N(x, T)$ is a very simple statistic and very easy to compute, it does have an important deficiency. It does not divide all the points up into mutually disjoint cluster sets. The statistic $N(x, T)$ does not tell us where one cluster starts and the other ends, and it may also "miss" some boundary points that should be considered part of the cluster. These problems can be solved by using more sophisticated clistering algorithms.

\section{Hierarchical Cluster Analysis}

The statistics $K(t), G(t)$, and $N(x, T)$ allow us to determine whether clusters exist, and if so, their approximate sizes and locations. However, these statistics cannot satisfactorily identify specific clusters. Ideally, one would want an algorithm to partition the points in the space into unique, disjoint sets. If the set contains a single point, then that point is not a member of a cluster; if a set contains more than one point, then the set represents a cluster. This is the description of the typical "cluster analysis" problem.

Clusters can be successfully identified by using a hierarchical clustering algorithm. A hierarchical clustering algorithm produces a tree-structure that gives several different clusterings of the point set. As one pioceeds down the tree, points are joined into larger and fewer clusters, until finally, all points are clustered into one set at the trunk.

Math cmatically, a hierarchical clustering produces a sequence of partitions, $P_{0}, P_{l}, \ldots P_{m}$. where $P_{O}$ is the weak clustering (1.e., the leaves on the tree), and $P_{m}$, the strong clustering (1.e., the trunk of the tree). Each "partition, " $P_{k}$ divides the point set into mutually disjoint subsets. 


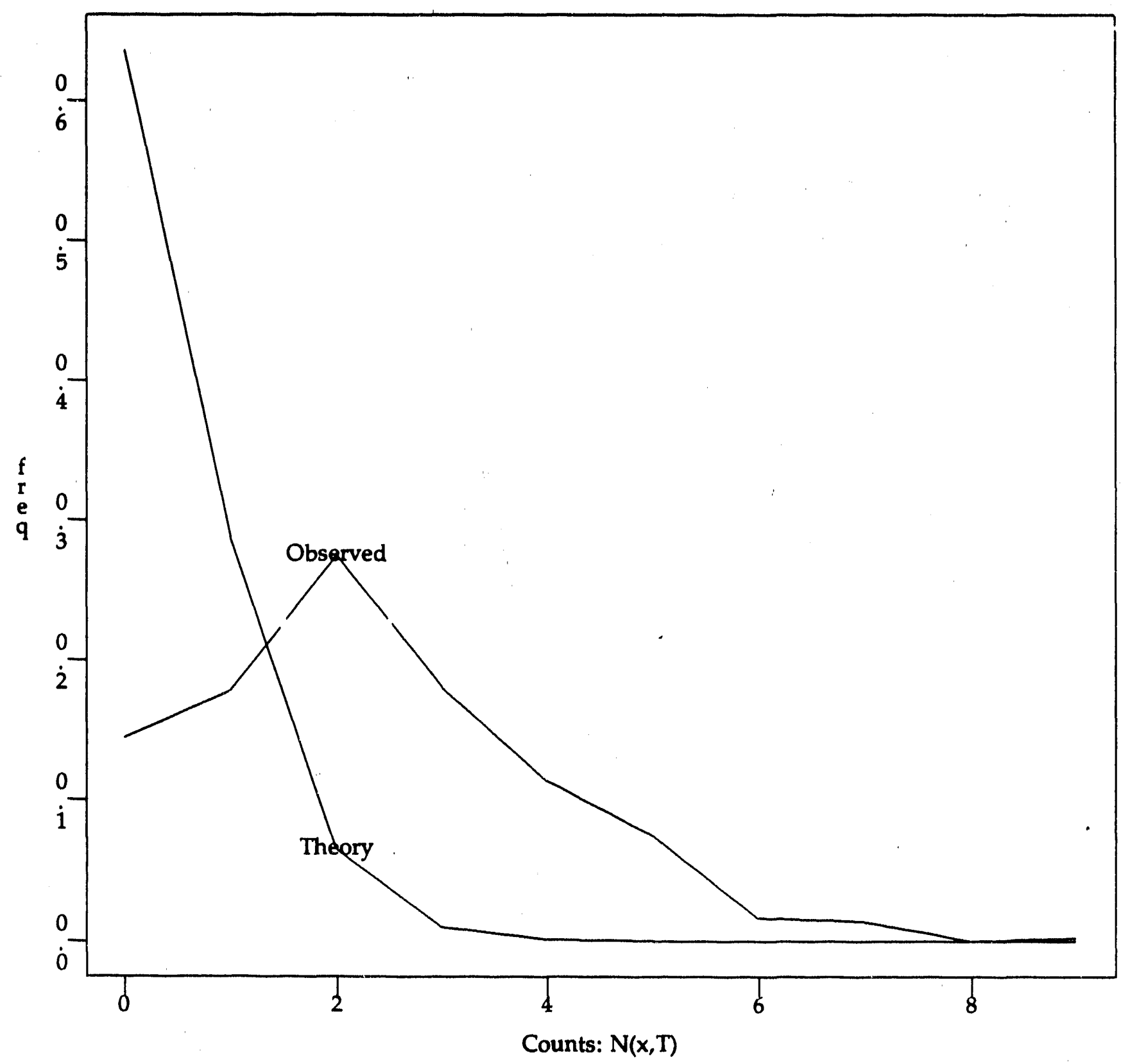

FIGURE A.5. Poisson Distribution of $N(x, 0.04)$ Versus Observed Distribution 


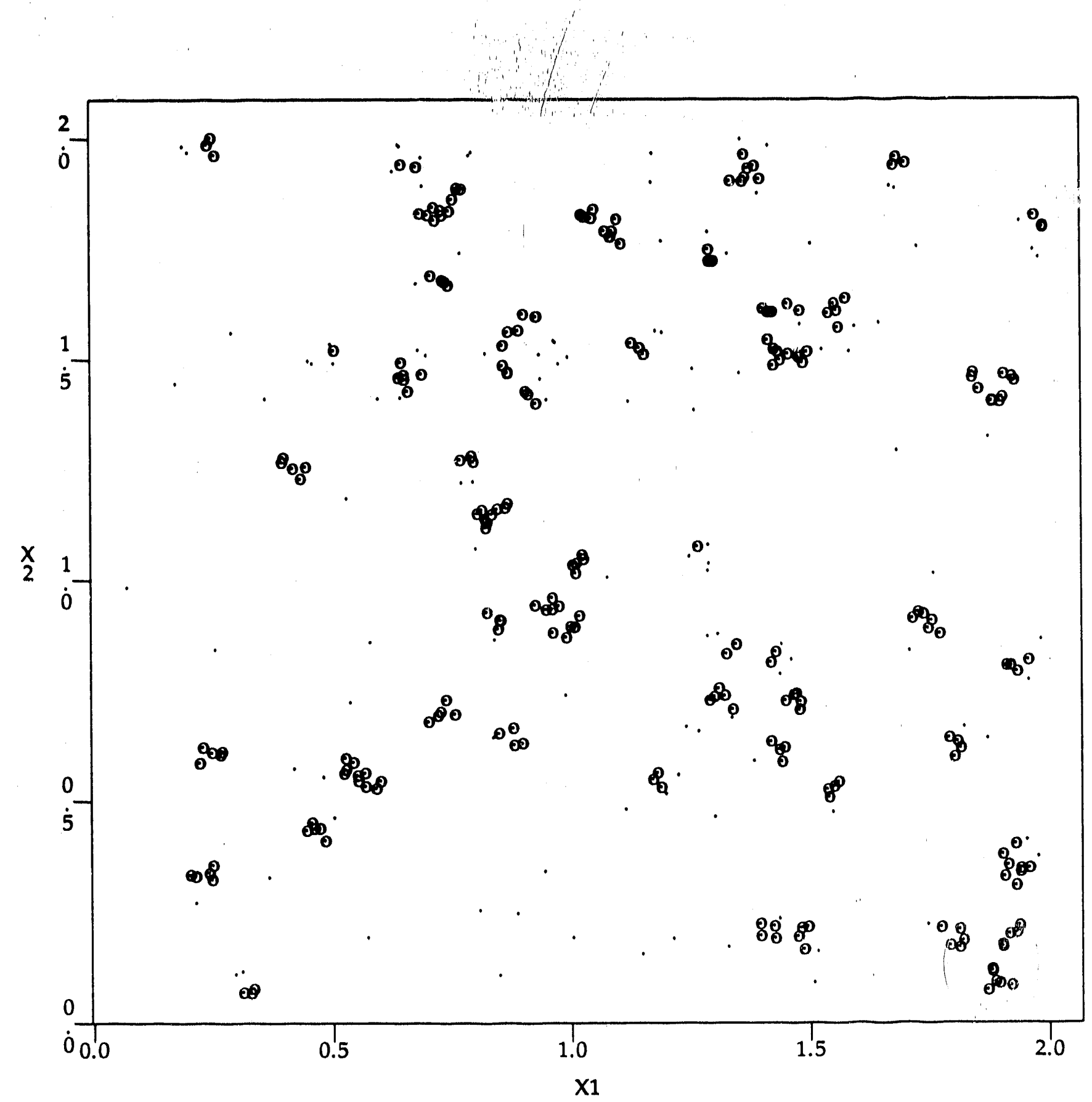

FIGURE A.6. Plot of Identifled Cluster Points 
That is, $P_{k}$ represents a set of mutually disjoint subsets of the space, and the subsets represent clusters.

The sequence of partitions $P_{0}, P_{1} \ldots$ is meant to represent a sequence of clusters that become "coarser" as the index increases. In fact, $P_{O}$, (the "weak" clustering) contains nothing but clusters (subsets) with a single point and the "strong" clustering $P_{m}$ contains only one cluster containing all the points. In order to define this idea of "coarseness," partition $P_{l}$ must have a definite relationship to $P_{(l+1)}$ which is

Every cluster in $P_{(l+1)}$ is the union of some clusters in $P_{l}$.

Also associated with this sequence of partitions $P_{k}$ is a value $\alpha k$ that measures cluster size. From our definition of the partition, it is obvious that $a_{0}=0$ and $\alpha_{k}<\alpha_{(k+1)}$. There are many ways of defining cluster size given a distance metric on the point space. The two methods that we employ are the "connected" cluster algorithm and the "compact" cluster algorithm.

For the compact algorithm, the "size" of a cluster is defined

$$
\operatorname{stze}(C)=\underset{x, y \in C}{\operatorname{Max}} d(x, y) \text {. }
$$

where $d(\lambda ; y)$ represents the distance between the two points $x$ and $y$ in the cluster. In other words, for compact clustering, the size of the cluster is its maximum dimension. The hierarchical cluster algorithm operates to produce clusters of minimum size at each stage in the construction of the tree.

For the connected algorithm, the size of a cluster is defined

$$
\operatorname{size}(C)=\underset{x \in C}{\operatorname{Max}} \operatorname{Min} d(x, y) \text {. }
$$

In other words, the size of the cluster is simply the largest nearest-neighbor distance of the points in the cluster. Instead of describing aspects of the largest dimension of the cluster, the connected dimension describes the density of the points in the cluster. In fact, if the connected size of Cluster $C$ is $\alpha$, it is possible to connect any two points $z$ and $y$ with a sequence of points $x_{i}$ so that $d\left(x_{i}, x_{i+1}\right)<a$ and $x_{1}=z$ and $x_{n}=y$.

Connected size imposes no constraint on the shape of the cluster, and therefore, sacrifices performance over compact size for the ability to detect elongated clusters. It is also important to realize that connected size tends to strip the edges off clusters.

Figure A.7 displays the hierarchical cluster tree produced when compact size is used on a portion of the point process displayed in Figure A.2. (To limit the size of the tree, only the points in the first quarter, $0<X_{1}, X_{2}<1$ were used.) From the analysis of $K(t)$, we should be looking for a cluster of approximately 0.05 , so to define the clusters, we cut the tree at this level. This resuits in the clusters plotted in Figure A.8.

Figure A.9 displays a similar cluster tree, this time using connected size. In this case, one should use a value of approximately 0.04 to cut the tree, which produces the clusters displayed in Figure A.10. According to the plots, both clustering methods produce very reasonable cluster groupings. 


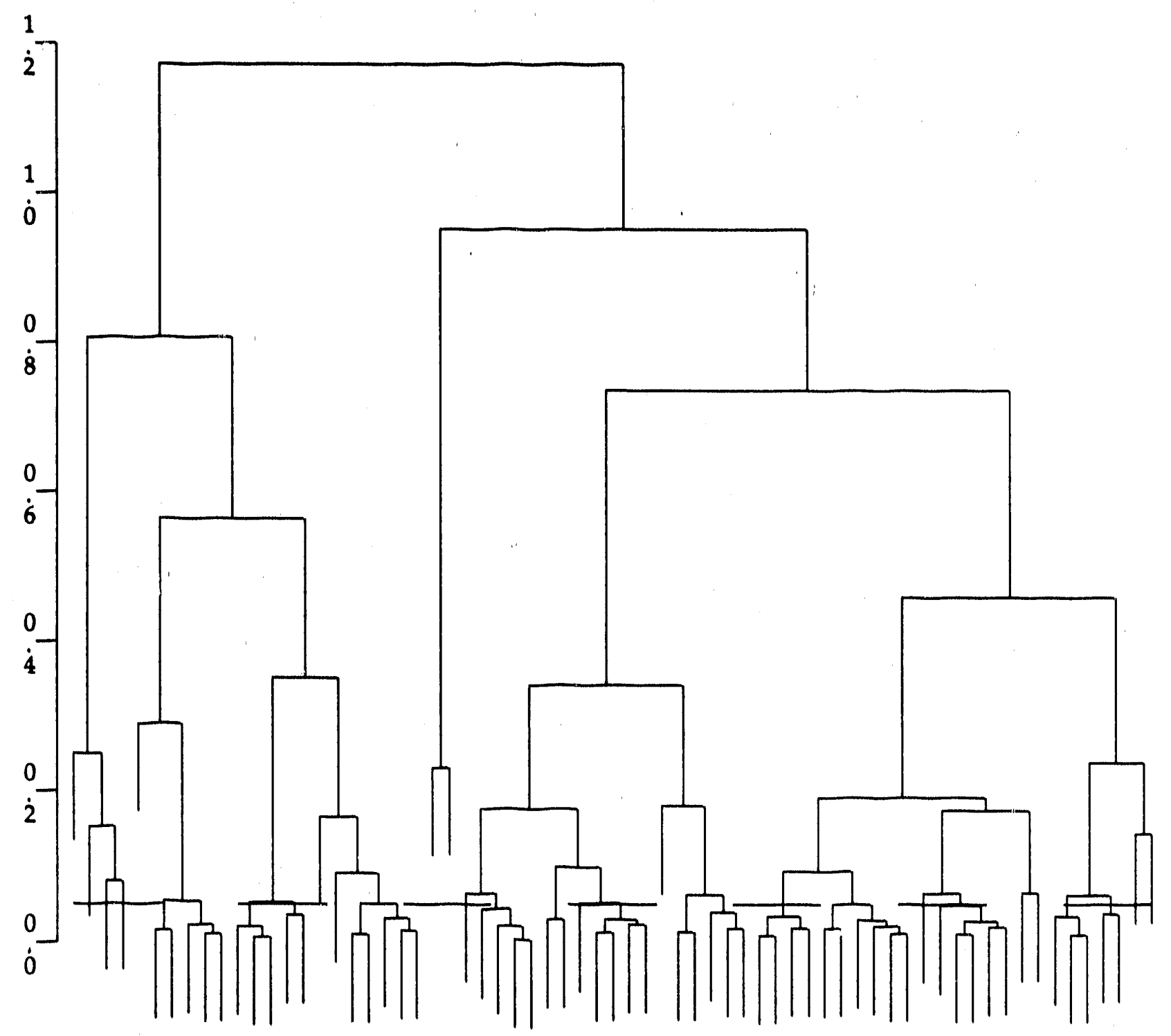

FIGURE A,7, Cluster Tree Using Compact Distance Metric on First Quadrant of Points in Figure A.2 


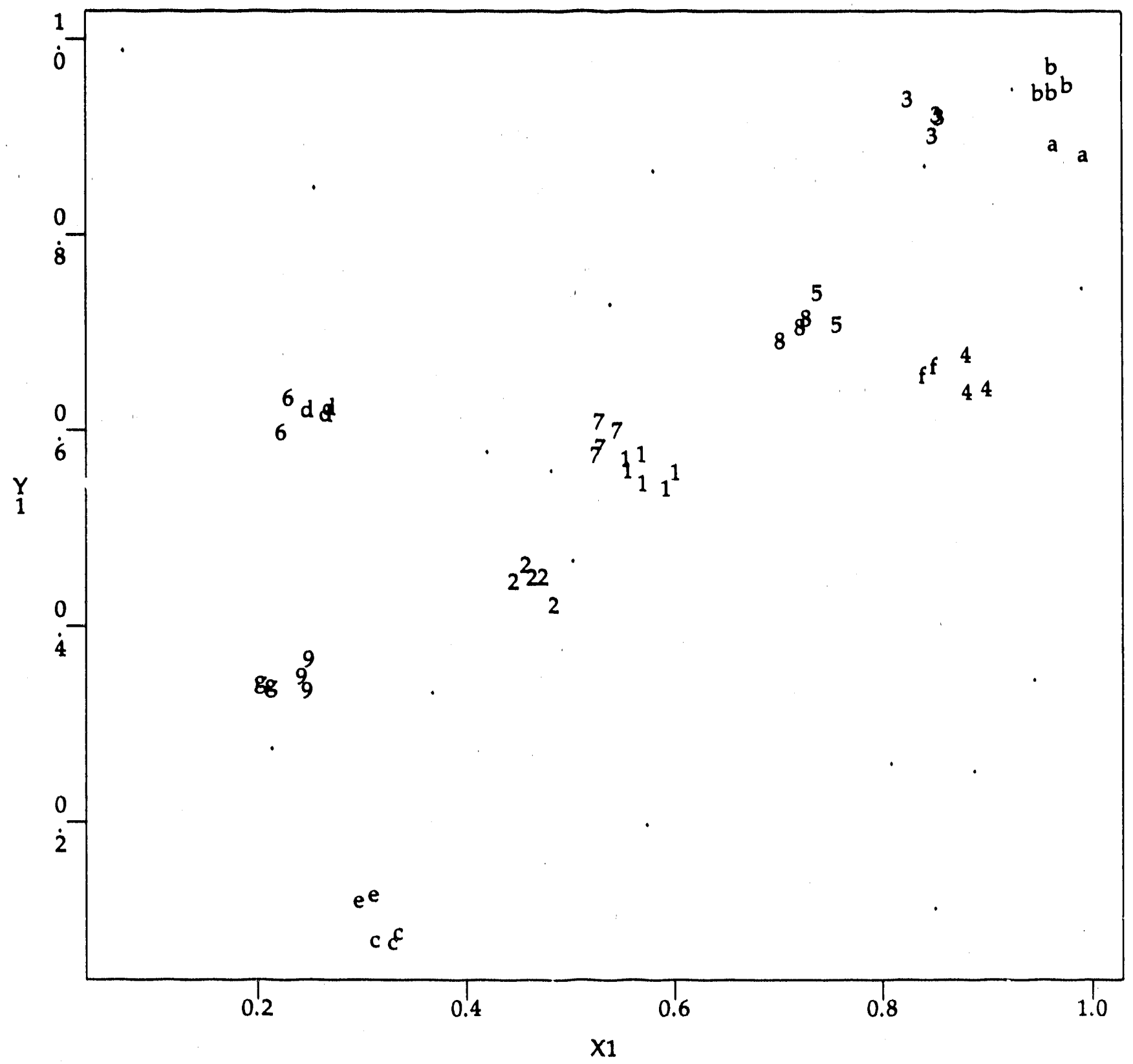

FIGURE A.8. Plot of Compact Clusters Identifled Using a Size of 0.05

A. 13 


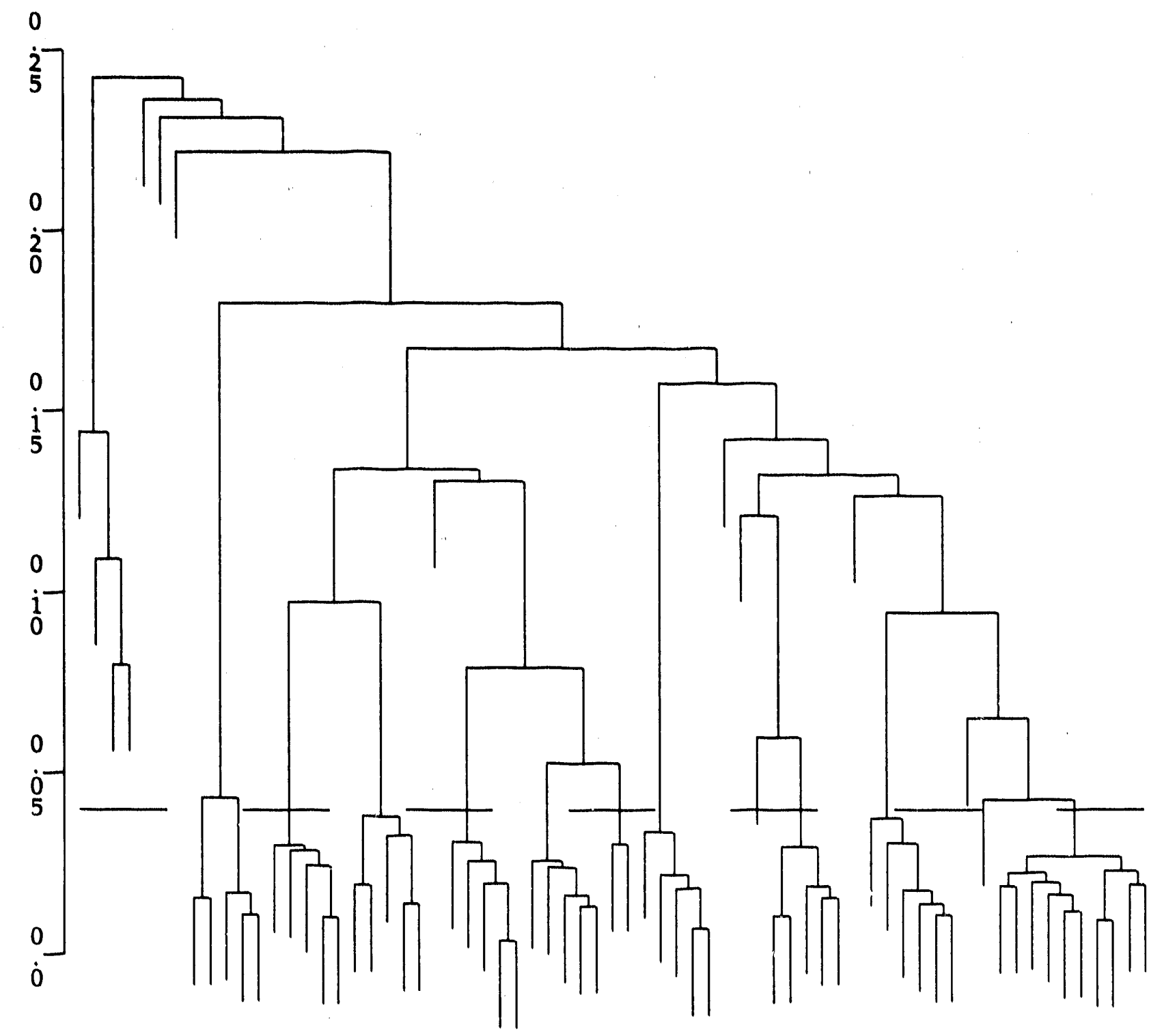

FIGURE A.9. Cluster Tree Using Connected Size on First Quadrant of Points in Figure A.2 


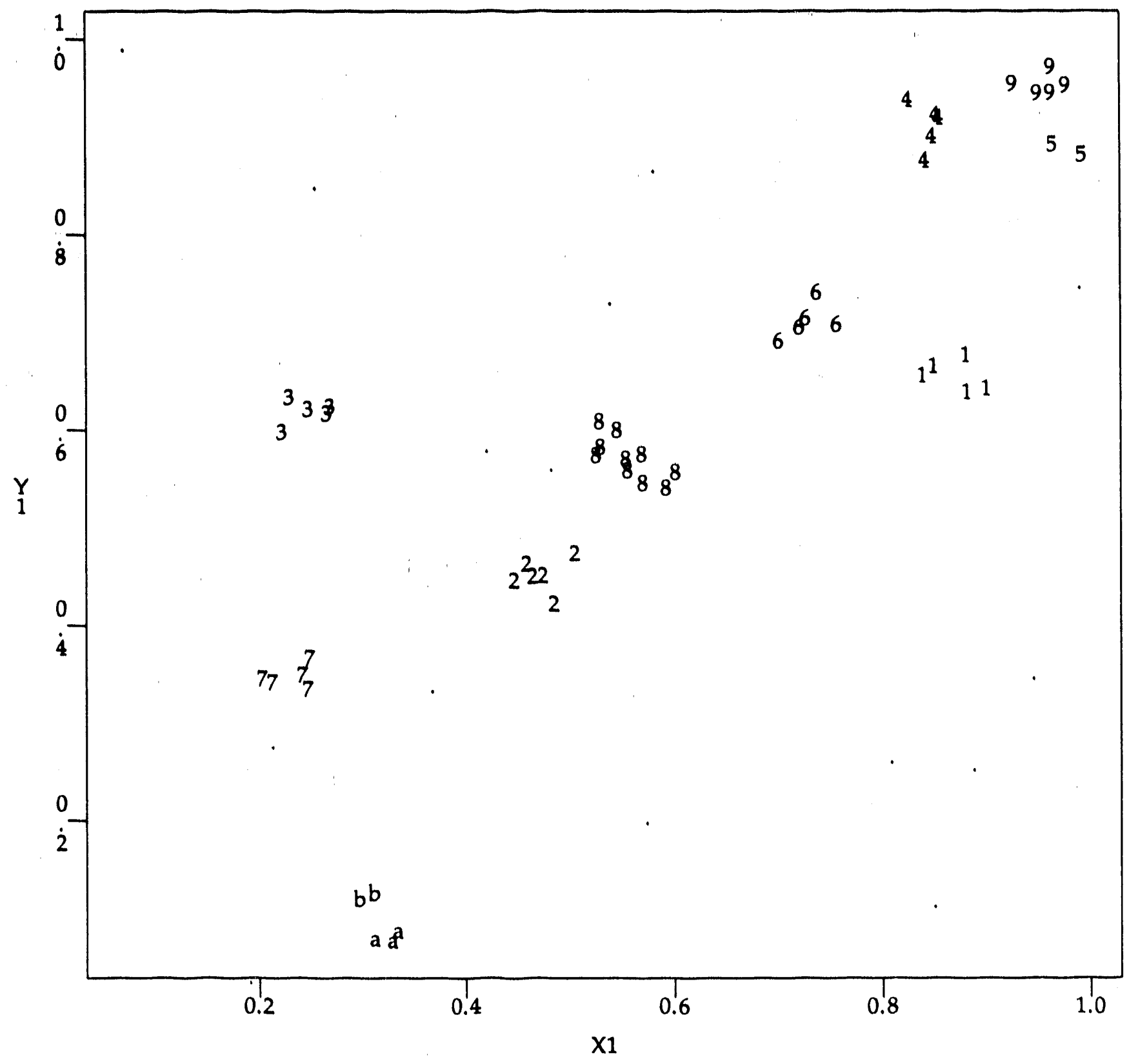

FIGURE A.10. Plot of Connected Clusters Identified Using a Size of 0.04

A. 15 


\section{PLANE PROCESSES: POISSON FLATS}

The previous discussion on point processes and assoclated clustering-methods processes can be very useful in its own right. However, we are interested in such material because it can be used to evaluate the distribution of fault planes within 3-space. A stochastic process that produces randomly distributed planes in 3-space is called a Poisson Flat, and an extenstve mathematical theory has been developed concerning such processes. A Poisson Flat has two important properties. First, the density of the planes is constant throughout the space; second, the position of each plane is independent of the others.

For our purposes, we are interested in only one key property of Poisson Flats. There is a unique transformation that will map randomly distributed planes into points so that the points represent a Polsson process. Because of this property, it is possible to transform cluster analysis of planes into a point cluster analysis problem and then employ the methods discussed previnusly.

Since a typical RGA plane data set may contain thousands of planes, even simple visual representations of the raw data are confusing. The -efore, this transformation of planes is also essential for something as basic as visualization of the fault-plane data. Note that it is easy to construct a transformation to map planes into points. What is significant about the transformation we use is that it maps plane "clusters" into point "clusters." Any other transformation will not do this; any other transformation will produce spurious clustering that is an artifact of the transformation.

\section{Construction of the Lambert-Space Transformation}

It is quite natural to represent planes in Euclidian 3-space by using "polar coordinates." Each plane is represented by the point $(\theta, \varphi, r)$, the polar coordinate of the point on the plane nearest the origin. This representation maps planes in 3-dimensional Euclidian space into points in a "column" (1.e. $0<\theta<2 \pi, 0<\varphi<\pi / 2$, and $-\infty<r<\infty$ ). This transformation should be extremely natural for a geologist because it is a slight varlant of the "strike" and "dip" method usually used to describe the orlentations of planar geologic features. In this polar-coordinate transformation. the "column" into which the planes are mapped is the polar coordinate space. This "polar coordinate representation" is basically the way planes are represented in the raw data set.

We desire a iransformation (i.e., the transformation that maps Poisson Flats into Poisson point processes) that is very similar to the above polar coordinate representation. In fact, this transformation, which we call the Lambert transformation, is defined by:

$$
\begin{aligned}
& x_{1}=2 \sin (\varphi / 2) \cos (\theta), \\
& x_{2}=2 \sin (\varphi / 2) \sin (\theta), \text { and } \\
& x_{3}=r .
\end{aligned}
$$

The points $\left(x_{1}, x_{2}, x_{3}\right)$ are points in Lambert space, which is a cylinder of radius $\sqrt{2}$. This is called a Lambert transformation because it is related to the Lambert map projection, which has the property of preserving areas. In fact, this property is key to the transformation.

Therefore, in order to view sets of planes and identify clusters, we first transform to a pointspace using the Lambert transformation. Clusters are identified by searching for non-Poisson clusters in the point space as described in the previous sections.

$$
\text { A.16 }
$$




\section{Calculation of Point Set Boundarles}

If the planes intersecting with topography in a map area are plotted in a Lambert space, one can only expect the points to be uniformly distributed within the reglon of space defined by:

( $X$ : Plane associated with $X$ intersects with the DEM).

Therefore, if we are interested in looking at points in the "Lambert" (or polar coordinate) space, we must also know location of the boundary. We will assume that the coordinate system origin is located in the center of a rectangular map area with east-west dimension of $2 a_{1}$ and north-south dimension of $2 a_{2}$. $\theta$ is defined so that $\theta=0$ corresponds to east and $\theta=\pi / 2$ is north. Finally, a positive value of $r$ corresponds to a plane whose nearest point to the origin is above the horizontal plane.

The boundaries delimiting those planes that intersect this arta from those that do not are

$$
\begin{aligned}
& \left.|r|=a_{1}|\sin (\varphi)| / \mid \cos (\theta)\right] \text { for }|\theta|<\theta_{1} \text { or }|\theta-\pi|<\theta_{1}, \text { and } \\
& |r|=a_{2}[\sin (\varphi)|/| \sin (\theta)] \text { for }|\theta-\pi / 2|<\theta_{2} \text { or }|\theta-3 \pi / 2|<\theta_{2} .
\end{aligned}
$$

In the aboye equations, $\theta_{1}=\operatorname{atan}\left(a_{2} / a_{1}\right)$, and $\theta_{2}=\pi / 2-\theta_{1}$. These equations can be further simplified to the single expression:

$$
\left.|r|=\sin (\varphi) \min \left(\left[a_{1}\right] /[|\cos (\theta)|], \mid a_{2}\right] /[|\sin (\theta)|]\right) .
$$

The formula generates something that looks like a torus whose outer rim has been flattened. The "side walls", of the torus also have peaks at $\pm \theta_{l}$, and $\pi \pm \theta_{l}$.

\section{Calculation of the Volume of the Point-Set}

The equations for the region boundary can be used to calculate its volume, which is necessary to calculate $\lambda$, the average density of points in the region. This parameter is necessary to calculate the theoretical value of the cluster statistics when they are applied to Poisson data. For the problem to conform more exactly to the avallable data. it is assiumed that the center of the torus has been removed; that is, planes with a dip from $\varphi_{1}$ to $\pi / 2$ are present. The volume will be measured in terms of radians ${ }^{2}$. distance.

The total volume $V_{T}$ of the torus is given by the integrals:

$$
V_{T}=8\left[a_{1} \int_{0}^{\theta} \int_{\varphi_{1}}^{\frac{\pi}{2}} \frac{\sin ^{2}(\varphi)}{\cos (\theta)} d \varphi d \theta+a_{2} \int_{0}^{\theta_{2}} \int_{\varphi_{1}}^{\frac{\pi}{2}} \frac{\sin ^{2}(\varphi)}{\cos (\theta)} d \varphi d \theta\right]
$$

These integrals represent the volume of sne-eighth of the torus; it is the upper half of the torus extending from $\theta=0$ to $\pi / 2$. These integrals can be solved, and the result is

$$
\begin{aligned}
& V_{T}=2\left(\pi+\sin \left(2 \varphi_{1}\right)-2 \varphi_{1}\right)\left(a_{1} \log \left(\sec \left(\theta_{1}\right)+\tan \left(\theta_{1}\right)\right)+a_{2} \log \left(\csc \left(\theta_{1}\right)+\operatorname{ctn}\left(\theta_{1}\right)\right]\right), \text { or } \\
& \left.V_{T}=2\left(\pi+\sin \left(2 \varphi_{1}\right)-2 \varphi_{1}\right) \mid a_{1} \log \left(|a| / a_{1}+a_{2} / a_{1}\right)+a_{2} \log \left(|a| / a_{2}+a_{1} / a_{2}\right)\right] .
\end{aligned}
$$

These equations are expressed in terms of polar coordinates; the boundaries can be easily transformed to the Lambert Space using the relations in the previous section. 


\section{BIBLIOGRAPHY}

Becker, R. A., J. M. Chambers, and A. R. Wllks. 1988. The New S Language: A Programming Envtronment for Data Analysis and Graphics. Wadsworth and Brooks/Cole, Pacific Grove, Callfornia.

Diggle, P. 1983. Statistical Analysis of Spatial Point Patterns. Academic Piess, London and New York.

Stoyan, D., W. S. Kendall, and J. Mecke. 1987. Stochastic Ceometry andi its Applications. Wlley, New York.

Schowengerdt, R. A. 1983. Techniques for Image Processing and Classification in Remote Sensing. Academic Press, New York. 
No. of

Coples

\section{UEFSITE}

12 DOE/Office of Scientific and Technical Information

\section{S. Herrick}

Department of Energy

Office of Arms Control, DP-5.1

Forrestal Bullding

1000 Independence Ave., S.W.

Washington, D.C. 20585

\section{A. Koontz}

Department of Energy

Office of Arms Control, DP-5.1

Forrestal Bullding

1000 Independence Ave., S.W.

Washington, D.C. 20585

W. C. Luth

Division of Engineering and Geosciences

Office of Basic Energy Sciences

Mail Stop ER-15

U.S. Department of Energy

Washington, D.C. 20545

\section{R. M. Mitterer}

Division of Engineering and Geosciences

Office of Basic Energy Sciences

Mall Stop ER-15

U.S. Department of Energy

Washington, D.C. 20545

\section{J. L. Alfaro}

710 Estes Road

Yakima, WA 98908

S. L. Dantinne

38 East Clayton Ave.

Clayton, NJ 08312

J. Hannon

Earth Sciences Department, L-205

Lawrence Livermore National Labora-

tory

7000 East Avenue

Livermore, CA 94551-0808

N. J. Rynes

Department of Geology

Northern Illinois University

DeKalb, IL 60115

R. L. Thiessen

Department of Geology

Washington State University

Pullman, WA 99164-2812
No. of

Conles

\section{E. S.Vergino}

Earth Sciences Department, L-205

Lawrence Livermore National Laboratory

7000 East Avenue

Ltvermore, CA 94551-0808

T. Weaver

Geophysics Group

Los Alamos National Laboratory

P.O. Box 1663, Mailstop C335

Los Alamos, New Mexdco 87545

\section{ONSITE}

DOE Richland Field Office

D. K. Jones

53

Pacific Northwest Laboratory

D. B. Baird

L. M. G. Ballou

J. W. Falco

M. G. Foley (25)

P. C. Hays

P. G. Heasler (5)

K. A. Hoover (5)

E. W. Kleckner

P. E. Long

L. M. Martucel

S. A. Rawson

A. C. Rohay

M. E. Schramm

R. L. Skaggs

C. E. Wukelic

Publishing Coordination

Technical Report Files (5) 

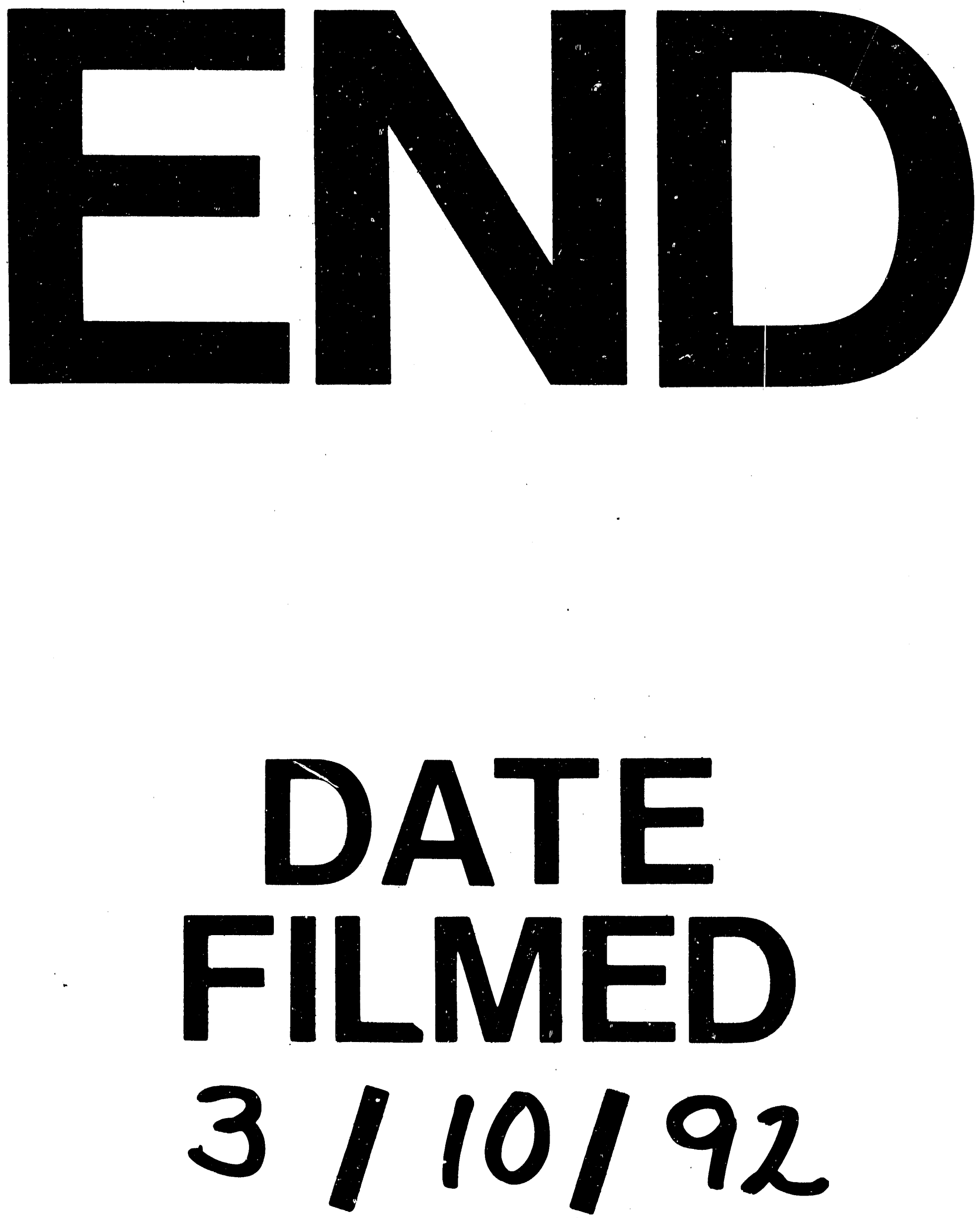
